\title{
QUANTIFICAÇÃO DE ALGUNS PARÂMETROS QUÍMICOS \\ VISANDO A RECUPERAÇÃO DE UM SOLO \\ SUBMETIDO À EROSÃO SIMULADA
}

JULIO CÉSAR GONZÁLEZ FRANCO

Engenheiro Agrônomo

Orientador: Dr. FRANCISCO LOMBARDI NETO

Tese apresentada à Escola Superior de Agricultura "Luiz de Queiroz" da Universidade de São Paulo, para a obtenção do Título de Doutor em Agronomia, Área de Concentração: Solos e Nutrição de Plantas

PIRACICABA

Estado de São Paulo - Brasil

Julho de 1995 
Dados internacionais de Catalogação na Publicação (CIP)

Divisão de Biblioteca e Documentação - CAMPUS "LUIZ DE QUEIROZ"/USP

González Franco, Julio César

Quant ificação de alguns parâmetros químicos visando a recuperação de un solo submetido à erosão simulada. Piracicaba, 1995.

68p.

Tese - ESALO

B ibl iografia.

1. Erosão - Simulação 2. Milho - Cultivo - Mane jo 3. Solo - Degrada ção - Recuperação 4. Solo - Química - Avaliação I. Escola Superior de Agricultura Luiz de Queiroz, Piracicaba 


\title{
QUANTIFICAÇÃo DE ALGUNS PARÂMETROS QUíMICOS \\ VISANDO A RECUPERAÇÃO DE UM SOLO \\ SUBMETIDO À EROSÃO SIMULADA
}

\author{
JULIO CÉSAR GONZÁLEZ FRANCO
}

Aprovada em: 18/10/1995

Comissão Julgadora:

Dr. Francisco Lombardi Neto

IAC/Campinas

Prof. Dr. Décio Barbin

ESALQ/USP

Prof. Dr. Geraldo Victorino de França

ESALQ/USP

Profa. Dra. Marlene Cristina Alves

UNESP/Ilha Solteira

Prof. Dr. Angelo Cataneo

UNESP/Botucatu

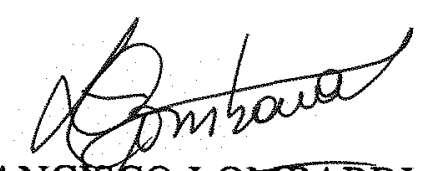

Prof. Dr. FRANCISCO $\triangle O M B A R D I$ NETO Orientador 
Aos meus pais

Anatolio e Agripina,

pelos seus exemplos de honestidade,

de fé, oração, trabalho e amor,

MINHA GRATIDÃO

À DEUS e a Nossa Senhora pelo ensino do desprendimento e da humildade como fonte de sabedoria e de amor,

\section{OFEREÇO}

À minha querida esposa Lurdes Aparecida, pela inestimável ajuda, estímulo e amor, e aos meus filhos Aline Beatriz e Rafael, 


\section{AGRADECIMENTOS}

- Ao Prof. Dr. Francisco Lombardi Neto, incansável pesquisador, pela eficiente orientação, dedicação, apoio moral e material.

- Ao Prof. Dr. Gerd Sparovek, pela continuidade do trabalho e eficaz colaboração na condução do experimento de campo, junto com os estudantes da residência agronômica.

- Ao Prof. Dr. Décio Barbin, pelo apoio nas análises estatísticas.

- Ao Prof. Dr. Geraldo Victorino de França, pela sincera amizade e consciente participação no deocrrer do Curso de Pós-Graduação.

- À Prof ${ }^{\mathrm{a}} \mathrm{Dr}^{\mathrm{a}}$ Marlene Cristina Alves, pela eficiente ajuda e acertadas sugestões na exploração dos resultados do trabalho.

- Ao Prof. Dr. Angelo Cataneo pela amizade e excelentes sugestões nas anélises dos dados.

- Ao Prof. Dr. Quirino Augusto de Camargo Carmello, pela amizade e colaboração ao trabalho.

- Ao Prof. Dr. Eurípedes Malavolta, pela colaboração e sugestões ao trabalho.

- Ao Prof. Dr. Henrique Paulo Haag, in memorian, pelo constante incentivo que manifestou durante o curso de Pós-Graduação.

- Ao Prof. Dr. Volker Kohler/GTZ, pela amizade e manifestações de apoio. 
- Ao amigo Prof. Dr. João Gil de Luna da Universidade Federal da Paraß̉a Campina Grande, pela eficaz colaboração na interpretação das análises estatísticas.

- Ao amigo, Eng ${ }^{\circ} \mathrm{Agr}^{\circ}$ Andrés H. Lai Reyes, do Centro de Informática na Agricultura-ESALQ, pelos auxílios prestados no processamento de dados para análise estatística.

- Às Bibliotecárias Eliana Maria Garcia Sabino e Kátia Maria de Andrade Ferraz, pela ajuda na elaboração das referências bibliográficas.

- À Clotilde Maria Batochio Cunha, pela amizade e digitação do trabalho.

- Aos funcionários do Setor de Nutrição Mineral de Plantas do Departamento de Química da ESALQ/USP, Piracicaba,SP e da Seçāo de Conservação e da Fertilidade do Solo do IAC-Capinas, pela amizade e facilidades oferecidas nas análises químicas.

- À Escola Superior de Agricultura "Luiz de Queiroz", pela acolhida e oportunidade de aperfeiçoamento.

- Ao Ministério da Agricultura e Pecuária-MAG e à Direção de Extensão Agrária-DEA do Paraguai, pela oportunidade concedida para a realização do curso.

- À Missão Técnica Alemã-GTZ e ao Serviço de Intercâmbio AcadêmicoDAAD, da República Federal da Alemanha, pelo apoio financeiro.

- Aos meus familiares, amigos na Fé, e a todos que, de alguma forma, colaboraram para a realização desse trabalho. 
SÜMÁRIO

Página

LISTA DE FIGURAS..................................................... v

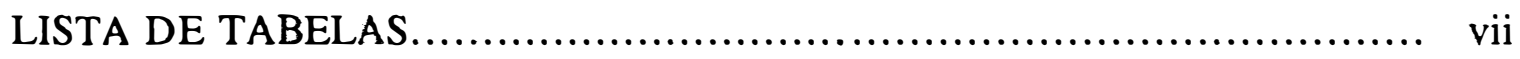

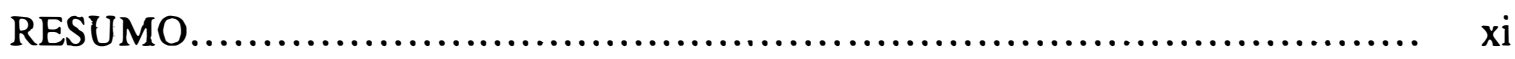

SUMMARY .................................................................... xiii

1. INTRODUÇĀO....................................................... 1

2. REVISÃO DE LITERATURA ............................................. 4

2.1. Degradação do solo e consequências.................................... 4

2.2. Recuperação do solo mediante adubação mineral ou orgânica............. 7

3. MATERIAL E MÉTODOS............................................... 15

3.1. Localização, montagem inicial do experimento e caracterização do solo. 15

3.2. Descrição da área e sistemas de manejo do solo considerados para a sua recuperação................................................... 18

3.3. Semeadura e condução do experimento................................ 21

3.4. Época de amostragem de solo.................................... 21

3.5. Parâmetros químicos do solo analisados, rendimento de milho e análises estatísticas. 
4. RESULTADOS E DISCUSSÃO............................................. 23

4.1. Parâmetros químicos do solo - comportamento geral nos três tratamentos considerados.

4.2. Características químicas do solo e seu comportamento em relação às profundidades de amostragem de solo e da remoção do solo nos três tratamentos.............................................................

4.3. Comportamento do rendimento de milho-espiga $(\mathrm{kg} / \mathrm{ha})$ em relação à profundidade de raspagem de 0 a $40 \mathrm{~cm}$.

5. CONCLUSÕES 61 


\section{LISTA DE FIGURAS}

Página

1. Esquema representativo da área experimental com as linhas de milho perpendicular à declividade, seguindo a profundidade de raspagem de solo de 0 até $45 \mathrm{~cm}$ de remoçāo....................................................

2. Comportamento geral das variáveis $\mathrm{P}$ (transformado), $\mathrm{MO}, \mathrm{pH}, \mathrm{K}$ (transformado), $\mathrm{Ca}, \mathrm{Mg}, \mathrm{H}+\mathrm{Al}, \mathrm{CTC}$ e Saturação por Bases em relação às linhas ou profundidade de raspagem de solo de 0 a $40 \mathrm{~cm}$. Obs: (Linha $\left.1=0 \mathrm{~cm} ; \mathrm{L}_{2}=2 \mathrm{~cm} ; \ldots . \mathrm{L}_{21}=40 \mathrm{~cm}\right)$ 28

3. Comportamento do $\mathrm{P}($ transformado) e $\mathrm{MO}$ em relaçāo às linhas, seguindo a profundidade de raspagem de solo de 0 a $40 \mathrm{~cm}$, dentro de cada tratamento e profundidade de amostragem do solo $\left(\mathrm{P}_{1}=0-10 \mathrm{~cm} ; \mathrm{P}_{2}=\right.$ $10-20 \mathrm{~cm} ; \mathrm{P}_{3}=20-40 \mathrm{~cm}$ ). Obs: (Linha $1=0 \mathrm{~cm} ; \mathrm{L}_{2}=2 \mathrm{~cm} ; \ldots$ $\left.\mathrm{L}_{21}=40 \mathrm{~cm}\right)$

4. Comportamento do $\mathrm{pH}$ e $\mathrm{Ca}$ em relação às linhas, seguindo a profundidade de raspagem de solo de 0 a $40 \mathrm{~cm}$, dentro de cada tratamento e profundidade de amostragem do solo $\left(\mathrm{P}_{1}=0-10 \mathrm{~cm} ; \mathrm{P}_{2}=10-20 \mathrm{~cm}\right.$; $\mathrm{P}_{3}=20-40 \mathrm{~cm}$ ). Obs: (Linha $1=0 \mathrm{~cm} ; \mathrm{L}_{2}=2 \mathrm{~cm} ; \ldots \mathrm{L}_{21}=40$ $\mathrm{cm})$. 
5. Comportamento do $\mathrm{CTC}$ e $\mathrm{H}+\mathrm{Al}$ em relação às linhas, seguindo a profundidade de raspagem de solo de 0 a $40 \mathrm{~cm}$, dentro de cada tratamento e profundidade de amostragem do solo $\left(\mathrm{P}_{1}=0-10 \mathrm{~cm} ; \mathrm{P}_{2}=10-\right.$ $\left.20 \mathrm{~cm} ; \mathrm{P}_{3}=20-40 \mathrm{~cm}\right)$. Obs: (Linha $1=0 \mathrm{~cm} ; \mathrm{L}_{2}=2 \mathrm{~cm} ; . . \mathrm{L}_{21}=$

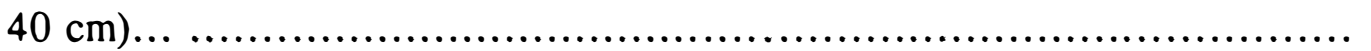

6. Comportamento do $\mathrm{K}, \mathrm{Mg}$ e Saturação por Bases (V\%) em relação às linhas, seguindo a profundidade de raspagem de solo de 0 a $40 \mathrm{~cm}$, dentro de cada tratamento e profundidade de amostragem do solo $\left(\mathrm{P}_{1}=0\right.$ $\left.10 \mathrm{~cm} ; P_{2}=10-20 \mathrm{~cm} ; P_{3}=20-40 \mathrm{~cm}\right)$. Obs: (Linha $1=0 \mathrm{~cm}$; $\left.\mathrm{L}_{2}=2 \mathrm{~cm} ; \ldots . \mathrm{L}_{21}=40 \mathrm{~cm}\right)$

7. Comportamento do rendimento de milho-espiga $(\mathrm{kg} / \mathrm{ha})$ em relação às linhas, seguindo a profundidade de raspagem de solo de 0 a $40 \mathrm{~cm}$. Obs:

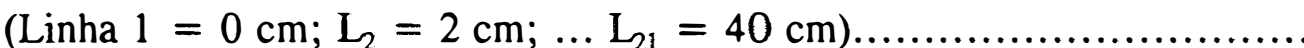




\section{LISTA DE TABELAS}

1. Atributos químicos e teor de argila do solo PELa da área de instalação do ensaio, antes da remoção de solo, em diferentes profun-

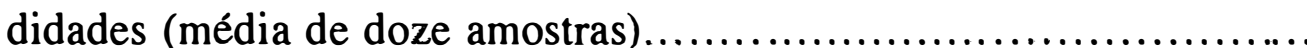

2. Períodos e sequências das culturas instaladas, da adubação orgânica e mineral, e da calagem do experimento

3. Resultados das análises de variância relativas as variáveis envolvidas no experimento.

4. Confronto das médias de interação T x P com respectivas DMS's.....

5. Confronto das médias de $P$ (transformado) dos tratamentos $\left(T_{1}, T_{2}\right.$

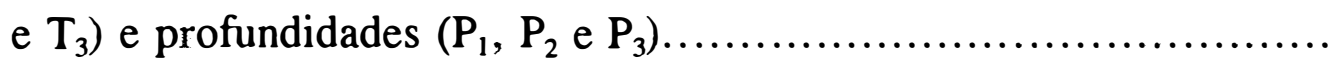

6. Confronto das médias de M.O. dos tratamentos $\left(\mathrm{T}_{1}, \mathrm{~T}_{2}\right.$ e $\left.\mathrm{T}_{3}\right)$ e profundidades $\left(\mathrm{P}_{1}, \mathrm{P}_{2}\right.$ e $\left.\mathrm{P}_{3}\right)$

7. Confronto das médias de $\mathrm{pH}$ dos tratamentos $\left(\mathrm{T}_{1}, \mathrm{~T}_{2}\right.$ e $\left.\mathrm{T}_{3}\right)$ e profundidades $\left(\mathrm{P}_{1}, \mathrm{P}_{2}\right.$ e $\left.\mathrm{P}_{3}\right)$

8. Confronto das médias de $\mathrm{K}$ (transformado) dos tratamentos $\left(\mathrm{T}_{1}, \mathrm{~T}_{2}\right.$ e $\left.T_{3}\right)$ e profundidades $\left(P_{1}, P_{2}\right.$ e $\left.P_{3}\right)$. 
9. Confronto das médias de Ca dos tratamentos $\left(T_{1}, T_{2}\right.$ e $\left.T_{3}\right)$ e profundidades $\left(\mathrm{P}_{1}, \mathrm{P}_{2}\right.$ e $\left.\mathrm{P}_{3}\right)$

10. Confronto das médias de $M g$ dos tratamentos $\left(T_{1}, T_{2}\right.$ e $\left.T_{3}\right)$ e profundidades $\left(\mathrm{P}_{1}, \mathrm{P}_{2}\right.$ e $\left.\mathrm{P}_{3}\right)$

11. Confronto das médias de $\mathrm{H}+\mathrm{Al}$ dos tratamentos $\left(\mathrm{T}_{1}, \mathrm{~T}_{2}\right.$ e $\left.\mathrm{T}_{3}\right)$ e profundidades $\left(\mathrm{P}_{1}, \mathrm{P}_{2}\right.$ e $\left.\mathrm{P}_{3}\right)$

12. Confronto das médias de CTC dos tratamentos $\left(T_{1}, T_{2}\right.$ e $\left.T_{3}\right)$ e profundidades $\left(\mathrm{P}_{1}, \mathrm{P}_{2}\right.$ e $\left.\mathrm{P}_{3}\right)$

13. Confronto das médias de saturação por bases dos tratamentos $\left(T_{1}\right.$, $\mathrm{T}_{2}$ e $\left.\mathrm{T}_{3}\right)$ e profundidades $\left(\mathrm{P}_{1}, \mathrm{P}_{2}\right.$ e $\left.\mathrm{P}_{3}\right)$

14. Quadrados médios relativos aos componentes de regressão polinomial para o fator Linha dentro de cada tratamento e dentro de cada profundidade e as estimativas dos coeficientes de regressão com respectivos coeficientes de determinação $\mathrm{R}^{2}$ em fósforo ( $\mathrm{P}$ transformado), $\mu \mathrm{g} / \mathrm{cm}^{3}$

15. Quadrados médios relativos aos componentes de regressão polinomial para o fator Linha dentro de cada tratamento e dentro de cada profundidade e as estimativas dos coeficientes de regressão com respectivos coeficientes de determinação $\mathrm{R}^{2}$ em matéria orgânica, M.O. $(\%)$ 
16. Quadrados médios relativos aos componentes de regressão polinomial para o fator Linha dentro de cada tratamento e dentro de cada profundidade e as estimativas dos coeficientes de regressão com respectivos coeficientes de determinação $\mathrm{R}^{2}$ em pH.......................

17. Quadrados médios relativos aos componentes de regressão polinomial para o fator Linha dentro de cada tratamento e dentro de cada profundidade e as estimativas dos coeficientes de regressão com respectivos coeficientes de determinação $\mathrm{R}^{2}$ em potássio ( $\mathrm{K}$ transformado), $\mathrm{meq} / 100 \mathrm{~cm}^{3}$

18. Quadrados médios relativos aos componentes de regressão polinomial para o fator Linha dentro de cada tratamento e dentro de cada profundidade e as estimativas dos coeficientes de regressão com respectivos coeficientes de determinação $\mathrm{R}^{2}$ em Cálcio $(\mathrm{Ca})$, meq/100 $\mathrm{cm}^{3}$

19. Quadrados médios relativos aos componentes de regressão polinomial para o fator Linha dentro de cada tratamento e dentro de cada profundidade e as estimativas dos coeficientes de regressão com respectivos coeficientes de determinação $R^{2}$ em Magnésio $(\mathrm{Mg})$, $\mathrm{meq} / 100 \mathrm{~cm}^{3}$ 
20. Quadrados médios relativos aos componentes de regressão polinomial para o fator Linha dentro de cada tratamento e dentro de cada profundidade e as estimativas dos coeficientes de regressão com respectivos coeficientes de determinação $R^{2}$ em $H+A l$, meq/100 $\mathrm{cm}^{3}$

21. Quadrados médios relativos aos componentes de regressão polinomial para o fator Linha dentro de cada tratamento e dentro de cada profundidade e as estimativas dos coeficientes de regressão com respectivos coeficientes de determinação $\mathrm{R}^{2}$ em CTC, meq/100 $\mathrm{cm}^{3} \ldots \ldots$.

22. Quadrados médios relativos aos componentes de regressão polinomial para o fator Linha dentro de cada tratamento e dentro de cada profundidade e as estimativas dos coeficientes de regressão com respectivos coeficientes de determinação $\mathrm{R}^{2}$ em Saturação por Bases (V\%)

23. Resultado da análise de variância da produção do milho dos tratamentos 1 e 2

24. Resultado da análise de variância da produção do milho do tratamento 3 (testemunha). 


\title{
QUANTIFICAÇÃO DE ALGUNS PARÂMETROS QUÍMICOS \\ VISANDO A RECUPERAÇÃO DE UM SOLO \\ SUBMETIDO À EROSÃO SIMULADA
}

\author{
Autor: JULIO CÉSAR GONZÁLEZ FRANCO \\ Orientador: Dr. FRANCISCO LOMBARDI NETO
}

\section{RESUMO}

Os efeitos de diferentes sistemas de manejo sobre a recuperação da produtividade de um solo submetido à erosão simulada foram avaliados mediante parâmetros químicos do solo e da produção do milho num Solo Podzólico VermelhoEscuro Latossólico endoálico de textura argilosa, na Fazenda Experimental da Escola Superior de Agricultura "Luiz de Queiroz", em Piracicaba, São Paulo.

A erosão simulada foi efetuada removendo artificial e gradualmente camadas superficiais do solo $2 \mathrm{em} 2 \mathrm{~cm}$, até atingir $40 \mathrm{~cm}$ de espessura de remoção de solo.

O experimento foi iniciado em 1989, com a seguinte sequência de culturas: milho (Zea mays L.), trigo (Triticum aestivum L.), crotalária (Crotalaria junceae L.), milho (Zea mays L.), tremoço branco (Lupinus albus L.), crotalária (Crotalaria junceae L.), milho (Zea mays L.). No ano agrícola de 1991/92, noventa dias após o plantio do milho foram retiradas amostragem de solo de $0-10 \mathrm{~cm}, 10-20$ 
$\mathrm{cm}$ e $20-40 \mathrm{~cm}$ para as seguintes análises químicas e determinações P, M.O., $\mathrm{pH}\left(\mathrm{CaCl}_{2}\right), \mathrm{K}, \mathrm{Ca}, \mathrm{Mg}, \mathrm{H}+\mathrm{Al}, \mathrm{CTC}$ e V\%.

Avaliaram-se dois sistemas de recuperação da produtividade do solo: Tratamento $1\left(T_{1}\right)$ : calagem + adubação orgânica com esterco de curral + adubação química com NPKZn e Tratamento $2\left(T_{2}\right)$ : calagem + adubação química com NPKZn, e Tratamento $3\left(\mathrm{~T}_{3}\right)$ : Testemunha sem calagem, sem esterco e sem adubação química. Após o terceiro ano de experimento, verificou-se que os teores de nutrientes no solo, nos dois sistemas de recuperação $T_{1}$ e $T_{2}$ foram superiores aos da testemunha $T_{3}$, sendo que $T_{1}$ foi superior à $T_{2}$, devido à presença da matéria orgânica adicionada que tomou os nutrientes mais disponiveis.

Verificou-se que, para todas as características químicas analisadas em relação à profundidade de amostragem, houve um comportamento decrescente, com exceção do $(\mathrm{H}+\mathrm{Al})$, principalmente na profundidade de 20 a $40 \mathrm{~cm}$, influenciando os valores de $\mathrm{pH}$ e a redução na disponibilidade dos nutrientes no solo.

Em todos os tratamentos houve uma diminuição do rendimento do milho nas profundidades de remoção de solo de $0 \mathrm{a} 40 \mathrm{~cm}$, porém os tratamentos $T_{1}$ e $T_{2}$ não apresentaram diferença estatística, havendo, todavia, uma diminuição acentuada do rendimento até $20 \mathrm{~cm}$ de remoção do solo. Essa queda relacionou-se principalmente com a presença da acidez potencial na profundidade de 20 a $40 \mathrm{~cm}$.

Foram ajustadas equações de regressão polinomial para explicar as características químicas do solo e a produção de milho em relação a profundidade de remoção de solo.

A recuperação da produtividade do solo submetido à erosão simulada é possível mediante calagem, adubação química e adubação orgânica - esterco ou adubo verde, mesmo com a remoção de $40 \mathrm{~cm}$ de solo. 


\title{
QUANTIFICATION OF SOME SOIL CHEMICAL \\ PARAMETERS IN THE RESTORING OF A \\ SOIL SUBMETTED TO A SIMULATED EROSION
}

\author{
Author: JULIO CÉSAR GONZÁLEZ FRANCO \\ Adviser: Dr. FRANCISCO LOMBARDI NETO
}

\section{SUMMARY}

The effect of some soil chemical characteristics on corn yield was evaluated in a field experiment with simulated soil erosion, in a clayed Dark Red Podzolic (Rhodic Kandiudox), at Piracicaba, São Paulo, Brazil.

Soil material was gradually removed from the surface to reach a depth of $45 \mathrm{~cm}$ using a mechanical scraper.

Two method of restoring corn productivity were tested: $T_{1}$ ) lime + NPKZn fertilizer + manure, and $T_{2}$ ) lime + NPKZn fertilizer. These treatments were compared whith the control treatment $T_{3}$, i.e., nothing added.

The nutrient contents in the soil were greater for both treatments $T_{1}$ and $T_{2}$ than for treatment $T_{3}$, and $T_{1}$ was greater than $T_{2}$, due the application of organic matter (manure) that became the nutrients more available.

The depth of soil sampling showed a decrease for all nutrients, except for $\mathrm{H}+\mathrm{Al}$, mainly at the depth of $20-40 \mathrm{~cm}$, affecting values of soil $\mathrm{pH}$ and nutrient availability. 
Corn productivity decreased with depth of soil removal for all treatment, but for $T_{1}$ and $T_{2}$ there were no statistical difference. The productivity decreased rapidly until the removal of $20 \mathrm{~cm}$ topsoil for both treatment. This decrease was related with the presence of $(\mathrm{H}+\mathrm{Al})$ at the depth of $20-40 \mathrm{~cm}$.

A polinomial equation was used to related corn yield with the depth of soil material removing.

The restoring of the soil productivity is possible by using liming, organic matter and fertilizer, even with a removal of a depth of $40 \mathrm{~cm}$ of this soil. 


\section{INTRODUÇÃO}

A erosão hídrica, como resultado de um uso impróprio da terra, causa a degradação de um dos recursos naturais de vital importância para a agricultura: o solo, e estabelece-se como o elo principal de uma corrente de problemas, com diferente nível de influência em cada um deles, colocando em perigo a produção econômica, a qualidade do ambiente e, consequentemente, o desenvolvimento sustentado no meio rural, com reflexos na área urbana. Assim, se faz necessário entender o problema com uma visão global, sem depauperar os recursos naturais e a qualidade de vida.

É de fundamental importância compreender como a perda de produtividade do solo se modifica com o tempo, conforme progride a erosão hídrica, sob um determinado uso da terra, e debelar o efeito no que diz respeito à capacidade de água disponível, nutrientes, crescimento e profundidade da raiz.

Considera-se, portanto, que a relação entre erosão e produtividade do solo, é, em essência, multivariada e muito sensível a qualquer mudança das variáveis. Contudo, é preciso definir objetivos específicos na pesquisa sobre perda na produtividade do solo, mesmo tentando dimensioná-la separadamente. 
Neste sentido, o presente trabalho faz parte da continuidade de um experimento de erosão simulada (SPAROVEK et al., 1991) iniciado em 1989, num Solo Podzólico Vermelho-Escuro Latossólico endoálico de textura argilosa, no município de Piracicaba-SP. Para isso, removeu-se artificial e gradualmente a camada superficial do solo de 0-45 $\mathrm{cm}$. Avaliaram-se dois sistemas de recuperação de produtividade: $T_{1}$ - calagem + adubação $N P K Z n+$ esterco, e $T_{2}$ - calagem + adubação NPKZn, comparando-os ao tratamento testemunha $T_{3}$ sem calagem, sem adubação e sem esterco. Continuou-se com o ensaio por mais 2 anos consecutivos num sistema de produção milho (Zea mays) - trigo (Triticum sp.) - crotalária (Crotalaria junceae) - tremoço branco (Lupinus albus L.).

O projeto proposto foi realizado no mesmo local, com intuito de quantificar os atributos químicos do solo, que influenciaram a recuperação da produtividade de um solo erodido por erosão simulada, e avaliar as respostas à diferentes tratamentos no experimento em nível de campo. Com isto, foi possível identificar as relações entre rendimento da cultura, erosão do solo e seus atributos, como resposta aos diferentes sistemas de manejo.

Vários trabalhos foram realizados para avaliar a diminuição da produtividade das terras agrícolas, ocasionada pela degradação do solo e, a sua recuperação aplicando diferentes sistemas de manejo, e elaborando modelos empíricos utilizando experimentos de simulação da erosão do solo. 
Este trabalho tem como objetivo uma avaliação química desse solo para a cultura do milho (Zea mays L.) sob manejos diferenciados, utilizando como ferramenta de análise a estatística convencional, a fim de verificar quais parâmetros explicam melhor as diferenças de rendimento observado e, em especial, a recuperação de um solo degradado por diferentes sistemas de manejo aplicados. 


\section{REVISÃO DE LITERATURA}

\subsection{Degradação do solo e consequências}

Erosão é o processo de desprendimento e arraste acelerado das partículas do solo causado pela água e pelo vento e se constitui na principal causa de depauperamento acelerado das terras, principalmente na sua produtividade (BERTONI \& LOMBARDI NETO, 1985).

A erosão provoca a diminuição da produtividade do solo, sendo esta produtividade definida por STOCKING (1984), como a capacidade do solo de produzir, em ambiente natural determinada planta, ou sequência de plantas, sob determinados sistemas de manejo, isto é, uma função de diversos fatores incluindo parâmetros individuais de solo, clima, manejo e declividade. Assim como a fertilidade do solo, ela é uma propriedade real, mas incapaz de medição física direta. A produção é o total de acúmulo de energia sem a necessária referência, sendo que a produção de uma cultura ou rendimento, é a quantidade de produção por unidade de área, em um dado tempo. 
Existe ainda, um limite de perda de solo que se considera como aceitável, sem que haja prejuízo do potencial produtivo do solo, muito importante na administração e planejamento agrícola.

A relação entre degradação do solo por erosão e produtividade das culturas depende da característica do perfil, do crescimento da cultura, manejo do solo e do microclima. Porém, as perdas de nutrientes na erosão de solos com subsolos edafologicamente favorável podem ser compensadas com a adição de fertilizante, com aumento de custo. Em solo com subsolo edafologica-mente não favorável e raso, a produtividade diminui com a erosão podendo tornar-se irreversivelmente degradado, ocorrendo com os das regiōes tropicais, onde de um modo geral, sua maior fertilidade concentra-se nos primeiros centíme-tros superficiais do solo. Ao se expor o subsolo pouco fértil, a produtividade decresce aceleradamente mesmo com pequenas perdas (LAL, 1985).

A erosão sem dúvida traz declínio na produtividade do solo e, embora a matéria orgânica seja geralmente citada como a chave da fertilidade, ela é somente um dos fatores que indicam a adaptabilidade do solo à produção de cultura. A textura do solo, o teor de minerais de argila, de água, a estrutura, a atividade biológica, a disponibilidade de nutrientes, bem como a radiação, temperatura, genótipo da planta, a sua densidade, a época de plantio e colheita, a susceptibilidade a doenças, ocorrência de pragas e manejo passado da área, combinados com o teor de matéria orgânica, determinam o potencial produtivo 
do solo ou produtividade, no sentido de acúmulo de energia em forma de vegetação (STOCKING, 1984 e NEWBOULD, 1980).

Os problemas de degradação do solo, segundo OOSTERBAAN (1982), podem ser de alta, média e baixa prioridade. Os de alta prioridade são: a perda de fertilidade, a degradação física, química e biológica, a perda e não reposição de matéria orgânica e a sobrecarga dos solos pelo uso de defensivos agrícolas.

Para qualquer situação a degradação e a acumulação de matéria orgânica são governadas pelas práticas de cultivo e manejo. SAUERBECK (1982), indica que as mais importantes são a rotação, a adubação e os sistemas de cultivos adotados.

Algumas das características e propriedades do solo podem ser afetadas pelo manejo inadequado, principalmente a profundidade, devido à remoção das camadas superficiais; a pedregosidade, aumentada pela remoção de partículas finas; o teor de matéria orgânica, diminuindo por causa da erosão e decomposição; o teor de nutrientes reduzido pela erosão e extração pelas culturas; incremento de alumínio trocável ou acidez potencial e a redução do $\mathrm{pH}$ ocasionado pela remoção das camadas superficiais (KLANT \& STAMMEL, 1984). A degradação, nas propriedades físicas e químicas do solo, está altamente correlacionada com a mineralização e consequente diminuição da matéria orgânica (MEDEIROS, 1980). 


\subsection{Recuperação do solo mediante adubação mineral ou orgânica}

Um solo erodido e degradado se apresenta aparentemente estéril, devido à ausência de fontes naturais de semente para o reinício de sua vegetação, inibido pelo processo erosivo, elevada acidez ou com grande variação em seu pH e característica química, e baixa fertilidade (MAYS \& BENGSTON, 1982) mas, uma vez diagnosticados corretamente os níveis de nutrientes e elementos tóxicos para serem recuperados se faz necessária a aplicação de calcário, fertilizantes e matéria orgânica.

A matéria orgânica é responsável por várias modificações nas condições físicas do solo, aumentando a faixa de fertilidade em solo argiloso, estabilidade dos agregados proporcionando-lhes maior resistência à ação desagregadora da água e a capacidade da mesma, favorecendo o aumento do espaço poroso, diminuindo a densidade, reduzindo o encrostamento superficial, aumentando significativamente a capacidade de troca catiônica em solos arenosos (FORSYTHE, 1980; JOHNSTON, 1982) e liberando nitrogênio, fósforo, enxofre e alguns micronutrientes.

Quanto ao fertilizante, BAVER et al. (1973) consideram que não se produzirá desestruturação do solo se as práticas agrícolas normais forem seguidas. Porém, com grandes aplicações de sais de sódio, ocorrerá dispersão dos agregados. No entanto, o aumento da produção da biomassa em função da adubação tem grande influência sobre a conservação e restauração da estrutura do solo. 
As perdas de nutrientes que resultam da erosão podem ser compensadas com o aumento da adubação para manter a produtividade do solo (DEDECEK, 1987). O aumento do custo de produção para recuperar a produtividade pode ser superior aos gastos com medidas de controle da erosão, e nem sempre a recuperação total é possível. Além disso, o efeito da adubação na recuperação é diminuído à medida que aumenta a camada de solo perdida.

MBAGWU (1985); AINA \& EGOLUM (1980), concluíram que a recuperação da fertilidade do solo mediante adição de matéria orgânica foi mais eficiente quando usada em conjunto com a adubação mineral. Em estudo em casa de vegetação, comparou-se a eficiência de vários resíduos orgânicos e fertilizantes minerais na melhoria da produtividade de um Ultisol, na Nigéria. Os níveis de adubos orgânicos foram de 0 a $5 \%$, e de fertilizantes minerais com nível 0 e, completo: 60 ppm de N, 15 ppm de P; 60 ppm de K e 20 ppm de Mg. Utilizaram também combinações de fertilizantes orgânicos e inorgânicos. A cultura avaliada foi o milho quanto a altura e produção de matéria seca. Concluiram ainda que a aplicação de fertilizante inorgânico teve mais influência no aumento de altura de plantas na camada superficial $0-20 \mathrm{~cm}$ do que no subsolo $20-40 \mathrm{~cm}$. Porém, a aplicação de adubo orgânico foi mais eficiente na camada do subsolo do que na camada superficial. A aplicação de fertilizantes minerais teve efeitos complementares. Nos tratamentos com adubação orgânica a deficiência de nitrogênio desapareceu após 3 semanas do crescimento inicial. 
Segundo LAL (1981), em experimento realizado em diferentes declives $(1,5,10$ e $15 \%)$, foram aplicados fertilizantes em todas as parcelas, subdividindo as áreas com subsolagem e sem subsolagem, com 7 anos de observação. Com relação à produção nos tratamentos sem subsolagem, variou em termos médios de 2,49 t/ha nas áreas que perderam, em média, $15,76 \mathrm{~mm}$ de solo para 4,57 t/ha para parcelas que perderam em média 9,67 $\mathrm{mm}$ de solo. Quando se comparou as áreas subsoladas, os valores da produção variaram de 4,06 t/ha nas áreas que perderam $15,76 \mathrm{~mm}$ de solo para $5,59 \mathrm{t} / \mathrm{ha}$ nas parcelas que perderam 0,63 mm de solo. Os trabalhos de YOST et al. (1985), CARLSON et al. (1961) e DEDECEK (1987), demonstraram que uma recuperação total da produtividade original das culturas, não foi possível apenas com o uso exclusivo de corretivos e adubos minerais.

Em experimentos de erosão simulada, DEDECEK (1987) removeu artificialmente camadas de solo de $0,2,5,10$ e $20 \mathrm{~cm}$ e procurou recuperá-las, usando dois níveis de fertilizantes ( 1 - $400 \mathrm{~kg}$ : 0-20-20 mais $750 \mathrm{~kg}$ de calcário dolomítico com 100\% PRNT e 2 - $500 \mathrm{~kg}$ : 0-20-20 e $1500 \mathrm{~kg}$ de calcário dolomítico) em soja. No primeiro nível da adubação observou-se uma diminuição de 16, 32, 47 e $67 \%$ na produção, para remoção de $2,5,10$ e $20 \mathrm{~cm}$ de solo, quando comparado com a testemunha $0 \mathrm{~cm}$, sem remoção. Para o nível 2 de adubação, as reduções de produção foram de 5, 14, 36 e $65 \%$. Concluiu-se que a adubação e correção do solo reduzem o efeito da remoção superficial no 
primeiro ano, mas não o eliminam, mesmo quando o solo removido é de apenas $2 \mathrm{~cm}$, isto num Latossolo Vermelho-Escuro Álico-Argiloso.

A remoção artificial de solo ou erosão simulada, tem sua vantagem pelo fácil controle das fontes de variaçōes externas, pela possibilidade de sua comparação com diversos níveis de manejo na recuperação da produtividade do solo e da extrapolação do resultado com relativa segurança para condições de campo (DEDECEK, 1987), comparado a outros métodos como ensaio simulado em casa-de-vegetação (MBAGWU, 1985) medidas realizadas diretamente no campo, em áreas afetadas pela erosão (DANIELS et al., 1989) ou ainda, considerando modelos empíricos baseados em atributos do solo (GANTZEK \& McCARTY, 1984).

Um entendimeno dos efeitos da perda de solo na produção de cultura é necessário para desenvolver práticas de manejo de restauração da produtividade do solo erodido. MBAGWU et al. (1984) conduziram um experimento para avaliar o efeito da remoção do solo nas produçōes de milho e feijão caupi, e sua resposta à aplicação de $\mathrm{N}$ e $\mathrm{P}$ num Ultisol da Nigéria, com 5 , 10 e $20 \mathrm{~cm}$ de remoção de solo. Nenhuma das combinações de fertilizantes usados foi substituto eficaz para corrigir a remoção do solo superficial.

Tentando relacionar remoção de solo superficial e aplicação de fertilizante com N e P em produção de trigo TANAKA \& AESE (1989) removeram, mecanicamente, a superfície do solo com $0,6,12$ e $18 \mathrm{~cm}$ e 
aplicaram 3 níveis de $\mathrm{N}(0-35-70 \mathrm{~kg} / \mathrm{ha})$ e 3 níveis de $\mathrm{P}(0-20-40 \mathrm{~kg} / \mathrm{ha})$ em combinação para cada tratamento antes do plantio. As aplicações de 35 e $70 \mathrm{~kg} / \mathrm{ha}$ de fertilizante com $\mathrm{N}$, em combinação com 20 ou $40 \mathrm{~kg} /$ ha de fertilizante com $\mathrm{P}$, resultou em maior produção de grãos, quando comparados separadamente. Os níveis de $70 \mathrm{~kg} / \mathrm{ha}$ de $\mathrm{N}$ e de $20 \mathrm{~kg} / \mathrm{ha}$ de $\mathrm{P}$ aumentaram a produção de grão nos 6,12 e $18 \mathrm{~cm}$ de remoção do solo a pelo menos, a mesma produção em $0 \mathrm{~cm}$ de remoção, sem aplicação de $\mathrm{N}$ e $\mathrm{P}$. Esses dados sugerem que $\mathrm{P}$ foi o nutriente mais limitante e adições de fertilizantes com $\mathrm{N}$ e sem $\mathrm{P}$, resultaram em pequena produção.

Em experimento realizado removendo-se 10, 20, 30 e $41 \mathrm{~cm}$ de profundidade da camada superior do solo, foi analisada a produção de matéria seca do sorgo (ECK, 1968), constatando-se que, com irrigação foram obtidos potenciais de produção similares, exceto no tratamento de maior remoção de solo $(41 \mathrm{~cm})$. Com umidade limitada, os tratamentos com fertilizantes não restauraram a produção da matéria seca para nenhuma profundidade de solo removida. As desigualdades foram atribuídas às diferenças no uso do solo e retenção de água.

Posteriormente (ECK, 1987), continuando o mesmo experimento, estudou os efeitos da remoção do horizonte superficial do solo, quanto às características químicas e propriedades físicas do solo por 23 anos, em relação às mudanças ocorridas com o tempo. Decorridos 23 anos, a matéria orgânica e o nitrogênio total diminuiram na parcela sem remoção de solo e aumentaram nas 
parcelas com subsolos expostos, onde os níveis iniciais eram baixos, mas cultivados inicialmente com sorgo por um ano agrícola, e logo seguido com capim até 1983. Os níveis iniciais de fósforo permaneceram inalteráveis. Todas as parcelas receberam novamente sorgo de grãos no ano seguinte.

A produção de grãos de sorgo nas parcelas com subsolos expostos aumentaram com o tempo. Em relação às produções nas parcelas igualmente tratadas, as reduções nas mesmas, a partir da remoção de solo (10, 20, 30 e 41 cm) em 1960 a 1962 e 1984 foram as seguintes: não fertilizado 55 e 83\%, fertilizado com fósforo 52 e 38\%, fertilizado com nitrogênio 31 e 16\%, fertilizado com nitrogênio e fósforo 2 e 14\%. O aumento da produção foi associado, principalmente aos efeitos combinados de nitrogênio e fósforo no solo. PRITCHARD et al. (1988) em experimentos de remoção da superfície do solo e redistribuição do mesmo, em produção de milho irrigado, observaram que a substituição com $7,5 \mathrm{~cm}$ de solo superficial restaurou totalmente o potencial produtivo do solo. A produção de milho nas parcelas com e sem remoção de solo, foram semelhantes quando $\mathrm{Zn}$ foi adicionado ao subsolo exposto junto a $\mathrm{N}, \mathrm{P}, \mathrm{K}$; porém, destacaram que a deficiência do $\mathrm{Zn}$ pode limitar a produção de milho no subsolo exposto. As propriedades físicas do solo foram uma causa maior na redução da produção e de difícil controle e restauração por níveis de manejo no campo. 
Os resultados de outros experimentos de remoção de solo foram relatados por CARLSON et al. (1961), BLACK (1968), MICKELSON (1968), HASS \& WILLIS (1968), HAUSER \& COX (1962). De um modo geral, observaram que as parcelas sem remoção de solo em relação ao subsolo exposto, foram marcadamente diferenciadas em suas características químicas e propriedades físicas e com consequente redução na produção de cultura. Se as diferenças de nutrientes eram os únicos problemas, as produções poderiam aumentar, comparáveis àquela parcela sem remoção de solo, mas se as condições físicas eram desfavoráveis no subsolo, tornavam-se muito difícil restaurar o potencial produtivo do solo.

SPAROVEK et al. (1991), num ensaio de campo sobre erosão simulada, encontraram que em todos os tratamentos houve uma queda apreciável da produção com aumento da remoção de solo. Considerando a mesma intensidade de remoção de solo, a produção da cultura decresceu do tratamento $\mathrm{T}_{3}$ (Testemunha) para o $\mathrm{T}_{1}$ (calagem $+\mathrm{NPKZn}+$ esterco), desde $0 \mathrm{~cm}$ de remoção até $45 \mathrm{~cm}$. O rendimento do tratamento $T_{2}$ (calagem + NPKZn) com remoção de solo acima de $25 \mathrm{~cm}$ foi semelhante ao da testemunha $\left(\mathrm{T}_{3}\right)$ sem remoção de solo; concluiram ainda que foi possível recuperar a fertilidade do solo estudado, após remoção completa do horizonte superficial, pelo uso conjunto de matéria orgânica e adubação química com prévia correção do solo, e no nível mais baixo de sua produtividade com uso apenas de adubação mineral. Além disso, o rendimento da cultura ao longo do tempo mostrou uma tendência de se 
igualar nos $T_{1}$ e $T_{2}$, que no início eram bem diferentes, sendo que o $T_{3}$ permaneceu quase invariável.

As perdas de solo, água e nutrientes por erosão hídrica em diferentes sistemas de manejo de solo, foram estudadas por SANTOS et al. (1994), onde foram avaliados $\mathrm{Ca}, \mathrm{Mg}, \mathrm{K}$ e $\mathrm{P}$ no $\mathrm{T}_{1}$ : parcelas descobertas; $\mathrm{T}_{2}$ : parcelas com cultivo mínimo - trigo e aveia; $T_{3}$ : parcelas com plantio direto e $T_{4}$ : parcelas com preparo convencional, todas com sistemas coletores. As menores e maiores perdas de nutrientes foram respectivamente de $\mathrm{P}$ e $\mathrm{K}$, tanto na água como no sedimento. A pequena perda de $\mathrm{P}$ pode ser atribuída a suas baixas concentraçōes no solo e por estar fortemente adsorvido aos colóides (BERTOL \& MICHELLUTI, 1993). As perdas de K são altas em função de sua maior solubilidade e maior concentração no solo, facilmente mobilizado junto com a água ou sedimento. Observou-se uma maior concentração de $\mathrm{Ca}, \mathrm{Mg}$ e $\mathrm{K}$ em suspensão na água coletada, devido ao transporte de resíduos de calcário e adubos pela enxurrada. 


\section{MATERIAL E MÉTODOS}

\subsection{Localização, montagem inicial do experimento e caracterização do solo}

O experimento foi implantado na Fazenda Experimental da Escola Superior de Agricultura "Luiz de Queiroz", no município de Piracicaba - SP. O Solo é um Podzólico Vermelho-Escuro Latossólico endoálico, horizonte A moderado, textura argilosa (PELa) do topo de uma colina suave. A declividade original (antes da remoção de solo) era de 3,9\%. A cultura nos seis anos antecedentes foi a cana-de-açúcar. A Tabela 1 apresenta os atributos químicos e o teor de argila do solo da área do experimento, antes da remoção de solo, em diferentes profundidades (SPAROVEK et al., 1991).

Numa área de $20 \mathrm{~m} \times 30 \mathrm{~m}$, com o menor comprimento no sentido da declividade, foram medidas as cotas relativas aos pontos distribuídos numa malha regular de $5 \mathrm{~m} \times 5 \mathrm{~m}$. Nessa área, fez-se a remoção de solo por raspagem, de modo tal que as camadas de solo ficassem gradualmente expostas, partindo-se de $0 \mathrm{~cm}$ de remoção até $45 \mathrm{~cm}$, conforme esquematizado na Figura 1. 

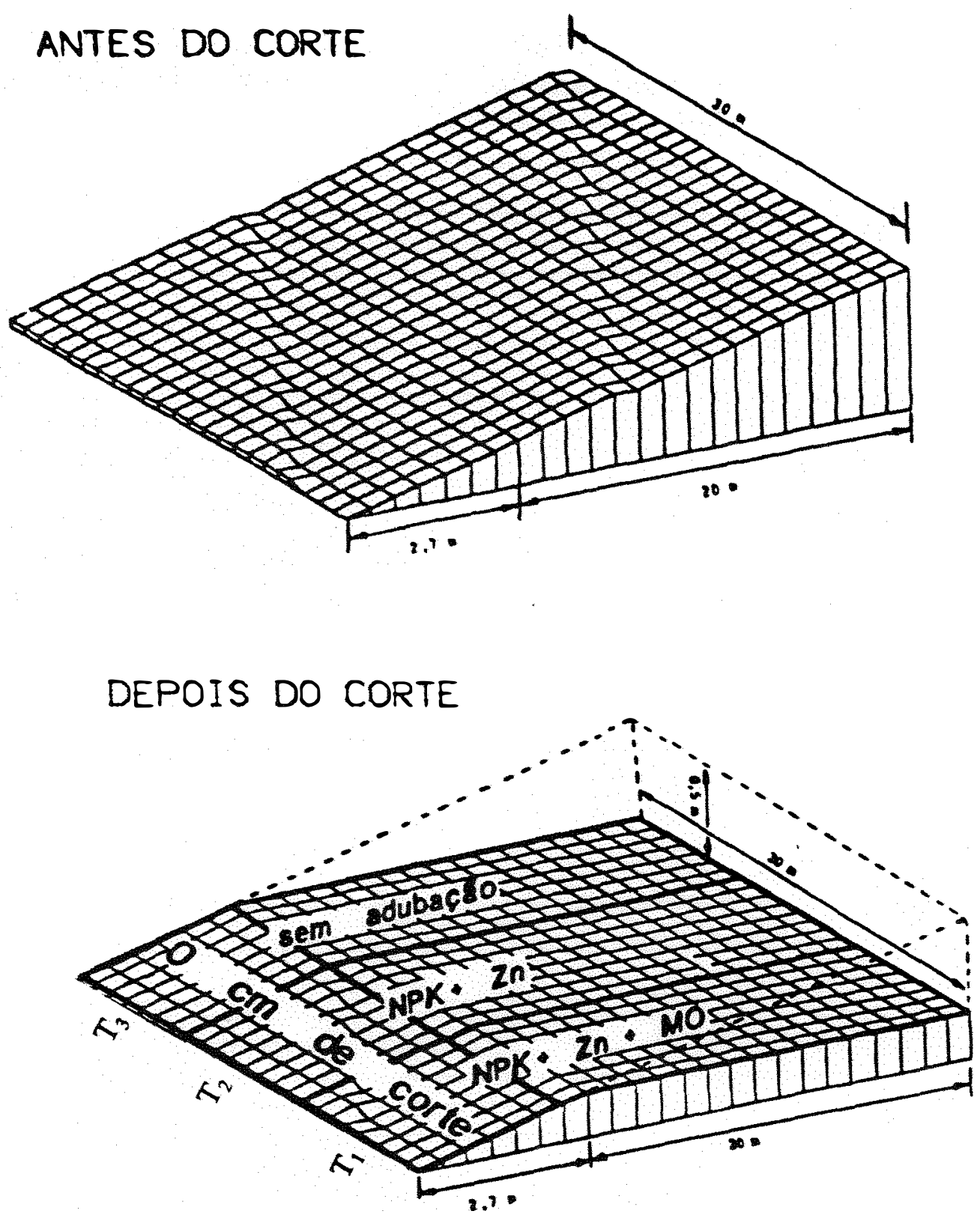

Figura 1 - Esquema representativo da área experimental com as linhas de milho perpendicular à declividade, seguindo a profundidade de raspagem de solo de 0 até $45 \mathrm{~cm}$ de remoção.

Legenda: T1 - Calagem + adubação orgânica com esterco de curral + adubação química com NPKZn

T2 - Calagem + adubação química com NPKZn.

T3 - Testemunha sem calagem, sem esterco e sem adubação química. 


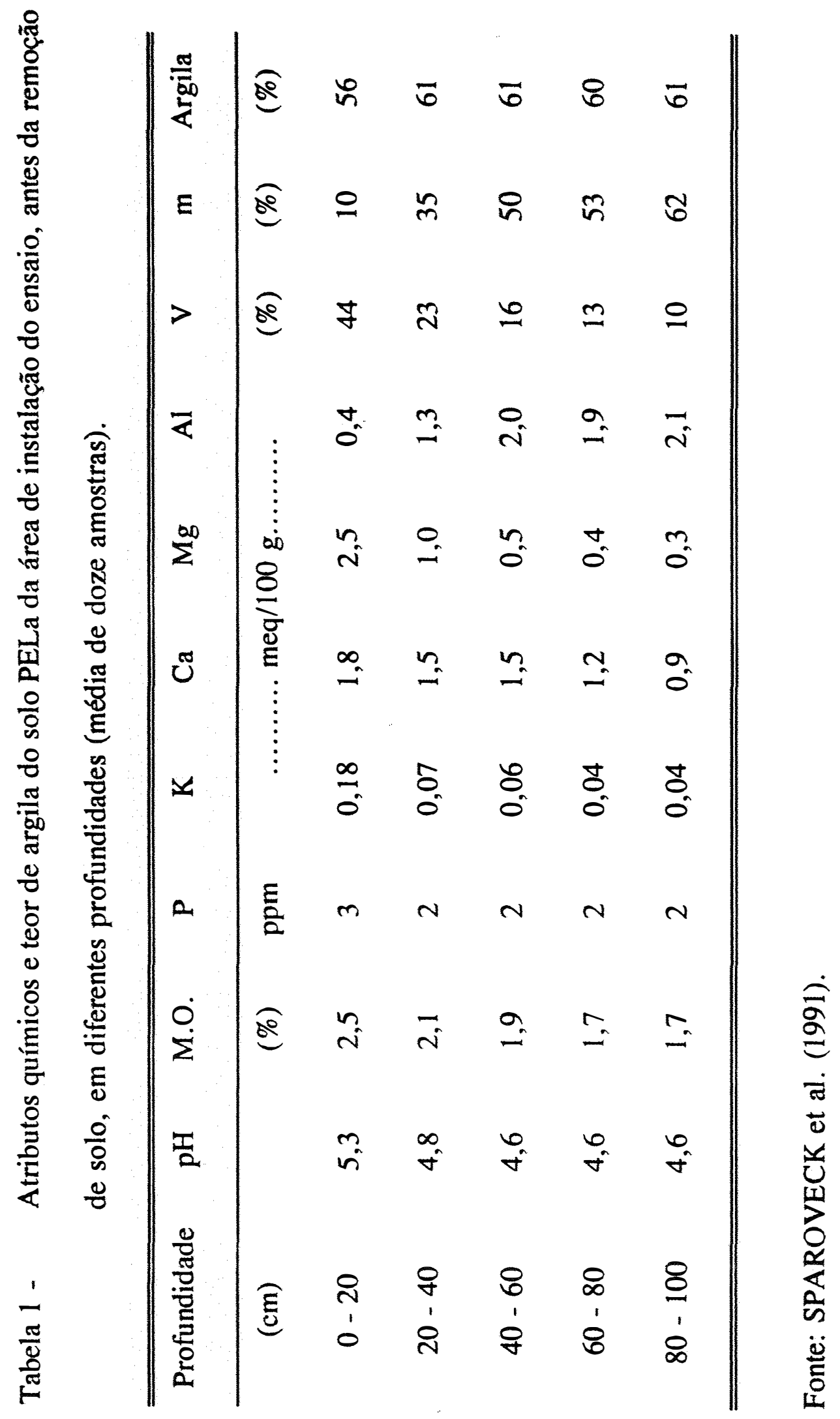


A raspagem do terreno foi realizada com um trator de pneu equipado com lâmina frontal, retirando-se a solo sempre em nível, no sentido do maior comprimento, para que não ocorresse mistura do material retirado das camadas superiores com o das inferiores. Durante as operações de remoção de solo, a cota relativa aos pontos da malha de $5 \mathrm{~m} \times 5 \mathrm{~m}$ foi frequentemente comparada com as medições feitas antes da remoção, a fim de orientar as operaçōes e verificar quando a profundidade de raspagem específica para cada ponto era atingida. A declividade do terreno após a remoção do solo foi alterada para $1,7 \%$.

Após as operações de raspagem, fez-se uma subsolagem com subsolador de três hastes, a $40 \mathrm{~cm}$ de profundidade, seguida de uma gradagem leve com grade niveladora de discos, visando descompactar o solo e deixá-lo em condiçōes de plantio (SPAROVEK et al., 1991).

3.2. Descrição da área e sistemas de manejo do solo considerados para a sua recuperação

A área de $20 \mathrm{~m} \times 30 \mathrm{~m}$ foi dividida em três parcelas de $10 \mathrm{~m} \mathrm{x}$ $20 \mathrm{~m}$ (Figura 1) de modo que, no sentido do maior comprimento, cada uma das três apresentasse uma remoção de solo progressiva de 0 a $45 \mathrm{~cm}$. Os três tratamentos $\left(T_{1}, T_{2}\right.$ e $\left.T_{3}\right)$, uma testemunha e dois de recuperação da 
produtividade, foram os seguintes: (1) $\mathrm{T}_{1}$ : calagem com $4.500 \mathrm{~kg} / \mathrm{ha}$ de calcário dolomítico, aplicação de $10.000 \mathrm{~kg} / \mathrm{ha}$ de matéria seca (MS) de esterco bovino e adubação de plantio NPKZn mais cobertura de $\mathrm{N}$; (2) $\mathrm{T}_{2}$ : calagem com 4.500 $\mathrm{kg} /$ ha de calcário dolomítico e adubação de plantio NPKZn mais cobertura de $\mathrm{N}$; e $\mathrm{T}_{3}$ : testemunha, só semeadura (sem calagem, sem aplicação de esterco e sem adubação de plantio ou cobertura).

As quantidades e os adubos aplicados nos sulcos no momento do plantio (a) e nas duas coberturas aos 32 (b) e 55 (c) dias após o plantio (DAP) foram: (a) $800 \mathrm{~kg} / \mathrm{ha}$ de superfosfato simples, $200 \mathrm{~kg} / \mathrm{ha}$ de cloreto de potássio; $45 \mathrm{~kg} / \mathrm{ha}$ de uréia e $6,3 \mathrm{~kg} / \mathrm{ha}$ de sulfato de zinco; (b) $100 \mathrm{~kg} / \mathrm{ha}$ de uréia e (c) $250 \mathrm{~kg} / \mathrm{ha}$ de sulfato de amônio.

O calcário e o esterco foram distribuídos manualmente, de forma homogênea, nas respectivas áreas e incorporados com grade niveladora. Cabe-se destacar que isto foi realizado apenas no início do experimento, assim como a aplicação de sulfato de zinco no solo, buscando o efeito residual dos mesmos. Na Tabela 2, pode-se observar a sequência e o período das culturas anteriores até o presente experimento e o tratamento aplicado.

O critério utilizado na adubação do experimento foi o de obter a maior produção possível de forma que a deficiência de alguns nutrientes não representasse um fator limitante à produção. 


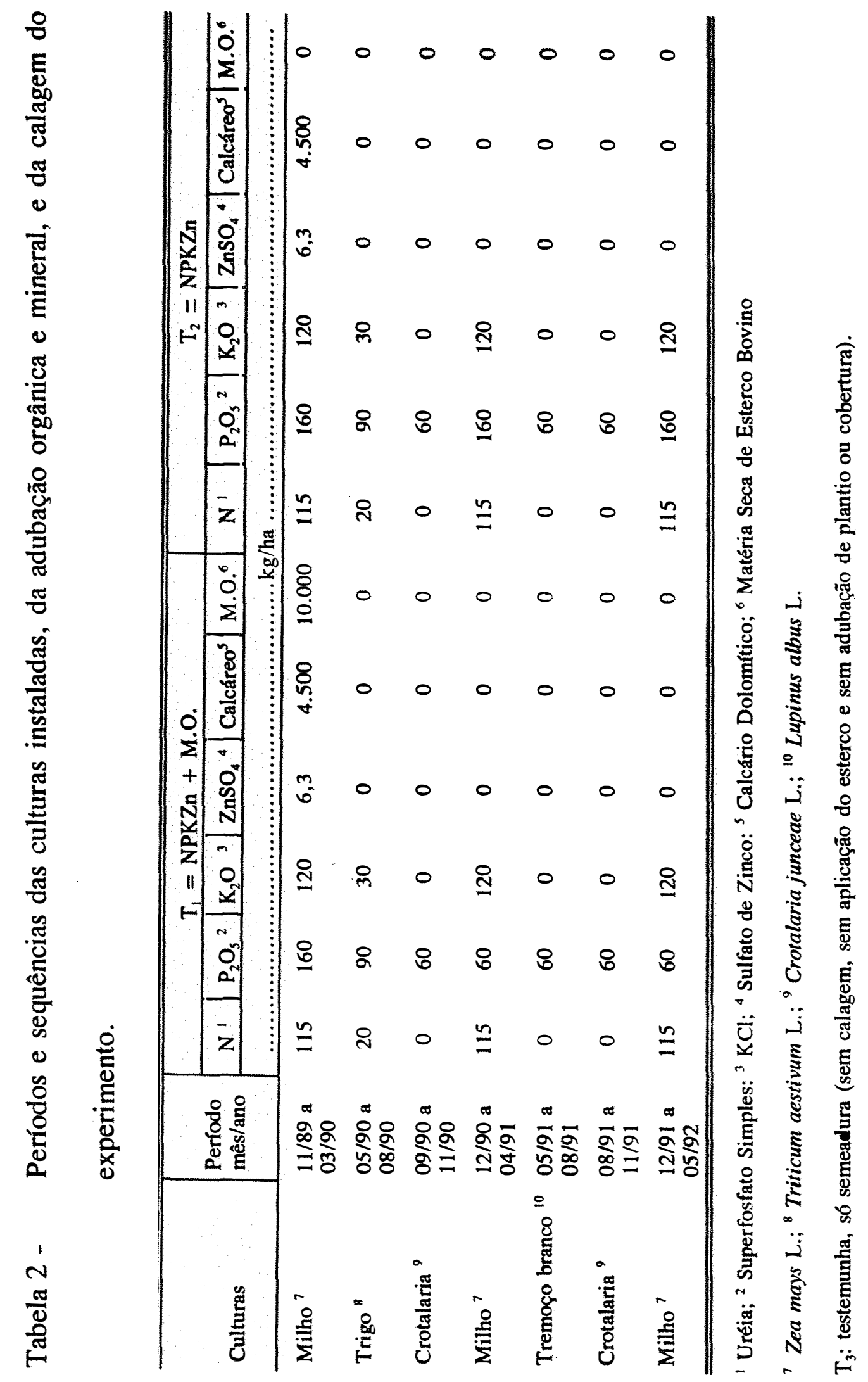




\subsection{Semeadura e condução do experimento}

No ano agrícola 1991/92 foi plantado o milho, em dezembro, logo após o corte da Crotalária. As sementes de milho híbrido Braskalb XL 678, foram previamente tratadas, semeadas no espaçamento de $0,90 \mathrm{~m}$ entre linhas e $0,20 \mathrm{~m}$ entre plantas, procurando atingir uma população inicial de 55.555 plantas/ha, após o desbaste.

Os sulcos de plantio ficaram perpendiculares ao sentido do aumento da remoçâo de solo e paralelos a o menor comprimento das parcelas. Cada linha de plantio acompanhou uma profundidade de remoção de solo, cobrindo todo o gradiente de 0 - $45 \mathrm{~cm}$. Assim, a primeira linha após o início do corte apresentou, ao longo de sua extensão $0 \mathrm{~cm}$ de remoção de solo; a segunda, distante $0,90 \mathrm{~m}, 2 \mathrm{~cm}$; a terceira $4 \mathrm{~cm}$, a quarta $6 \mathrm{~cm}$, e assim por diante, até a última, com $45 \mathrm{~cm}$ de remoção, totalizando 23 linhas de milho em cada parcela, sendo que as 2 últimas linhas não foram consideradas analisando-se 21 linhas, correspondendo à remoção de solo de 0 a $40 \mathrm{~cm}$.

\section{4. Época de amostragem de solo}

Foram realizadas coletas de amostra de solo para análise de fertilidade aos 90 dias do plantio do milho, em quatro posições de cada linha, nas 21 linhas e nos três tratamentos e, em três profundidades $(0-10 \mathrm{~cm}, 10-20 \mathrm{~cm}$ e $20-40 \mathrm{~cm}$ ) totalizando 792 amostras (Figura 1). 
3.5. Parâmetros químicos do solo analisados, rendimento de milho e análises estatísticas

Foram realizadas as seguintes análises químicas do solo: $\mathrm{pH}$ em $\mathrm{CaCl}_{2} 0,01 \mathrm{M}$, matéria orgânica pela oxidação com $\mathrm{Na}_{2} \mathrm{SO}_{4}$ e quantificação por colorimetria, e dos teores de $\mathrm{P}, \mathrm{K}, \mathrm{Ca}, \mathrm{Mg}, \mathrm{H}+\mathrm{Al}$, segundo RAIJ \& QUAGGIO (1983); com esses valores foram calculadas a saturação por bases (V\%) e capacidade de troca catiônica (CTC).

$\mathrm{O}$ rendimento de milho em espiga dos três tratamentos foi determinado em quatro posiçōes de cada linha, considerando-se uma área útil de $1,8 \mathrm{~m}^{2}$, por posição, para análise e comparação dos dados.

Os efeitos dos tratamentos foram estudados estatisticamente, mediante análise de variância dos resultados. As médias dos fatores: tratamentos considerados ou sistemas de manejo, profundidade de amostragem e linhas seguindo a profundidade de remoção da camada de solo de $0-45 \mathrm{~cm}$ foram comparadas pelo teste de Tukey a nível de $5 \%$ de probabilidade e por regressão polinomial, num arranjo fatorial $3 \times 3 \times 21$, com 4 repetiçōes, num delineamento inteiramente casualizado, totalizando 756 parcelas. 


\section{RESULTADOS E DISCUSSĀO}

Os dados originais de P e K apresentaram grande variação e para que fosse possível proceder às análises de variância foi necessário fazer uma transformação. Adotou-se portanto, para as duas variáveis, a transformação $\ln (\mathrm{x}$ $+1,2)$ ou $\log e^{(x+1,2)}$.

A variável produtividade apresentou muitas observações nulas para a testemunha, de modo que houve necessidade de se fazer a análise de variância considerando-se apenas os dois tratamentos que foram adubados.

4.1. Parâmetros químicos do solo - comportamento geral nos três tratamentos considerados

Após os dados originais das análises químicas terem sido examinados e adaptados às exigências dos procedimentos estatísticos empregados, as análises foram executadas. A Tabela 3 apresenta os resultados dos quadrados médios, relativos as fontes de variação e a cada variável levantada no experimento, bem como, as médias dos tratamentos e das profundidades seguidas 


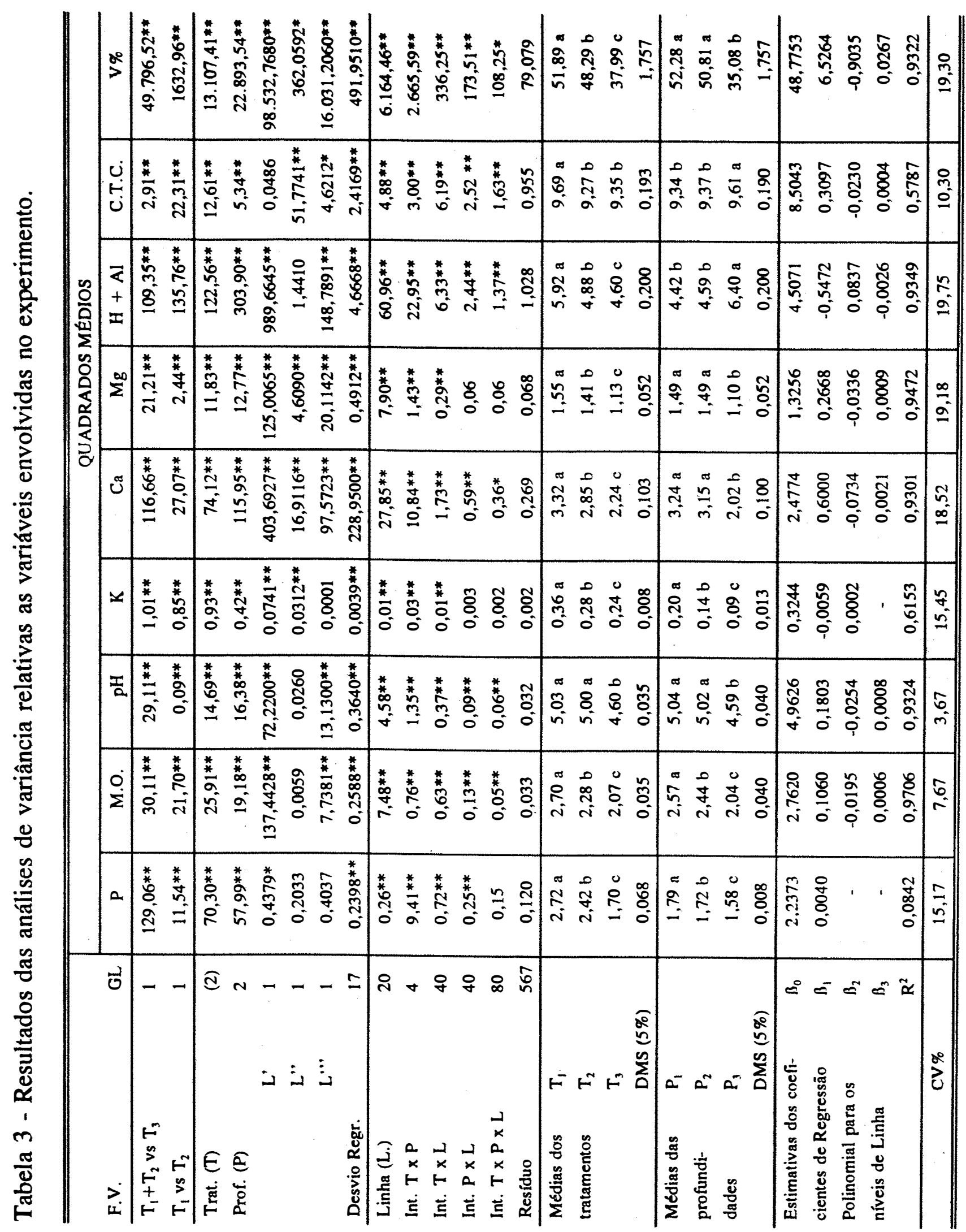


de letras indicativas dos confrontos delas pelo teste de Tukey a $5 \%$ de probabilidade. Apresenta ainda as estimativas dos coeficientes da regressão polinomial dos modelos que explicam as variações de cada variável em relação às linhas e, ainda, as diferenças mínimas significativas (D.M.S.) e finalmente os coeficientes de variação relativa a cada variável.

Os coeficientes de variação (C.V.) para as variáveis envolvidas no experimento foram da ordem de $3,67 \%$ a $19,75 \%$ os quais são plenamente admissíveis para ensaios de campo e, em especial, para teores de nutrientes no solo que, geralmente, apresentam grandes variações.

Conforme mostra a Tabela 3, houve efeito estatístico altamente significativo (a $1 \%$ de probabilidade) para tratamento em todas as variáveis relativas às características químicas do solo. No desdobramento dos graus de liberdade, observou-se que os teores dos nutrientes no solo, dos tratamentos que levaram adubação $\left(T_{1}\right.$ e $\left.T_{2}\right)$ em média foi superior a testemunha. Os teores dos nutrientes no solo do tratamento 1 foram também, superiores aos do tratamento 2, indicando que esses teores estão relacionados com a presença da matéria orgânica, complementado pela fertilização química e correção do solo. MBAGWU (1985), SPAROVEK et al. (1991) e MBAGWU et al. (1984) também observaram a importância da matéria orgânica na recuperação da fertilidade do solo, restaurando o seu potencial produtivo, com uso conjunto de fertilizante mineral. 
Ao confrontar as médias pelo teste de Tukey a $5 \%$ de probabilidade verificou-se que $T_{1}>T_{2}>T_{3}$ em todas as variáveis estudadas, exceto para CTC onde $T_{1}>T_{2}=T_{3}$.

Para o fator profundidade de amostragem do solo, observou-se que ele apresentou significância estatística para todos os componentes químicos do solo analisado. Em geral, os teores dos elementos químicos do solo em relação às profundidades de amostragem são decrescentes, conforme evidenciam as médias estimadas, com exceção da variável $\mathrm{H}+\mathrm{Al}$ que apresentou comportamento inverso aos dos demais elementos.

No confronto das médias pelo teste de Tukey a $5 \%$ de probabilidade verificou-se que $\mathrm{P}_{1}>\mathrm{P}_{2}>\mathrm{P}_{3}$ para as variáveis $\mathrm{P}, \mathrm{M}$.O. e K; $\mathrm{P}_{1}$ $=\mathrm{P}_{2}>\mathrm{P}_{3}$ para as variáveis $\mathrm{pH}, \mathrm{Ca}, \mathrm{Mg} ; \mathrm{P}_{1}=\mathrm{P}_{2}<\mathrm{P}_{3}$ para as variáveis $\mathrm{H}+$ Al e $P_{1}>P_{2}=P_{3}$ em CTC. FORSYTHE (1980), JOHNSTON (1982) e MEDEIROS (1980) indicam também a importância da matéria orgânica na CTC do solo e na liberação de alguns nutrientes para as plantas.

Com relação ao fator linha, apresentou efeito estatístico significativo a $1 \%$ de probabilidade para todos os componentes químicos do solo estudado. Nesse caso, achou-se necessário proceder-se ao estudo do comportamento dos teores no solo, em relação às linhas através da regressão polinomial.

Foi proposto no planejamento que seriam verificados os componentes da regressão polinomial de $1^{\circ}, 2^{\circ}$ e $3^{\circ}$ graus, tendo em vista que 
um polinômio de mais alto grau poderia até explicar melhor o comportamento das variáveis, porém, não traduziria o comportamento lógico esperado.

$\mathrm{O}$ que se espera, logicamente, é que o comportamento dos elemen-tos em relação às linhas seja bem explicado por um polinômio do $1^{\circ}$ ou $2^{\circ}$ ou do $3^{\circ}$ grau. Neste sentido, de acordo com a Tabela 3 , observou-se que para todas as variáveis o desvio da regressão apresentou significância estatística a $1 \%$ de probabilidade, indicando que existe pelo menos um componente de regressão polinomial de grau superior a 3 que apresenta significância estatística. Isto ocorreu, talvez, pela variabilidade das variáveis que, como foi dito, é muito grande.

Portanto, procedendo de acordo com o planejamento e observando-se a significância estatística dos componentes da regressão polinomial, foi proposta uma regressão linear para explicar as variações de $\mathrm{P}$ transformado em $\mathrm{R}^{2}=0,08$ (muito baixo), um polinômio do $2^{\circ}$ grau para $\mathrm{K}$ transformado com $\mathrm{R}^{2}=0,62$ e finalmente um polinômio do $3^{\circ}$ grau para as variáveis M.O., $\mathrm{pH}$, $\mathrm{Ca}, \mathrm{Mg}, \mathrm{H}+\mathrm{Al}$, CTC e V\% com coeficientes de determinação $\mathrm{R}^{2}=0,97$; 0,$93 ; 0,93 ; 0,95 ; 0,93 ; 0,58 ; 0,93$ respectivamente. Assim, com exceção das variáveis $\mathrm{P}$ e $\mathrm{K}$ transformadas, as variações das demais variáveis foram muito bem explicadas pelo polinômio do $3^{\circ}$ grau; isto pode ser observado na Figura 2, que mostra o comportamento geral das variáveis. 

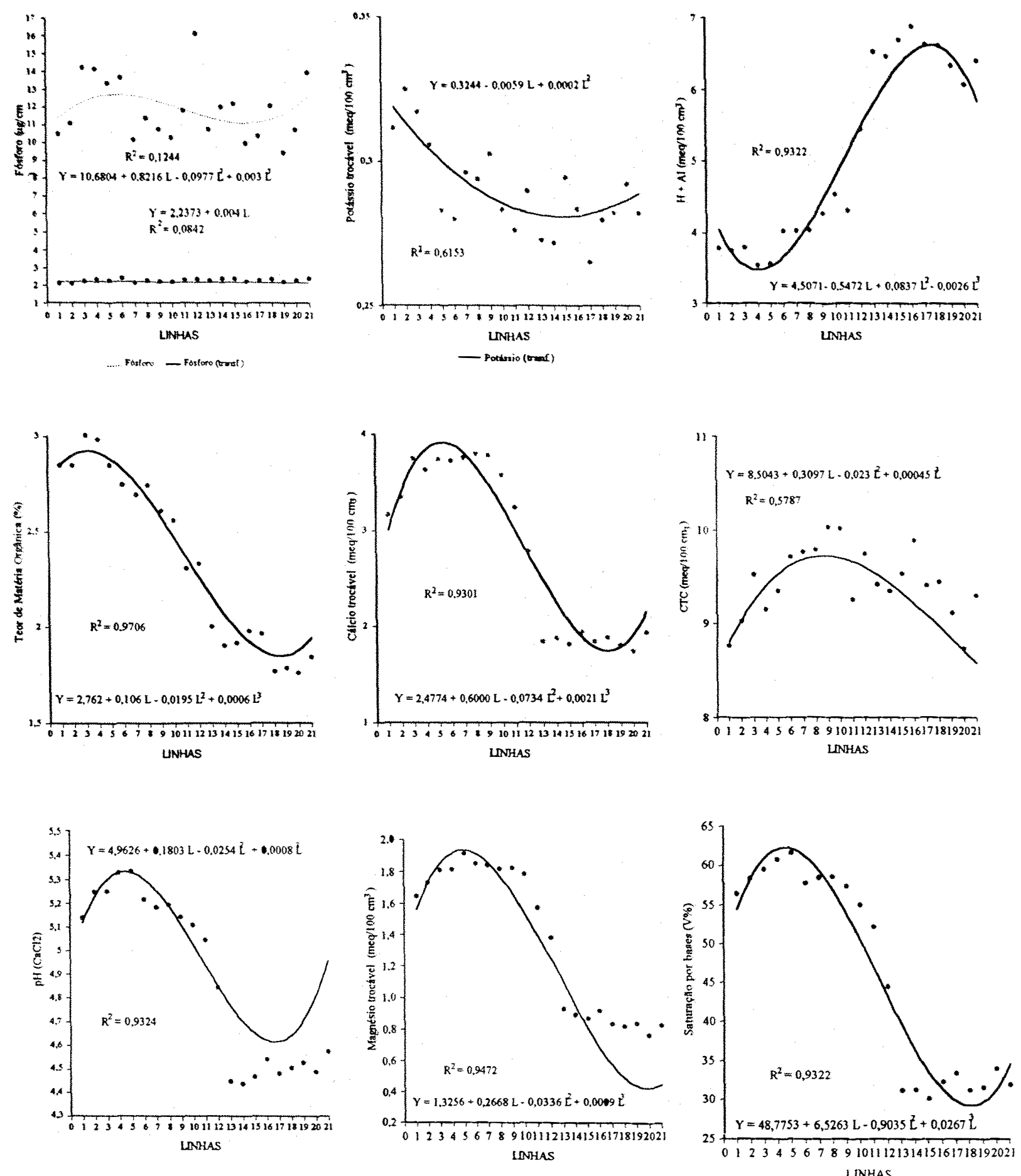

Figura 2. Comportamento geral das variáveis $\mathrm{P}$ (transformado), $\mathrm{MO}, \mathrm{pH}, \mathrm{K}$ (transformado), $\mathrm{Ca}, \mathrm{Mg}, \mathrm{H}+\mathrm{Al}, \mathrm{CTC}$ e Percentagens de Saturação por bases (V\%) em relação às linhas ou profundidade de raspagem de solo de $0 \mathrm{a} 40 \mathrm{~cm}$.

Obs: ( Linha $1=0 \mathrm{~cm}, \mathrm{~L} 2=2 \mathrm{~cm}, \ldots \ldots \mathrm{L} 21=40 \mathrm{~cm}$ ). 


\subsection{Características químicas do solo e seu comportamento em relação às profundidades de amostragem de solo e da remoção do solo nos três tratamentos}

A interação tratamento $x$ profundidade de amostragem de solo ( $T$ x P) apresentou significância estatística ao nível de $1 \%$ de probabilidade para todas as variáveis estudadas, indicando que os comportamentos das variáveis em relação aos tratamentos não são os mesmos nas diferentes profundidades, ou seja, os comportamentos das variáveis em relação às profundidades não são os mesmos de tratamento para tratamento, isso pode ser visto, observando-se a Tabela 4 do confronto das médias da interação T x P.

Observa-se, de modo geral, que os tratamentos $T_{1}>T_{2}>T_{3}$ dentro das profundidades $P_{1}$ e $P_{2}$, mas não ocorrendo na profundidade $P_{3}$, onde os tratamentos $T_{1}=T_{2}>T_{3}$.

Analisando a variável $\mathrm{P}$ (transformado) verificou-se que os tratamentos $T_{1}>T_{2}>T_{3}$.dentro das profundidades $P_{1}$ e $P_{2}$, mas na profundidade $P_{3}(20-40 \mathrm{~cm}) T_{1}=T_{2}>T_{3}$. Por outro lado, as profundidades $P_{1}>P_{2}>P_{3}$ dentro dos tratamentos $T_{1}$ e $T_{2}$, sendo que $P_{1}=P_{2}>P_{3}$ para 0 tratamento $\mathrm{T}_{3}$.

Para a variável M.O. verificou-se que os tratamentos $T_{1}>T_{2}>$ $T_{3}$ nas três profundidades. Para as profundidades $P_{1}>P_{2}>P_{3}$ nos três tratamentos.

Para a variável $p H$ verificou-se que os tratamentos $T_{1}=T_{2}>T_{3}$ nas três profundidades. Para as profundidades $P_{1}=P_{2}>P_{3}$ nos três tratamentos. 
Para a variável K(transformado) ocorreu o mesmo comportamento verificado para a variável M.O.

Para a variável Ca verificou-se que os tratamentos $T_{1}>T_{2}>T_{3}$ dentro das profundidades $P_{1}$ e $P_{2}$, mas na profundidade $P_{3}, T_{1}>T_{2}=T_{3}$. Para as profundidades $P_{1}=P_{2}>P_{3}$ para os tratamentos $T_{2}$ e $T_{3}$, sendo que $P_{1}>P_{2}$ $>\mathrm{P}_{3}$ no tratamento $\mathrm{T}_{1}$.

Para a variável $\mathrm{Mg}$, verificou-se que para os tratamentos $T_{1}>$ $T_{2}>T_{3}$ dentro das profundidades $P_{1}$ e $P_{2}$, sendo que $T_{1}=T_{2}>T_{3}$ na profundidade $\mathrm{P}_{3}$. Para as profundidades $\mathrm{P}_{1}=\mathrm{P}_{2}>\mathrm{P}_{3}$ para os três tratamentos.

Para a variável $\mathrm{H}+\mathrm{Al}$ verificou-se que para os tratamentos $\mathrm{T}_{3}$ $>T_{2}>T_{1}$ dentro das profundidades $P_{1}$ e $P_{2}$, sendo que $T_{1}=T_{2}=T_{3}$ na profundidade $P_{3}$. Para as profundidades $P_{3}>P_{2}=P_{1}$ para os três tratamentos.

Para a variável CTC verificou-se que os tratamentos $T_{1}>T_{2}=$ $T_{3}$ dentro das profundidades $P_{1}$ e $P_{2}$, sendo que $T_{1}=T_{2}=T_{3}$ na profundidade $P_{3}$. Para as profundidades $P_{1}=P_{3}>P_{2}$ nos tratamentos $T_{1}$ e $T_{2}$, e $P_{1}=P_{2}=$ $\mathrm{P}_{3}$ para os três tratamentos.

Para variável V\% verificou-se que os tratamentos $T_{1}>T_{2}>T_{3}$ dentro das profundidades $P_{1}$ e $P_{2}$, sendo que $T_{1}=T_{2}=T_{3}$ na profundidade $P_{3}$. Para as profundidades $\mathrm{P}_{1}=\mathrm{P}_{2}>\mathrm{P}_{3}$ para os três tratamentos. 
Tabela 4 - Confronto das médias de interação $\mathrm{T}$ x $\mathrm{P}$ com respectivas DMS's

\begin{tabular}{|c|c|c|c|c|c|}
\hline \multirow[b]{2}{*}{ Variável } & \multirow[b]{2}{*}{ Tratamento } & \multicolumn{3}{|c|}{ Profundidade } & \multirow{2}{*}{$\begin{array}{l}\text { DMS (Td.P) }= \\
=\text { DMS }(\mathrm{Pd} . \mathrm{T}\end{array}$} \\
\hline & & $P_{1}$ & $\mathrm{P}_{2}$ & $\mathrm{P}_{3}$ & \\
\hline \multirow{3}{*}{$\mathrm{P}$ (transformado) } & $T_{1}$ & 3,341 aA & $2,952 \mathrm{aB}$ & $1,880 \mathrm{aC}$ & \multirow{3}{*}{0,118} \\
\hline & $\mathrm{T}_{2}$ & $2,834 \mathrm{bA}$ & $2,666 \mathrm{bB}$ & $1,766 \mathrm{aC}$ & \\
\hline & $\mathrm{T}_{3}$ & $1,794 \mathrm{cA}$ & $1,720 \mathrm{cA}$ & $1,575 \mathrm{bB}$ & \\
\hline \multirow{3}{*}{ M.O. } & $\mathrm{T}_{1}$ & 3,01 aA & $2,80 \mathrm{aB}$ & $2,29 \mathrm{aC}$ & \multirow{3}{*}{0,06} \\
\hline & $\mathrm{T}_{2}$ & $2,47 \mathrm{bA}$ & $2,40 \mathrm{bB}$ & $1,98 \mathrm{bC}$ & \\
\hline & $\mathrm{T}_{3}$ & $2,22 \mathrm{cA}$ & $2,13 \mathrm{cB}$ & $1,86 \mathrm{cC}$ & \\
\hline \multirow{3}{*}{$\mathrm{pH}$} & $\mathrm{T}_{1}$ & $5,23 \mathrm{aA}$ & $5,22 \mathrm{aA}$ & $4,64 \mathrm{aB}$ & \multirow{3}{*}{0,06} \\
\hline & $\mathrm{T}_{2}$ & 5,20 aA & 5,18 aA & $4,64 \mathrm{aB}$ & \\
\hline & $\mathrm{T}_{3}$ & $4,67 \mathrm{bA}$ & $4,66 \mathrm{bA}$ & $4,48 \mathrm{bB}$ & \\
\hline \multirow{3}{*}{$\mathrm{K}$ (transformado) } & $\mathrm{T}_{1}$ & $0,409 \mathrm{aA}$ & $0,362 \mathrm{aB}$ & $0,295 \mathrm{aC}$ & \multirow{3}{*}{0,015} \\
\hline & $\mathrm{T}_{2}$ & $0,328 \mathrm{bA}$ & $0,273 \mathrm{bB}$ & $0,235 \mathrm{bC}$ & \\
\hline & $\mathrm{T}_{3}$ & $0,255 \mathrm{cA}$ & $0,235 \mathrm{cB}$ & $0,216 \mathrm{cC}$ & \\
\hline \multirow{3}{*}{$\mathrm{Ca}$} & $\mathrm{T}_{1}$ & 4,02 aA & $3,75 \mathrm{aB}$ & $2,18 \mathrm{aC}$ & \multirow{3}{*}{0,18} \\
\hline & $\mathrm{T}_{2}$ & $3,28 \mathrm{bA}$ & $3,28 \mathrm{bA}$ & $1,99 \mathrm{bB}$ & \\
\hline & $\mathrm{T}_{3}$ & $2,40 \mathrm{cA}$ & $2,42 \mathrm{cA}$ & $1,89 \mathrm{bB}$ & \\
\hline \multirow{3}{*}{$\mathrm{Mg}$} & $\overline{T_{1}}$ & $1,79 \mathrm{aA}$ & $1,72 \mathrm{aA}$ & $1,15 \mathrm{aB}$ & \multirow{3}{*}{0,09} \\
\hline & $\mathrm{T}_{2}$ & $1,52 \mathrm{bA}$ & $1,57 \mathrm{bA}$ & $1,15 \mathrm{aB}$ & \\
\hline & $\mathrm{T}_{3}$ & $1,17 \mathrm{cA}$ & $1,19 \mathrm{cA}$ & $1,02 \mathrm{bB}$ & \\
\hline \multirow{3}{*}{$\mathrm{H}+\mathrm{Al}$} & $T_{1}$ & $3,69 \mathrm{cB}$ & $3,82 \mathrm{cB}$ & $6,28 \mathrm{aA}$ & \multirow{3}{*}{0,35} \\
\hline & $\mathrm{T}_{2}$ & $4,04 \mathrm{bB}$ & $4,20 \mathrm{bB}$ & $6,42 \mathrm{aA}$ & \\
\hline & $\mathrm{T}_{3}$ & $5,53 \mathrm{aB}$ & $5,75 \mathrm{aB}$ & $6,50 \mathrm{aA}$ & \\
\hline \multirow{3}{*}{ СТC } & $\mathrm{T}_{1}$ & $9,80 \mathrm{aA}$ & $9,54 \mathrm{aA}$ & $9,75 \mathrm{aA}$ & \multirow{3}{*}{0,33} \\
\hline & $\mathrm{T}_{2}$ & $9,03 \mathrm{bB}$ & $9,16 \mathrm{abB}$ & $9,62 \mathrm{aA}$ & \\
\hline & $\mathrm{T}_{3}$ & $9,19 \mathrm{bA}$ & $9,41 \mathrm{bA}$ & $9,45 \mathrm{aA}$ & \\
\hline \multirow{3}{*}{ V\% } & $\mathrm{T}_{1}$ & $61,44 \mathrm{aA}$ & $58,53 \mathrm{aA}$ & $35,70 \mathrm{aB}$ & \multirow{3}{*}{3,04} \\
\hline & $\mathrm{T}_{2}$ & $55,22 \mathrm{bA}$ & $54,34 \mathrm{bA}$ & $35,30 \mathrm{aB}$ & \\
\hline & $\mathrm{T}_{3}$ & $40,18 \mathrm{cA}$ & $39,55 \mathrm{cA}$ & $34,25 \mathrm{aB}$ & \\
\hline
\end{tabular}

Obs.: Médias seguidas da mesma letra minúscula não diferem entre si no sentido vertical e médias seguidas da mesma letra maiúscula não diferem entre si no sentido horizontal (Tukey a $5 \%$ de probabilidade). 
Com respeito à interação Tratamento $\mathrm{x}$ Linha, onde as linhas seguem a profundidade de raspagem de 0 a $40 \mathrm{~cm}(\mathrm{~T} \times \mathrm{L})$, observou-se que a mesma apresentou significância estatística a $1 \%$ de probabilidade pelo teste $\mathrm{F}$ em todas as variáveis observadas em relação aos tratamentos dentro das diferentes linhas, como pode ser visto na tabela dos confrontos das médias da interação $T$ $\mathrm{x} \mathrm{L}$ pelo teste de Tukey a $5 \%$ de probabilidade nas Tabelas 5 a 13 e, além disso, há diferença de comportamento das variáveis analisadas em relação as linhas dentro dos tratamentos, conforme mostram as Tabelas 14 a 22 e as Figuras 3, 4, 5 e 6, considerando apenas as correspondentes a interação $(T \times L)$, para todas as variáveis. DEDECEK (1987), YOST et al. (1985) e CARLSON et al. (1961) também observaram que o efeito da adubação na recuperação do potencial produtivo do solo é diminuido a medida que aumenta a camada de solo removida, com a consequente perda de nutrientes. 
Tabela 5 - Confronto das médias de $\mathrm{P}$ (transformado) dos tratamentos $\left(\mathrm{T}_{1}, \mathrm{~T}_{2} \mathrm{e}\right.$ $T_{3}$ ) e profundidades $\left(P_{1}, P_{2}\right.$ e $\left.P_{3}\right)$.

\begin{tabular}{|c|c|c|c|c|c|c|}
\hline \multirow[b]{2}{*}{ Linha } & \multicolumn{6}{|c|}{ Variável $=\mathrm{P}$ (transformado $)-\mathrm{ug} / \mathrm{cm}^{3}$} \\
\hline & $T_{1}$ & $T_{2}$ & $\mathrm{~T}_{3}$ & $P_{1}$ & $\mathrm{P}_{2}$ & $\mathrm{P}_{3}$ \\
\hline 1 & $2,54 \mathrm{a}$ & $2,29 \mathrm{a}$ & $1,58 \mathrm{~b}$ & $2,70 \mathrm{a}$ & $2,31 \mathrm{~b}$ & $1,41 \mathrm{c}$ \\
\hline 2 & $2,44 \mathrm{a}$ & $2,60 \mathrm{a}$ & $1,39 \mathrm{~b}$ & $2,66 \mathrm{a}$ & $2,44 \mathrm{a}$ & $1,33 \mathrm{~b}$ \\
\hline 3 & $2,73 \mathrm{a}$ & $2,81 \mathrm{a}$ & $1,25 \mathrm{~b}$ & $2,90 \mathrm{a}$ & $2,47 \mathrm{~b}$ & $1,42 \mathrm{c}$ \\
\hline 4 & $3,03 \mathrm{a}$ & $2,55 \mathrm{~b}$ & $1,53 \mathrm{c}$ & $2,81 \mathrm{a}$ & $2,55 \mathrm{a}$ & $1,75 \mathrm{~b}$ \\
\hline 5 & $3,06 \mathrm{a}$ & $2,50 \mathrm{~b}$ & $1,27 \mathrm{c}$ & 2,73 a & $2,45 \mathrm{a}$ & $1,65 \mathrm{~b}$ \\
\hline 6 & $2,91 \mathrm{a}$ & $2,50 \mathrm{~b}$ & $1,88 \mathrm{c}$ & $2,76 \mathrm{a}$ & $2,64 \mathrm{a}$ & $1,89 \mathrm{~b}$ \\
\hline 7 & 2,48 a & $2,47 \mathrm{a}$ & $1,53 \mathrm{~b}$ & $2,65 \mathrm{a}$ & $2,18 \mathrm{~b}$ & $1,64 \mathrm{c}$ \\
\hline 8 & $2,92 \mathrm{a}$ & $2,33 \mathrm{~b}$ & $1,63 \mathrm{c}$ & $2,63 \mathrm{a}$ & $2,39 a$ & $1,86 \mathrm{~b}$ \\
\hline 9 & $2,47 \mathrm{a}$ & $2,38 \mathrm{a}$ & $1,89 \mathrm{~b}$ & $2,68 \mathrm{a}$ & $2,49 a$ & $1,57 \mathrm{~b}$ \\
\hline 10 & $2,69 \mathrm{a}$ & $2,13 \mathrm{~b}$ & $1,83 \mathrm{~b}$ & $2,58 \mathrm{a}$ & $2,41 a$ & $1,66 \mathrm{~b}$ \\
\hline 11 & $2,78 \mathrm{a}$ & $2,46 \mathrm{~b}$ & $1,75 \mathrm{c}$ & $2,63 \mathrm{a}$ & $2,48 a$ & $1,87 \mathrm{~b}$ \\
\hline 12 & $3,12 \mathrm{a}$ & $2,42 \mathrm{~b}$ & $1,51 \mathrm{c}$ & $2,64 \mathrm{a}$ & $2,52 \mathrm{a}$ & $1,88 \mathrm{~b}$ \\
\hline 13 & $2,80 \mathrm{a}$ & $2,44 \mathrm{~b}$ & $1,53 \mathrm{c}$ & $2,43 a$ & $2,43 \mathrm{a}$ & $1,91 \mathrm{~b}$ \\
\hline 14 & $2,89 \mathrm{a}$ & $2,48 \mathrm{~b}$ & $1,77 \mathrm{c}$ & $2,60 \mathrm{a}$ & $2,52 \mathrm{a}$ & $2,01 \mathrm{~b}$ \\
\hline 15 & $2,59 \mathrm{a}$ & $2,62 \mathrm{a}$ & $1,90 \mathrm{~b}$ & $2,65 \mathrm{a}$ & $2,41 \mathrm{a}$ & $2,05 \mathrm{~b}$ \\
\hline 16 & $2,31 \mathrm{a}$ & $2,30 \mathrm{a}$ & $2,03 \mathrm{a}$ & $2,67 \mathrm{a}$ & $2,38 \mathrm{a}$ & $1,60 \mathrm{~b}$ \\
\hline 17 & $2,74 \mathrm{a}$ & $2,39 \mathrm{~b}$ & $1,70 \mathrm{c}$ & $2,47 \mathrm{a}$ & $2,49 a$ & $1,87 \mathrm{~b}$ \\
\hline 18 & $2,84 \mathrm{a}$ & $2,38 \mathrm{~b}$ & $1,83 \mathrm{c}$ & $2,62 \mathrm{a}$ & $2,53 \mathrm{a}$ & $1,91 \mathrm{~b}$ \\
\hline 19 & $2,67 \mathrm{a}$ & $2,96 \mathrm{~b}$ & $1,92 \mathrm{~b}$ & $2,46 \mathrm{a}$ & $2,29 \mathrm{a}$ & $1,80 \mathrm{~b}$ \\
\hline 20 & $2,55 \mathrm{a}$ & $2,19 \mathrm{~b}$ & $2,07 \mathrm{~b}$ & $2,79 a$ & $2,38 \mathrm{~b}$ & $1,64 \mathrm{c}$ \\
\hline \multirow[t]{2}{*}{21} & $2,66 \mathrm{a}$ & $2,71 \mathrm{a}$ & $1,79 \mathrm{~b}$ & $2,73 \mathrm{a}$ & $2,60 \mathrm{a}$ & $1,84 \mathrm{~b}$ \\
\hline & \multicolumn{3}{|c|}{ DMS $5 \%($ Td.L $)=0,31$} & \multicolumn{3}{|c|}{ DMS 5\% $($ Pd.L $)=0,31$} \\
\hline
\end{tabular}

Obs: Médias seguidas de mesma letra minúscula não diferem entre si no sentido vertical pelo teste Tukey a $5 \%$ de probabilidade. 
Tabela 6 - Confronto das médias de M.O. dos tratamentos $\left(T_{1}, T_{2}\right.$ e $\left.T_{3}\right)$ e profundidades $\left(\mathrm{P}_{1}, \mathrm{P}_{2}\right.$ e $\left.\mathrm{P}_{3}\right)$.

\begin{tabular}{crrrrrr}
\hline \hline \multirow{2}{*}{ Linha } & \multicolumn{7}{c}{ Variável $=$ M.O. (\%) } \\
\cline { 2 - 7 } & $\mathrm{T}_{1}$ & $\mathrm{~T}_{2}$ & \multicolumn{1}{c}{$\mathrm{T}_{3}$} & $\mathrm{P}_{1}$ & \multicolumn{1}{c}{$\mathrm{P}_{2}$} & $\mathrm{P}_{3}$ \\
\hline 1 & $3,62 \mathrm{a}$ & $2,41 \mathrm{~b}$ & $2,51 \mathrm{~b}$ & $3,22 \mathrm{a}$ & $2,93 \mathrm{~b}$ & $2,32 \mathrm{c}$ \\
2 & $3,58 \mathrm{a}$ & $2,56 \mathrm{~b}$ & $2,40 \mathrm{~b}$ & $3,13 \mathrm{a}$ & $3,00 \mathrm{a}$ & $2,40 \mathrm{~b}$ \\
3 & $3,72 \mathrm{a}$ & $2,77 \mathrm{~b}$ & $2,51 \mathrm{c}$ & $3,29 \mathrm{a}$ & $3,14 \mathrm{a}$ & $2,55 \mathrm{~b}$ \\
4 & $3,81 \mathrm{a}$ & $2,69 \mathrm{~b}$ & $2,43 \mathrm{c}$ & $3,32 \mathrm{a}$ & $3,15 \mathrm{~b}$ & $2,45 \mathrm{c}$ \\
5 & $3,38 \mathrm{a}$ & $2,76 \mathrm{~b}$ & $2,39 \mathrm{c}$ & $3,10 \mathrm{a}$ & $3,02 \mathrm{a}$ & $2,42 \mathrm{~b}$ \\
6 & $3,03 \mathrm{a}$ & $2,68 \mathrm{~b}$ & $2,52 \mathrm{c}$ & $2,97 \mathrm{a}$ & $2,89 \mathrm{a}$ & $2,37 \mathrm{~b}$ \\
7 & $2,83 \mathrm{a}$ & $2,72 \mathrm{a}$ & $2,52 \mathrm{~b}$ & $2,93 \mathrm{a}$ & $2,78 \mathrm{a}$ & $2,35 \mathrm{~b}$ \\
8 & $3,00 \mathrm{a}$ & $2,78 \mathrm{~b}$ & $2,44 \mathrm{c}$ & $2,93 \mathrm{a}$ & $2,86 \mathrm{a}$ & $2,43 \mathrm{~b}$ \\
9 & $2,82 \mathrm{a}$ & $2,68 \mathrm{a}$ & $2,32 \mathrm{~b}$ & $2,81 \mathrm{a}$ & $2,78 \mathrm{a}$ & $2,23 \mathrm{~b}$ \\
10 & $2,83 \mathrm{a}$ & $2,62 \mathrm{~b}$ & $2,23 \mathrm{c}$ & $2,76 \mathrm{a}$ & $2,69 \mathrm{a}$ & $2,22 \mathrm{~b}$ \\
11 & $2,53 \mathrm{a}$ & $2,47 \mathrm{a}$ & $1,93 \mathrm{~b}$ & $2,55 \mathrm{a}$ & $2,41 \mathrm{a}$ & $1,97 \mathrm{~b}$ \\
12 & $2,41 \mathrm{a}$ & $2,52 \mathrm{a}$ & $2,08 \mathrm{~b}$ & $2,52 \mathrm{a}$ & $2,48 \mathrm{~b}$ & $2,00 \mathrm{c}$ \\
13 & $2,13 \mathrm{a}$ & $2,56 \mathrm{a}$ & $1,63 \mathrm{~b}$ & $2,28 \mathrm{a}$ & $2,03 \mathrm{~b}$ & $1,71 \mathrm{c}$ \\
14 & $2,24 \mathrm{a}$ & $1,93 \mathrm{~b}$ & $1,53 \mathrm{c}$ & $2,03 \mathrm{a}$ & $1,99 \mathrm{a}$ & $1,68 \mathrm{~b}$ \\
15 & $2,28 \mathrm{a}$ & $1,88 \mathrm{~b}$ & $1,59 \mathrm{c}$ & $2,06 \mathrm{a}$ & $1,96 \mathrm{a}$ & $1,73 \mathrm{~b}$ \\
16 & $2,31 \mathrm{a}$ & $1,76 \mathrm{~b}$ & $1,88 \mathrm{~b}$ & $2,10 \mathrm{a}$ & $2,01 \mathrm{a}$ & $1,83 \mathrm{~b}$ \\
17 & $2,28 \mathrm{a}$ & $1,72 \mathrm{c}$ & $1,90 \mathrm{~b}$ & $2,11 \mathrm{a}$ & $2,03 \mathrm{a}$ & $1,76 \mathrm{~b}$ \\
18 & $1,96 \mathrm{a}$ & $1,68 \mathrm{~b}$ & $1,64 \mathrm{~b}$ & $1,89 \mathrm{a}$ & $1,82 \mathrm{a}$ & $1,53 \mathrm{~b}$ \\
19 & $2,04 \mathrm{a}$ & $1,63 \mathrm{~b}$ & $1,66 \mathrm{~b}$ & $1,98 \mathrm{a}$ & $1,78 \mathrm{~b}$ & $1,58 \mathrm{c}$ \\
20 & $1,83 \mathrm{a}$ & $1,69 \mathrm{a}$ & $1,74 \mathrm{a}$ & $1,94 \mathrm{a}$ & $1,73 \mathrm{~b}$ & $1,59 \mathrm{~b}$ \\
21 & $2,11 \mathrm{a}$ & $1,78 \mathrm{~b}$ & $1,63 \mathrm{~b}$ & $2,04 \mathrm{a}$ & $1,83 \mathrm{~b}$ & $1,65 \mathrm{c}$ \\
& $\mathrm{DMS} 5 \%(T \mathrm{~T} . \mathrm{L})$ & 0,16 & $\mathrm{DMS} 5 \%(P d . \mathrm{L})=0,16$ \\
\hline & & & & & &
\end{tabular}

Obs: Médias seguidas de mesma letra minúscula não diferem entre si no sentido vertical pelo teste Tukey a $5 \%$ de probabilidade. 
Tabela 7 - Confronto das médias de $\mathrm{pH}$ dos tratamentos $\left(T_{1}, T_{2}\right.$ e $\left.T_{3}\right)$ e profundidades $\left(\mathrm{P}_{1}, \mathrm{P}_{2}\right.$ e $\left.\mathrm{P}_{3}\right)$.

\begin{tabular}{|c|c|c|c|c|c|c|}
\hline \multirow[b]{2}{*}{ Linha } & \multicolumn{6}{|c|}{ Variável $=\mathrm{pH}$} \\
\hline & $\mathrm{T}_{1}$ & $T_{2}$ & $T_{3}$ & $P_{1}$ & $\mathrm{P}_{2}$ & $P_{3}$ \\
\hline 1 & $5,17 \mathrm{a}$ & $5,33 \mathrm{a}$ & $4,93 \mathrm{~b}$ & $5,20 \mathrm{a}$ & $5,26 \mathrm{a}$ & $4,96 \mathrm{~b}$ \\
\hline 2 & $5,12 \mathrm{~b}$ & $5,71 \mathrm{a}$ & $4,92 \mathrm{c}$ & $5,40 \mathrm{a}$ & $5,43 \mathrm{a}$ & $4,92 \mathrm{~b}$ \\
\hline 3 & $5,02 \mathrm{~b}$ & $5,68 \mathrm{a}$ & $5,05 \mathrm{~b}$ & $5,38 \mathrm{a}$ & $5,43 \mathrm{a}$ & $4,93 \mathrm{~b}$ \\
\hline 4 & 5,35 a & $5,43 \mathrm{a}$ & $5,18 \mathrm{~b}$ & $5,54 \mathrm{a}$ & $5,47 \mathrm{a}$ & $4,98 \mathrm{~b}$ \\
\hline 5 & $5,39 \mathrm{~b}$ & $5,60 \mathrm{a}$ & $5,01 \mathrm{c}$ & 5,48 a & $5,53 \mathrm{a}$ & $4,99 \mathrm{~b}$ \\
\hline 6 & $5,31 \mathrm{a}$ & $5,37 \mathrm{a}$ & $4,98 \mathrm{~b}$ & $5,42 \mathrm{a}$ & $5,38 \mathrm{a}$ & $4,85 \mathrm{~b}$ \\
\hline 7 & $5,13 \mathrm{~b}$ & $5,33 \mathrm{a}$ & $5,09 \mathrm{~b}$ & $5,43 \mathrm{a}$ & $5,28 \mathrm{a}$ & $4,84 \mathrm{~b}$ \\
\hline 8 & $5,36 \mathrm{a}$ & $5,33 \mathrm{a}$ & $4,89 \mathrm{~b}$ & $5,41 \mathrm{a}$ & $5,33 \mathrm{a}$ & $4,84 \mathrm{~b}$ \\
\hline 9 & $5,28 \mathrm{a}$ & 5,33 a & $4,83 \mathrm{~b}$ & $5,38 \mathrm{a}$ & $5,38 \mathrm{a}$ & $4,67 \mathrm{~b}$ \\
\hline 10 & $5,53 \mathrm{a}$ & $5,13 \mathrm{~b}$ & $4,66 \mathrm{c}$ & $5,29 \mathrm{a}$ & $5,35 \mathrm{a}$ & $4,68 \cdot b$ \\
\hline 11 & $5,45 \mathrm{a}$ & $5,19 b$ & $4,49 \mathrm{c}$ & $5,22 \mathrm{a}$ & $5,28 \mathrm{a}$ & $4,64 \mathrm{~b}$ \\
\hline 12 & $5,30 \mathrm{a}$ & $4,82 \mathrm{~b}$ & $4,42 \mathrm{c}$ & $5,04 \mathrm{a}$ & $5,07 \mathrm{a}$ & $4,43 \mathrm{~b}$ \\
\hline 13 & $4,50 \mathrm{a}$ & $4,56 \mathrm{a}$ & $4,28 \mathrm{~b}$ & $4,56 \mathrm{a}$ & $4,53 \mathrm{a}$ & $4,24 \mathrm{~b}$ \\
\hline 14 & $4,54 \mathrm{a}$ & $4,51 \mathrm{a}$ & $4,25 \mathrm{~b}$ & $4,53 \mathrm{a}$ & $4,53 \mathrm{a}$ & $4,24 \mathrm{~b}$ \\
\hline 15 & $4,61 \mathrm{a}$ & $4,53 \mathrm{a}$ & $4,26 \mathrm{~b}$ & $4,55 \mathrm{a}$ & $4,55 \mathrm{a}$ & $4,30 \mathrm{~b}$ \\
\hline 16 & $4,73 \mathrm{a}$ & $4,53 \mathrm{~b}$ & $4,38 \mathrm{~b}$ & $4,68 \mathrm{a}$ & $4,62 \mathrm{a}$ & $4,33 \mathrm{~b}$ \\
\hline 17 & $4,70 \mathrm{a}$ & $4,53 \mathrm{~b}$ & $4,22 \mathrm{c}$ & $4,58 \mathrm{a}$ & $4,55 \mathrm{a}$ & $4,32 \mathrm{~b}$ \\
\hline 18 & $4,78 \mathrm{a}$ & $4,57 \mathrm{~b}$ & $4,17 \mathrm{c}$ & $4,65 \mathrm{a}$ & $4,62 \mathrm{a}$ & $4,25 \mathrm{~b}$ \\
\hline 19 & $4,89 \mathrm{a}$ & $4,53 \mathrm{~b}$ & $4,17 \mathrm{c}$ & $4,63 \mathrm{a}$ & $4,63 \mathrm{a}$ & $4,33 \mathrm{~b}$ \\
\hline 20 & $4,64 \mathrm{a}$ & $4,58 \mathrm{a}$ & $4,25 \mathrm{~b}$ & $4,64 \mathrm{a}$ & $4,56 \mathrm{a}$ & $4,27 \mathrm{~b}$ \\
\hline 21 & $4,90 \mathrm{a}$ & $4,57 \mathrm{~b}$ & $4,26 \mathrm{c}$ & $4,74 \mathrm{a}$ & $4,67 \mathrm{a}$ & $4,32 \mathrm{~b}$ \\
\hline & DMS & (Td.L) & 0,16 & DMs & $\%(\mathrm{Pd} . \mathrm{L})$ & 0,16 \\
\hline
\end{tabular}

Obs: Médias seguidas de mesma letra minúscula não diferem entre si no sentido vertical pelo teste Tukey a $5 \%$ de probabilidade. 
Tabela 8 - Confronto das médias de $\mathrm{K}$ (transformado) dos tratamentos $\left(\mathrm{T}_{1}, \mathrm{~T}_{2} \mathrm{e}\right.$ $\left.T_{3}\right)$ e profundidades $\left(P_{1}, P_{2}\right.$ e $\left.P_{3}\right)$.

\begin{tabular}{|c|c|c|c|c|c|c|}
\hline \multirow[b]{2}{*}{ Linha } & \multicolumn{6}{|c|}{ Variável $=\mathrm{K}\left(\right.$ transformado) $\mathrm{meq} / 100 \mathrm{~cm}^{3}$} \\
\hline & $T_{1}$ & $\mathrm{~T}_{2}$ & $\mathrm{~T}_{3}$ & $P_{1}$ & $\mathrm{P}_{2}$ & $\mathrm{P}_{3}$ \\
\hline 1 & $0,37 \mathrm{a}$ & $0,33 \mathrm{~b}$ & $0,24 \mathrm{c}$ & 0,39 & 0,31 & 0,24 \\
\hline 2 & $0,36 \mathrm{a}$ & $0,34 \mathrm{a}$ & $0,28 \mathrm{~b}$ & 0,37 & 0,30 & 0,31 \\
\hline 3 & $0,39 \mathrm{a}$ & $0,32 \mathrm{~b}$ & $0,24 \mathrm{c}$ & 0,37 & 0,33 & 0,25 \\
\hline 4 & 0,41 a & $0,28 \mathrm{~b}$ & $0,23 \mathrm{c}$ & 0,35 & 0,31 & 0,26 \\
\hline 5 & 0,39 a & $0,26 \mathrm{~b}$ & $0,20 \mathrm{c}$ & 0,32 & 0,29 & 0,23 \\
\hline 6 & $0,37 \mathrm{a}$ & $0,24 \mathrm{~b}$ & $0,23 \mathrm{~b}$ & 0,32 & 0,28 & 0,24 \\
\hline 7 & $0,38 \mathrm{a}$ & $0,28 \mathrm{~b}$ & $0,24 \mathrm{~b}$ & 0,34 & 0,30 & 0,25 \\
\hline 8 & $0,37 \mathrm{a}$ & $0,28 \mathrm{~b}$ & $0,23 \mathrm{c}$ & 0,33 & 0,29 & 0,26 \\
\hline 9 & $0,38 \mathrm{a}$ & $0,31 \mathrm{~b}$ & $0,22 \mathrm{c}$ & 0,34 & 0,31 & 0,25 \\
\hline 10 & $0,36 \mathrm{a}$ & $0,28 \mathrm{~b}$ & $0,21 \mathrm{c}$ & 0,32 & 0,29 & 0,24 \\
\hline 11 & $0,36 \mathrm{a}$ & $0,25 \mathrm{~b}$ & $0,21 \mathrm{~b}$ & 0,31 & 0,28 & 0,24 \\
\hline 12 & $0,36 \mathrm{a}$ & $0,28 \mathrm{~b}$ & $0,23 c$ & 0,33 & 0,29 & 0,24 \\
\hline 13 & $0,34 \mathrm{a}$ & $0,27 \mathrm{~b}$ & $0,21 \mathrm{c}$ & 0,30 & 0,27 & 0,24 \\
\hline 14 & 0,31 a & $0,28 \mathrm{a}$ & $0,22 \mathrm{~b}$ & 0,31 & 0,27 & 0,24 \\
\hline 15 & $0,35 \mathrm{a}$ & $0,29 \mathrm{~b}$ & $0,25 \mathrm{~b}$ & 0,32 & 0,29 & 0,27 \\
\hline 16 & 0,32 a & $0,27 \mathrm{~b}$ & $0,26 \mathrm{~b}$ & 0,32 & 0,28 & 0,25 \\
\hline 17 & $0,31 \mathrm{a}$ & $0,26 \mathrm{~b}$ & $0,23 \mathrm{~b}$ & 0,30 & 0,27 & 0,23 \\
\hline 18 & $0,32 \mathrm{a}$ & $0,27 \mathrm{~b}$ & $0,26 \mathrm{~b}$ & 0,30 & 0,29 & 0,25 \\
\hline 19 & $0,34 \mathrm{a}$ & $0,26 \mathrm{~b}$ & $0,25 \mathrm{~b}$ & 0,32 & 0,29 & 0,24 \\
\hline 20 & 0,37 a & $0,26 \mathrm{~b}$ & $0,25 \mathrm{~b}$ & 0,35 & 0,28 & 0,25 \\
\hline 21 & $0,32 \mathrm{a}$ & $0,28 \mathrm{~b}$ & $0,25 \mathrm{~b}$ & 0,33 & 0,27 & 0,25 \\
\hline & DMS & $\%$ (Td.L) & 0,04 & & & \\
\hline
\end{tabular}

Obs: Médias seguidas de mesma letra minúscula não diferem entre si no sentido vertical pelo teste Tukey a $5 \%$ de probabilidade. 
Tabela 9 - Confronto das médias de $\mathrm{Ca}$ dos tratamentos $\left(\mathrm{T}_{1}, \mathrm{~T}_{2}\right.$ e $\left.\mathrm{T}_{3}\right)$ e profundidades $\left(\mathrm{P}_{1}, \mathrm{P}_{2}\right.$ e $\left.\mathrm{P}_{3}\right)$.

\begin{tabular}{|c|c|c|c|c|c|c|}
\hline \multirow[b]{2}{*}{ Linha } & \multicolumn{6}{|c|}{ Variável $=\mathrm{Ca}\left(\mathrm{meq} / 100 \mathrm{~cm}^{3}\right)$} \\
\hline & $T_{1}$ & $\mathrm{~T}_{2}$ & $\mathrm{~T}_{3}$ & $P_{1}$ & $\mathrm{P}_{2}$ & $P_{3}$ \\
\hline 1 & $4,05 \mathrm{a}$ & $2,77 \mathrm{~b}$ & $2,65 \mathrm{~b}$ & $3,65 \mathrm{a}$ & $3,38 \mathrm{a}$ & $2,43 \mathrm{~b}$ \\
\hline 2 & $3,82 \mathrm{a}$ & $3,69 \mathrm{a}$ & $2,53 \mathrm{~b}$ & $3,83 \mathrm{a}$ & $3,78 \mathrm{a}$ & $2,43 \mathrm{~b}$ \\
\hline 3 & $3,87 \mathrm{~b}$ & $4,53 \mathrm{a}$ & $2,83 \mathrm{c}$ & $4,35 \mathrm{a}$ & $4,19 \mathrm{a}$ & $2,69 \mathrm{~b}$ \\
\hline 4 & $4,10 \mathrm{a}$ & $3,99 \mathrm{a}$ & $2,78 \mathrm{~b}$ & $4,13 a$ & $4,00 \mathrm{a}$ & $2,75 \mathrm{~b}$ \\
\hline 5 & $4,46 \mathrm{a}$ & $3,93 \mathrm{~b}$ & $2,80 \mathrm{c}$ & $4,18 \mathrm{a}$ & $4,23 \mathrm{a}$ & $2,79 \mathrm{~b}$ \\
\hline 6 & $4,44 \mathrm{a}$ & $3,52 \mathrm{~b}$ & $3,18 \mathrm{~b}$ & $4,18 \mathrm{a}$ & $3,94 \mathrm{a}$ & $3,03 \mathrm{~b}$ \\
\hline 7 & $3,88 \mathrm{a}$ & $3,80 \mathrm{a}$ & $3,56 \mathrm{a}$ & $4,45 \mathrm{a}$ & $3,98 \mathrm{a}$ & $2,81 \mathrm{~b}$ \\
\hline 8 & $4,44 \mathrm{a}$ & $3,79 \mathrm{~b}$ & $3,13 \mathrm{c}$ & $4,31 \mathrm{a}$ & $4,18 \mathrm{a}$ & $2,88 \mathrm{~b}$ \\
\hline 9 & $4,45 \mathrm{a}$ & $3,82 \mathrm{~b}$ & $3,06 \mathrm{c}$ & $4,35 \mathrm{a}$ & $4,40 \mathrm{a}$ & $2,58 \mathrm{~b}$ \\
\hline 10 & $4,73 \mathrm{a}$ & $3,18 \mathrm{~b}$ & $2,78 \mathrm{~b}$ & $4,12 a$ & $4,16 \mathrm{a}$ & $2,43 \mathrm{~b}$ \\
\hline 11 & $4,47 \mathrm{a}$ & $3,36 \mathrm{~b}$ & $1,88 \mathrm{c}$ & $3,73 a$ & $3,76 \mathrm{a}$ & $2,22 \mathrm{~b}$ \\
\hline 12 & $3,84 \mathrm{a}$ & $2,41 \mathrm{~b}$ & $2,09 \mathrm{~b}$ & $3,22 \mathrm{a}$ & $3,38 \mathrm{a}$ & $1,74 \mathrm{~b}$ \\
\hline 13 & $2,11 \mathrm{a}$ & $1,93 \mathrm{ab}$ & $1,48 \mathrm{~b}$ & $2,10 \mathrm{a}$ & $2,16 \mathrm{a}$ & $1,26 \mathrm{~b}$ \\
\hline 14 & $2,18 \mathrm{a}$ & $1,88 \mathrm{ab}$ & $1,56 \mathrm{~b}$ & $2,14 \mathrm{a}$ & $2,15 \mathrm{a}$ & $1,33 \mathrm{~b}$ \\
\hline 15 & $2,01 \mathrm{a}$ & $1,90 \mathrm{ab}$ & $1,53 \mathrm{~b}$ & $2,08 \mathrm{a}$ & $1,94 \mathrm{a}$ & $1,41 \mathrm{~b}$ \\
\hline 16 & $2,10 \mathrm{a}$ & $1,92 \mathrm{a}$ & $1,79 \mathrm{a}$ & $2,22 \mathrm{a}$ & $2,18 \mathrm{a}$ & $1,41 \mathrm{~b}$ \\
\hline 17 & $2,28 \mathrm{a}$ & $1,82 \mathrm{ab}$ & $1,42 \mathrm{~b}$ & $2,09 \mathrm{a}$ & $2,00 \mathrm{a}$ & $1,42 b$ \\
\hline 18 & $2,09 \mathrm{a}$ & $1,92 \mathrm{a}$ & $1,63 \mathrm{a}$ & $2,19 \mathrm{a}$ & $2,20 \mathrm{a}$ & $1,24 \mathrm{~b}$ \\
\hline 19 & $2,25 \mathrm{a}$ & $1,79 \mathrm{ab}$ & $1,35 \mathrm{~b}$ & $2,10 \mathrm{a}$ & $2,07 \mathrm{a}$ & $1,23 \mathrm{~b}$ \\
\hline 20 & $1,78 \mathrm{ab}$ & $1,98 \mathrm{a}$ & $1,44 \mathrm{~b}$ & $2,14 \mathrm{a}$ & $1,90 \mathrm{a}$ & $1,17 \mathrm{~b}$ \\
\hline \multirow[t]{2}{*}{21} & $2,30 \mathrm{a}$ & $2,00 \mathrm{a}$ & $1,50 \mathrm{~b}$ & $2,40 \mathrm{a}$ & $2,18 \mathrm{a}$ & $1,22 \mathrm{~b}$ \\
\hline & \multicolumn{3}{|c|}{ DMS $5 \%(\mathrm{Td} . \mathrm{L})=0,47$} & \multicolumn{3}{|c|}{ DMS 5\% (Pd.L) $=0,47$} \\
\hline
\end{tabular}

Obs: Médias seguidas de mesma letra minúscula não diferem entre si no sentido vertical pelo teste Tukey a $5 \%$ de probabilidade. 
Tabela 10 - Confronto das médias de $\mathrm{Mg}$ dos tratamentos $\left(T_{1}, T_{2}\right.$ e $\left.T_{3}\right)$ e profundidades $\left(\mathrm{P}_{1}, \mathrm{P}_{2}\right.$ e $\left.\mathrm{P}_{3}\right)$.

\begin{tabular}{crrrrrr}
\hline \multicolumn{7}{c}{ Variável $=\mathrm{Mg}\left(\mathrm{meq} / 100 \mathrm{~cm}^{3}\right)$} \\
\hline 1 & $1,98 \mathrm{a}$ & $1,43 \mathrm{~b}$ & $1,52 \mathrm{~b}$ & 1,84 & 1,67 & 1,43 \\
2 & $1,80 \mathrm{a}$ & $1,91 \mathrm{a}$ & $1,48 \mathrm{~b}$ & 1,87 & 1,88 & 1,44 \\
3 & $1,78 \mathrm{~b}$ & $2,11 \mathrm{a}$ & $1,53 \mathrm{c}$ & 1,97 & 1,97 & 1,49 \\
4 & $1,91 \mathrm{a}$ & $1,93 \mathrm{a}$ & $1,61 \mathrm{~b}$ & 1,92 & 1,95 & 1,56 \\
5 & $2,06 \mathrm{a}$ & $2,03 \mathrm{a}$ & $1,65 \mathrm{~b}$ & 1,93 & 2,06 & 1,74 \\
6 & $2,04 \mathrm{a}$ & $1,81 \mathrm{ab}$ & $1,69 \mathrm{~b}$ & 1,98 & 1,90 & 1,67 \\
7 & $1,86 \mathrm{a}$ & $1,83 \mathrm{a}$ & $1,83 \mathrm{a}$ & 2,08 & 1,92 & 1,52 \\
8 & $1,95 \mathrm{a}$ & $1,92 \mathrm{a}$ & $1,58 \mathrm{~b}$ & 1,98 & 1,92 & 1,55 \\
9 & $1,95 \mathrm{a}$ & $1,88 \mathrm{ab}$ & $1,64 \mathrm{~b}$ & 1,99 & 2,05 & 1,43 \\
10 & $2,09 \mathrm{a}$ & $1,78 \mathrm{~b}$ & $1,48 \mathrm{c}$ & 1,87 & 1,93 & 1,55 \\
11 & $2,04 \mathrm{a}$ & $1,62 \mathrm{~b}$ & $1,06 \mathrm{c}$ & 1,65 & 1,75 & 1,31 \\
12 & $1,75 \mathrm{a}$ & $1,23 \mathrm{~b}$ & $1,17 \mathrm{~b}$ & 1,52 & 1,64 & 0,98 \\
13 & $0,88 \mathrm{a}$ & $1,02 \mathrm{a}$ & $0,88 \mathrm{a}$ & 1,02 & 1,08 & 0,68 \\
14 & $0,97 \mathrm{a}$ & $0,93 \mathrm{a}$ & $0,77 \mathrm{a}$ & 0,98 & 1,04 & 0,64 \\
15 & $0,98 \mathrm{a}$ & $0,91 \mathrm{ab}$ & $0,71 \mathrm{~b}$ & 0,93 & 0,94 & 0,72 \\
16 & $1,08 \mathrm{a}$ & $0,91 \mathrm{ab}$ & $0,75 \mathrm{~b}$ & 1,00 & 1,07 & 0,68 \\
17 & $1,11 \mathrm{a}$ & $0,88 \mathrm{a}$ & $0,51 \mathrm{~b}$ & 0,94 & 0,92 & 0,63 \\
18 & $1,08 \mathrm{a}$ & $0,93 \mathrm{a}$ & $0,43 \mathrm{~b}$ & 0,97 & 0,97 & 0,51 \\
19 & $1,16 \mathrm{a}$ & $0,90 \mathrm{~b}$ & $0,46 \mathrm{c}$ & 0,98 & 0,95 & 0,59 \\
20 & $0,86 \mathrm{a}$ & $0,94 \mathrm{a}$ & $0,48 \mathrm{~b}$ & 0,95 & 0,83 & 0,50 \\
21 & $1,25 \mathrm{a}$ & $0,78 \mathrm{~b}$ & $0,43 \mathrm{c}$ & 1,02 & 0,92 & 0,53 \\
& $\mathrm{DMS} 5 \%(\mathrm{Td} . \mathrm{L})$ & 0,24 & & & \\
\hline \hline & & & & & &
\end{tabular}

Obs: Médias seguidas de mesma letra minúscula não diferem entre si no sentido vertical pelo teste Tukey a $5 \%$ de probabilidade. 
Tabela 11 - Confronto das médias de $\mathrm{H}+\mathrm{Al}$ dos tratamentos $\left(\mathrm{T}_{1}, \mathrm{~T}_{2}\right.$ e $\left.\mathrm{T}_{3}\right)$ e profundidades $\left(\mathrm{P}_{1}, \mathrm{P}_{2}\right.$ e $\left.\mathrm{P}_{3}\right)$.

\begin{tabular}{ccrrrrr}
\hline \hline & \multicolumn{6}{c}{ Variável $=\mathrm{H}+\mathrm{Al}\left(\mathrm{meq} / 100 \mathrm{~cm}^{3}\right)$} \\
\cline { 2 - 7 } Linha & $\mathrm{T}_{1}$ & $\mathrm{~T}_{2}$ & \multicolumn{1}{c}{$\mathrm{T}_{3}$} & $\mathrm{P}_{1}$ & $\mathrm{P}_{2}$ & $\mathrm{P}_{3}$ \\
\hline 1 & $3,77 \mathrm{~b}$ & $2,87 \mathrm{~b}$ & $4,72 \mathrm{a}$ & $3,47 \mathrm{~b}$ & $3,38 \mathrm{~b}$ & $4,51 \mathrm{a}$ \\
2 & $4,08 \mathrm{a}$ & $2,50 \mathrm{~b}$ & $4,67 \mathrm{a}$ & $3,21 \mathrm{~b}$ & $3,19 \mathrm{~b}$ & $4,85 \mathrm{a}$ \\
3 & $4,31 \mathrm{a}$ & $2,89 \mathrm{~b}$ & $4,18 \mathrm{a}$ & $3,35 \mathrm{~b}$ & $3,22 \mathrm{~b}$ & $4,82 \mathrm{a}$ \\
4 & $3,48 \mathrm{a}$ & $3,18 \mathrm{a}$ & $3,98 \mathrm{a}$ & $2,92 \mathrm{~b}$ & $3,17 \mathrm{~b}$ & $4,56 \mathrm{a}$ \\
5 & $3,28 \mathrm{~b}$ & $2,98 \mathrm{~b}$ & $4,46 \mathrm{a}$ & $3,03 \mathrm{~b}$ & $3,13 \mathrm{~b}$ & $4,55 \mathrm{a}$ \\
6 & $3,69 \mathrm{~b}$ & $3,49 \mathrm{~b}$ & $4,88 \mathrm{a}$ & $3,33 \mathrm{~b}$ & $3,60 \mathrm{~b}$ & $5,14 \mathrm{a}$ \\
7 & $4,04 \mathrm{a}$ & $3,73 \mathrm{a}$ & $4,32 \mathrm{a}$ & $3,34 \mathrm{~b}$ & $3,58 \mathrm{~b}$ & $5,15 \mathrm{a}$ \\
8 & $3,59 \mathrm{~b}$ & $3,55 \mathrm{~b}$ & $4,98 \mathrm{a}$ & $3,33 \mathrm{~b}$ & $3,57 \mathrm{~b}$ & $5,23 \mathrm{a}$ \\
9 & $4,04 \mathrm{~b}$ & $3,65 \mathrm{~b}$ & $5,13 \mathrm{a}$ & $3,28 \mathrm{~b}$ & $3,46 \mathrm{~b}$ & $6,08 \mathrm{a}$ \\
10 & $3,27 \mathrm{c}$ & $4,29 \mathrm{~b}$ & $6,04 \mathrm{a}$ & $3,67 \mathrm{~b}$ & $3,74 \mathrm{~b}$ & $6,19 \mathrm{a}$ \\
11 & $3,54 \mathrm{~b}$ & $4,05 \mathrm{~b}$ & $5,37 \mathrm{a}$ & $3,52 \mathrm{~b}$ & $3,50 \mathrm{~b}$ & $5,94 \mathrm{a}$ \\
12 & $4,12 \mathrm{c}$ & $5,52 \mathrm{~b}$ & $6,69 \mathrm{a}$ & $4,33 \mathrm{~b}$ & $4,39 \mathrm{~b}$ & $7,60 \mathrm{a}$ \\
13 & $6,91 \mathrm{a}$ & $6,38 \mathrm{a}$ & $6,31 \mathrm{a}$ & $5,58 \mathrm{~b}$ & $5,74 \mathrm{~b}$ & $8,28 \mathrm{a}$ \\
14 & $6,76 \mathrm{a}$ & $6,76 \mathrm{a}$ & $5,88 \mathrm{a}$ & $5,58 \mathrm{~b}$ & $5,68 \mathrm{~b}$ & $8,14 \mathrm{a}$ \\
15 & $6,40 \mathrm{a}$ & $6,75 \mathrm{a}$ & $6,99 \mathrm{a}$ & $5,73 \mathrm{~b}$ & $5,98 \mathrm{~b}$ & $8,44 \mathrm{a}$ \\
16 & $6,02 \mathrm{~b}$ & $7,23 \mathrm{a}$ & $7,48 \mathrm{a}$ & $5,72 \mathrm{c}$ & $6,86 \mathrm{~b}$ & $8,15 \mathrm{a}$ \\
17 & $5,82 \mathrm{~b}$ & $6,56 \mathrm{~b}$ & $7,53 \mathrm{a}$ & $6,53 \mathrm{a}$ & $6,62 \mathrm{a}$ & $6,76 \mathrm{a}$ \\
18 & $4,90 \mathrm{c}$ & $6,68 \mathrm{~b}$ & $8,19 \mathrm{a}$ & $5,71 \mathrm{~b}$ & $6,01 \mathrm{~b}$ & $8,15 \mathrm{a}$ \\
19 & $4,46 \mathrm{c}$ & $6,69 \mathrm{~b}$ & $7,88 \mathrm{a}$ & $5,77 \mathrm{~b}$ & $5,64 \mathrm{~b}$ & $7,63 \mathrm{a}$ \\
20 & $5,50 \mathrm{~b}$ & $5,84 \mathrm{~b}$ & $6,91 \mathrm{a}$ & $5,79 \mathrm{a}$ & $6,11 \mathrm{a}$ & $6,35 \mathrm{a}$ \\
21 & $4,57 \mathrm{~b}$ & $6,89 \mathrm{a}$ & $7,78 \mathrm{a}$ & $5,58 \mathrm{~b}$ & $5,81 \mathrm{~b}$ & $7,85 \mathrm{a}$ \\
\hline \hline & $\mathrm{DMS} 5 \%(T d . \mathrm{L})=0,92$ & $\mathrm{DMS} 5 \%(\mathrm{Pd} . \mathrm{L})=0,92$ \\
\hline
\end{tabular}

Obs: Médias seguidas de mesma letra minúscula não diferem entre si no sentido vertical pelo teste Tukey a $5 \%$ de probabilidade. 
Tabela 12 - Confronto das médias de CTC dos tratamentos $\left(T_{1}, T_{2}\right.$ e $\left.T_{3}\right)$ e profundidades $\left(\mathrm{P}_{1}, \mathrm{P}_{2}\right.$ e $\left.\mathrm{P}_{3}\right)$.

\begin{tabular}{|c|c|c|c|c|c|c|}
\hline \multirow[b]{2}{*}{ Linha } & \multicolumn{6}{|c|}{ Variável $=$ CTC $\left(\mathrm{meq} / 100 \mathrm{~cm}^{3}\right)$} \\
\hline & $T_{1}$ & $T_{2}$ & $\mathrm{~T}_{3}$ & $P_{1}$ & $\mathrm{P}_{2}$ & $\mathrm{P}_{3}$ \\
\hline 1 & $10,06 \mathrm{a}$ & $7,26 \mathrm{c}$ & $8,95 \mathrm{~b}$ & $9,24 \mathrm{a}$ & $8,59 \mathrm{a}$ & $8,43 \mathrm{a}$ \\
\hline 2 & 9,94 a & $8,31 \mathrm{~b}$ & $8,82 \mathrm{~b}$ & 9,15 a & 9,01 a & 8,91 a \\
\hline 3 & $10,23 \mathrm{a}$ & $9,72 \mathrm{a}$ & $8,63 \mathrm{~b}$ & 9,92 a & 9,58 a & 9,09 a \\
\hline 4 & $9,79 \mathrm{a}$ & $9,23 \mathrm{ab}$ & $8,43 \mathrm{~b}$ & 9,19 a & $9,28 \mathrm{a}$ & 8,98 a \\
\hline 5 & $10,07 \mathrm{a}$ & $9,03 \mathrm{~b}$ & $8,93 \mathrm{~b}$ & 9,33 a & 9,57 a & 9,15 a \\
\hline 6 & $10,42 \mathrm{a}$ & $8,89 \mathrm{~b}$ & $9,82 \mathrm{a}$ & 9,65 a & $9,57 \mathrm{a}$ & 9,91 a \\
\hline 7 & $10,04 \mathrm{a}$ & 9,48 a & 9,77 a & $10,08 \mathrm{a}$ & $9,64 \mathrm{a}$ & 9,57 a \\
\hline 8 & $10,23 \mathrm{a}$ & 9,39 a & 9,75 a & 9,81 a & 9,81 a & $9,74 \mathrm{a}$ \\
\hline 9 & $10,71 \mathrm{a}$ & $9,87 \mathrm{ab}$ & $9,50 \mathrm{~b}$ & $9,84 \mathrm{a}$ & $10,08 \mathrm{a}$ & $10,17 \mathrm{a}$ \\
\hline 10 & $10,33 \mathrm{a}$ & $9,38 \mathrm{~b}$ & $10,34 \mathrm{a}$ & 9,83 a & 9,97 a & $10,24 \mathrm{a}$ \\
\hline 11 & $10,29 a$ & $9,11 \mathrm{~b}$ & $8,34 \mathrm{~b}$ & $9,06 \mathrm{a}$ & $9,14 \mathrm{a}$ & $9,54 \mathrm{a}$ \\
\hline 12 & 9,95 a & $9,27 \mathrm{a}$ & $10,01 \mathrm{a}$ & $9,27 \mathrm{~b}$ & $9,56 \mathrm{ab}$ & $10,40 \mathrm{a}$ \\
\hline 13 & $10,11 \mathrm{a}$ & $9,44 a b$ & $8,70 \mathrm{~b}$ & $8,85 \mathrm{~b}$ & $9,10 \mathrm{~b}$ & $10,30 \mathrm{a}$ \\
\hline 14 & $10,08 \mathrm{a}$ & 9,70 a & $8,26 \mathrm{~b}$ & $8,87 \mathrm{~b}$ & $8,98 \mathrm{~b}$ & $10,19 \mathrm{a}$ \\
\hline 15 & $9,60 \mathrm{a}$ & 9,69 a & 9,31 a & $8,92 \mathrm{~b}$ & $8,99 \mathrm{~b}$ & $10,69 \mathrm{a}$ \\
\hline 16 & 9,38 a & $10,16 \mathrm{a}$ & $10,13 \mathrm{a}$ & $9,11 b$ & $10,24 \mathrm{a}$ & $10,32 \mathrm{a}$ \\
\hline 17 & $9,36 \mathrm{a}$ & $9,35 \mathrm{a}$ & $9,52 \mathrm{a}$ & $9,71 \mathrm{a}$ & $9,65 \mathrm{a}$ & 8,87 a \\
\hline 18 & $8,25 \mathrm{~b}$ & $9,72 \mathrm{a}$ & $10,36 \mathrm{a}$ & 9,02 a & $9,32 \mathrm{ab}$ & 9,99 a \\
\hline 19 & $8,08 \mathrm{~b}$ & 9,47 a & $9,79 \mathrm{a}$ & $9,02 \mathrm{a}$ & 8,80 a & 9,51 a \\
\hline 20 & $8,40 \mathrm{a}$ & $8,86 \mathrm{a}$ & 8,92 a & $9,12 \mathrm{a}$ & $8,96 \mathrm{ab}$ & $8,10 \mathrm{a}$ \\
\hline 21 & $8,30 \mathrm{~b}$ & 9,80 a & 9,79 a & 9,19 a & $9,02 \mathrm{a}$ & $9,68 \mathrm{a}$ \\
\hline & \multicolumn{3}{|c|}{ DMS 5\% $($ Td.L $)=0,88$} & \multicolumn{3}{|c|}{ DMS 5\% (Pd.L) $=0,88$} \\
\hline
\end{tabular}

Obs: Médias seguidas de mesma letra minúscula não diferem entre si no sentido vertical pelo teste Tukey a $5 \%$ de probabilidade. 
Tabela 13 - Confronto das médias de saturação por bases dos tratamentos $\left(T_{1}, T_{2}\right.$ e $\left.T_{3}\right)$ e profundidades $\left(P_{1}, P_{2}\right.$ e $\left.P_{3}\right)$.

\begin{tabular}{|c|c|c|c|c|c|c|}
\hline \multirow[b]{2}{*}{ Linha } & \multicolumn{6}{|c|}{ Variável = Saturação por Bases $(\mathrm{V} \%)$} \\
\hline & $T_{1}$ & $\mathrm{~T}_{2}$ & $\mathrm{~T}_{3}$ & $P_{1}$ & $\mathrm{P}_{2}$ & $\mathrm{P}_{3}$ \\
\hline 1 & $61,77 \mathrm{a}$ & $60,14 \mathrm{a}$ & $47,37 \mathrm{~b}$ & $61,99 \mathrm{a}$ & 60,52 a & $46,77 \mathrm{~b}$ \\
\hline 2 & $58,42 \mathrm{~b}$ & 69,45 a & $47,17 \mathrm{c}$ & $64,87 \mathrm{a}$ & $64,24 \mathrm{a}$ & $45,93 \mathrm{~b}$ \\
\hline 3 & $57,35 \mathrm{~b}$ & 69,76 a & $51,48 \mathrm{~b}$ & $65,91 \mathrm{a}$ & $65,69 \mathrm{a}$ & $46,99 \mathrm{~b}$ \\
\hline 4 & $64,26 \mathrm{a}$ & $65,31 \mathrm{a}$ & $52,71 \mathrm{~b}$ & $67,65 \mathrm{a}$ & $65,53 \mathrm{a}$ & $49,10 \mathrm{~b}$ \\
\hline 5 & 67,03 a & 66,89 a & $50,82 \mathrm{~b}$ & $67,01 \mathrm{a}$ & 67,08 a & $50,65 \mathrm{~b}$ \\
\hline 6 & $62,61 \mathrm{a}$ & 60,32 a & $50,40 \mathrm{~b}$ & $64,86 \mathrm{a}$ & $61,09 \mathrm{a}$ & $47,38 \mathrm{~b}$ \\
\hline 7 & 58,91 a & $60,76 \mathrm{a}$ & 55,78 a & $66,51 \mathrm{a}$ & $62,74 \mathrm{a}$ & $46,19 \mathrm{~b}$ \\
\hline 8 & $64,55 \mathrm{a}$ & $62,08 \mathrm{a}$ & $49,13 \mathrm{~b}$ & 65,93 a & $63,29 \mathrm{a}$ & $46,54 \mathrm{~b}$ \\
\hline 9 & $62,29 \mathrm{a}$ & $61,69 \mathrm{a}$ & $48,23 \mathrm{~b}$ & 66,19 a & $65,38 \mathrm{a}$ & $40,65 \mathrm{~b}$ \\
\hline 10 & $67,91 \mathrm{a}$ & $55,32 \mathrm{~b}$ & $41,75 \mathrm{c}$ & $62,50 \mathrm{a}$ & $62,48 \mathrm{a}$ & $40,01 \mathrm{~b}$ \\
\hline 11 & $65,39 \mathrm{a}$ & $55,44 \mathrm{~b}$ & $35,83 \mathrm{c}$ & 58,88 a & $60,19 a$ & $37,60 \mathrm{~b}$ \\
\hline 12 & $58,35 \mathrm{a}$ & $41,40 \mathrm{~b}$ & $33,65 \mathrm{~b}$ & 52,63 a & $53,54 \mathrm{a}$ & $27,23 \mathrm{~b}$ \\
\hline 13 & $32,53 \mathrm{a}$ & $33,07 \mathrm{a}$ & $27,76 \mathrm{a}$ & $36,88 \mathrm{a}$ & $36,80 \mathrm{a}$ & $19,69 \mathrm{~b}$ \\
\hline 14 & $34,00 \mathrm{a}$ & $30,88 \mathrm{a}$ & $28,87 \mathrm{a}$ & $36,80 \mathrm{a}$ & $36,42 \mathrm{a}$ & $20,53 \mathrm{~b}$ \\
\hline 15 & $34,05 \mathrm{a}$ & $30,87 \mathrm{ab}$ & $25,29 \mathrm{~b}$ & $35,70 \mathrm{a}$ & $33,44 \mathrm{a}$ & $21,09 \mathrm{~b}$ \\
\hline 16 & $36,49 \mathrm{a}$ & $29,28 \mathrm{a}$ & $30,97 \mathrm{a}$ & $37,46 \mathrm{a}$ & $33,41 \mathrm{ab}$ & $25,86 \mathrm{~b}$ \\
\hline 17 & $38,45 \mathrm{a}$ & $30,62 \mathrm{a}$ & $31,09 \mathrm{a}$ & $33,38 \mathrm{a}$ & $32,87 \mathrm{a}$ & 33,91 a \\
\hline 18 & $41,24 \mathrm{a}$ & $31,29 \mathrm{~b}$ & $20,93 \mathrm{c}$ & $37,93 \mathrm{a}$ & $36,96 \mathrm{a}$ & $18,58 \mathrm{~b}$ \\
\hline 19 & 44,93 a & $30,13 \mathrm{~b}$ & $19,50 \mathrm{c}$ & $37,45 \mathrm{a}$ & $36,90 \mathrm{a}$ & $20,23 \mathrm{~b}$ \\
\hline 20 & $34,59 a b$ & $38,95 \mathrm{a}$ & $28,31 \mathrm{~b}$ & $37,06 \mathrm{a}$ & $32,46 \mathrm{a}$ & $32,34 \mathrm{a}$ \\
\hline \multirow[t]{2}{*}{21} & $34,56 \mathrm{a}$ & $30,36 \mathrm{~b}$ & $20,77 \mathrm{c}$ & $40,29 a$ & $36,01 \mathrm{a}$ & $19,40 \mathrm{~b}$ \\
\hline & \multicolumn{3}{|c|}{ DMS 5\% (Td.L) $=8,05$} & \multicolumn{3}{|c|}{ DMS 5\% (Pd.L) $=8,05$} \\
\hline
\end{tabular}

Obs: Médias seguidas de mesma letra minúscula não diferem entre si no sentido vertical pelo teste Tukey a $5 \%$ de probabilidade. 
Tabela 14 - Quadrados médios relativos aos componentes de regressão polinomial para o fator Linha dentro de cada tratamento e dentro de cada profundidade e as estimativas dos coeficientes de regressão com respectivos coeficientes de determinação $R^{2}$ em fósforo (P transformado) $-\mu \mathrm{g} / \mathrm{cm}^{3}$.

\begin{tabular}{lccccccc}
\hline & & \multicolumn{6}{c}{ QUADRADOS MÉDIOS } \\
\cline { 3 - 8 } F.V. & G.L. & $\mathrm{T}_{1}$ & $\mathrm{~T}_{2}$ & $\mathrm{~T}_{3}$ & $\mathrm{P}_{1}$ & $\mathrm{P}_{2}$ & $\mathrm{P}_{3}$ \\
\hline $\mathrm{L}$ ' & 1 & 0,14 & $0,99^{* *}$ & $6,35^{* *}$ & $0,54^{*}$ & 0,02 & $3,08^{* *}$ \\
L"' & 1 & $0,69^{* *}$ & 0,07 & 0,05 & 0,41 & 0,01 & $2,20^{* *}$ \\
L', & 1 & $0,57^{*}$ & 0,19 & 0,01 & $0,45^{*}$ & 0,11 & 0,01 \\
Desvio de Regr. & 17 & $0,58^{* *}$ & $0,47^{* *}$ & $0,40^{* *}$ & 0,09 & 0,15 & $0,25^{* *}$ \\
Resíduo & 567 & 0,12 & 0,12 & 0,12 & 0,12 & 0,12 & 0,12 \\
\hline Estimativas dos & $B_{0}$ & 2,4450 & 2,5360 & 1,4084 & 2,6953 & $\mathrm{NS}$ & 1,2987 \\
Coeficientes de & $\mathrm{B}_{1}$ & 0,1187 & $-0,0110$ & 0,0262 & 0,0383 & $\mathrm{NS}$ & 0,0811 \\
Regressão Poli- & $\mathrm{B}_{2}$ & $-0,0109$ & - & - & $-0,0069$ & $\mathrm{NS}$ & $-0,0029$ \\
nomial p/linha & $\mathrm{B}_{3}$ & 0,0003 & - & - & 0,0002 & $\mathrm{NS}$ & - \\
\hline Coeficiente de & & & & & & & \\
Determinação & $\mathrm{R}^{2}$ & 0,141 & 0,107 & 0,482 & 0,453 & - & 0,557 \\
\hline \hline
\end{tabular}

OBS: As equações ajustadas foram construídas em função das linhas cujos valores empregados são (1, 2, $3,4, \ldots .21)$. Então, se quizermos saber a estimativa do $P$ transformado $\left(\mu \mathrm{g} / \mathrm{cm}^{3}\right)$, por exemplo, para uma profundidade de raspagem (PR) de $20 \mathrm{~cm}$, deveremos usar a transformação

$$
L=\frac{P R+2}{2}=\frac{20+2}{2}=11
$$

e substituir na equação correspondente, isto é, $P R=20 \mathrm{~cm}$, que corresponde à linha 11 , ou $P R$ $=40 \mathrm{~cm}$ que corresponderá à linha 21 , também válida para as demais tabelas e figuras apresentadas, ao se analisar as interações dos fatores considerados. 
Tabela 15 - Quadrados médios relativos aos componentes de regressão polinomial para o fator Linha dentro de cada tratamento e dentro de cada profundidade e as estimativas dos coeficientes de regressão com respectivos coeficientes de determinação $R^{2}$ em matéria orgânica, M.O. (\%).

\begin{tabular}{lccccccc}
\hline \hline & & \multicolumn{6}{c}{ QUADRADOS MÉDIOS } \\
\cline { 3 - 8 } F.V. & G.L. & $\mathrm{T}_{1}$ & $\mathrm{~T}_{2}$ & $\mathrm{~T}_{3}$ & $\mathrm{P}_{1}$ & $\mathrm{P}_{2}$ & $\mathrm{P}_{3}$ \\
\hline $\mathrm{L}^{\prime}$ & 1 & $84,73^{* *}$ & $35,695^{* *}$ & $26,2827^{*}$ & $57,5468^{* *}$ & 57,4837 & 26,4001 \\
L" & 1 & $2,85^{*}$ & $4,047^{* *}$ & 0,0366 & $0,1317^{*}$ & $0,1310^{*}$ & 0,0180 \\
L”' & 1 & $0,65^{* *}$ & $5,7417^{* *}$ & $2,6024^{* *}$ & $2,8682^{* *}$ & $3,1224^{* *}$ & 1,8429 \\
Desvio de Regr. & 17 & $0,35^{* *}$ & $0,0974^{* *}$ & $0,2710^{* *}$ & $0,0901^{* *}$ & $0,1265^{* *}$ & 0,0941 \\
Resíduo & 567 & 0,0325 & 0,0325 & 0,0325 & 0,0325 & 0,0325 & 0,0325 \\
\hline Estimativas dos & $\mathrm{B}_{0}$ & 3,8480 & 2,1095 & 2,3285 & 3,1208 & 2,8592 & 2,306 \\
Coeficientes de & $B_{1}$ & $-0,0794$ & 0,2836 & 0,1139 & 0,0898 & 0,1285 & 0,0998 \\
Regressão Poli- & $B_{2}$ & $-0,0065$ & $-0,0328$ & $-0,0191$ & $-0,0197$ & $-0,0220$ & $-0,01664$ \\
nomial p/Linha & $B_{3}$ & 0,0003 & 0,0009 & 0,0006 & 0,0006 & 0,0006 & 0,0005 \\
\hline Coeficiente de & & & & & & & \\
Determinação & $\mathrm{R}^{2}$ & 0,9366 & 0,9649 & 0,8626 & 0,9753 & 0,9658 & 0,9464 \\
\hline \hline
\end{tabular}


Tabela 16 - Quadrados médios relativos aos componentes de regressão polinomial para o fator Linha dentro de cada tratamento e dentro de cada profundidade e as estimativas dos coeficientes de regressão com respectivos coeficientes de determinação $\mathrm{R}^{2} \mathrm{em}$ pH.

\begin{tabular}{|c|c|c|c|c|c|c|c|}
\hline \multirow[b]{2}{*}{ F.V. } & \multirow[b]{2}{*}{ G.L. } & \multicolumn{6}{|c|}{ QUADRADOS MÉDIOS } \\
\hline & & $T_{1}$ & $\mathrm{~T}_{2}$ & $\mathrm{~T}_{3}$ & $P_{1}$ & $\mathrm{P}_{2}$ & $\mathrm{P}_{3}$ \\
\hline$L^{\prime}$ & 1 & $10,002 * *$ & $41,321^{* *}$ & $26,304^{*}$ & $26,069 * *$ & $28,938 * *$ & $17,9274 * *$ \\
\hline L"' & 1 & $0,7929 * *$ & $0,179 * *$ & 0,0361 & $0,1397^{*}$ & $0,165^{*}$ & $0,2528 * *$ \\
\hline$L^{\prime \prime}$ & 1 & $4,9884 * *$ & $4,5741^{* *}$ & $3,6289 * *$ & $7,1808 * *$ & $5,3809 * *$ & $1,6328 * *$ \\
\hline Desvio de Regr. & 17 & $0,6015^{* *}$ & $0,1744 * *$ & $0,0883^{* *}$ & $0,1600 * *$ & $0,2235 * *$ & $0,0633^{* *}$ \\
\hline Resíduo & 567 & 0,0321 & 0,0321 & 0,0321 & 0,0321 & 0,0321 & 0,0321 \\
\hline Estimativas dos & $B_{0}$ & 4,7533 & 5,3374 & 4,7971 & 4,9637 & 5,0551 & 4,8689 \\
\hline Coeficientes de & $B_{1}$ & 0,2476 & 0,1476 & 0,1456 & 0,254 & 0,2133 & 0,0735 \\
\hline Regressão Poli- & $B_{2}$ & $-0,028$ & $-0,0249$ & $-0,0226$ & $-0,0331$ & $-0,0287$ & $-0,0144$ \\
\hline nomial $\mathrm{p} /$ Linha & $B_{3}$ & 0,0008 & 0,0007 & 0,0006 & 0,0009 & 0,0008 & 0,0005 \\
\hline \multicolumn{8}{|l|}{ Coeficiente de } \\
\hline Determinação & $\mathrm{R}^{2}$ & 0,6068 & 0,9395 & 0,9523 & 0,9246 & 0,9007 & 0,9485 \\
\hline
\end{tabular}


Tabela 17 - Quadrados médios relativos aos componentes de regressão polinomial para o fator Linha dentro de cada tratamento e dentro de cada profundidade e as estimativas dos coeficientes de regressão com respectivos coeficientes de determinação $R^{2}$ em potássio $(K$ transformado), meq $/ 100 \mathrm{~cm}^{3}$.

\begin{tabular}{|c|c|c|c|c|c|c|c|}
\hline \multirow[b]{2}{*}{ F.V. } & \multirow[b]{2}{*}{ G.L. } & \multicolumn{6}{|c|}{ QUADRADOS MÉDIOS } \\
\hline & & $T_{1}$ & $\mathrm{~T}_{2}$ & $\mathrm{~T}_{3}$ & $P_{1}$ & $\mathrm{P}_{2}$ & $\mathrm{P}_{3}$ \\
\hline$L^{\prime}$ & 1 & $0,09 * *$ & $0,05 * *$ & 0,05 & NS & NS & $\mathrm{N}$ \\
\hline L"' & 1 & 0,0001 & $0,02 * *$ & $0,028 * *$ & NS & NS & NS \\
\hline L"” & 1 & $0,03 * *$ & $0,01^{* *}$ & 0,005 & NS & NS & NS \\
\hline Desvio de Regr. & 17 & $0,003 * *$ & $0,004 * *$ & 0,0032 & NS & NS & NS \\
\hline Resíduo & 567 & 0,002 & 0,002 & 0,002 & - & - & - \\
\hline Estimativas dos & $\mathrm{B}_{0}$ & 0,3527 & 0,3531 & 0,2550 & NS & NS & NS \\
\hline Coeficientes de & $\beta_{1}$ & 0,0154 & $-0,0209$ & $-0,0064$ & NS & NS & NS \\
\hline Regressão Poli- & $\beta_{2}$ & $-0,0021$ & 0,0017 & 0,0003 & NS & NS & NS \\
\hline nomial $p /$ Linha & $\boldsymbol{B}_{3}$ & 0,0001 & $-0,00004$ & - & NS & NS & NS \\
\hline \multicolumn{8}{|l|}{ Coeficiente de } \\
\hline Determinação & $R^{2}$ & 0,683 & 0,533 & 0,3563 & - & - & - \\
\hline
\end{tabular}


Tabela 18 - Quadrados médios relativos aos componentes de regressão polinomial para o fator Linha dentro de cada tratamento e dentro de cada profundidade e as estimativas dos coeficientes de regressão com respectivos coeficientes de determinação $R^{2}$ em Cálcio (Ca), meq/100 $\mathrm{cm}^{3}$.

\begin{tabular}{|c|c|c|c|c|c|c|c|}
\hline \multirow[b]{2}{*}{ F.V. } & \multirow[b]{2}{*}{ G.L. } & \multicolumn{6}{|c|}{ QUADRADOS MÉDIOS } \\
\hline & & $T_{1}$ & $\mathrm{~T}_{2}$ & $\mathrm{~T}_{3}$ & $P_{1}$ & $\mathrm{P}_{2}$ & $\mathrm{P}_{3}$ \\
\hline$L^{\prime}$ & 1 & $180,097 * *$ & $149,876 * *$ & $83,505 * *$ & $164,987 * *$ & $156,52 * *$ & $89,2080 * *$ \\
\hline L'” & 1 & $16,521^{* *}$ & $1,5143 *$ & $3,3404 * *$ & $5,2608 * *$ & $10,827 * *$ & $2,3678 * *$ \\
\hline L"' & 1 & $35,517 * *$ & $42,141 * *$ & $21,6943 * *$ & $46,428 * *$ & $38,3622 * *$ & $16,822 * *$ \\
\hline Desvio de Regr. & 17 & $3,1541 * *$ & $1,2082 * *$ & $1,0632 * *$ & $1,1259 * *$ & $1,3711 * *$ & 0,4286 \\
\hline Resíduo & 567 & 0,2694 & 0,2694 & 0,2694 & 0,2694 & 0,2694 & 0,2694 \\
\hline Estimativas dos & $\mathrm{B}_{0}$ & 2,8686 & 2,6133 & 1,9504 & 2,8192 & 2,6725 & 1,9405 \\
\hline Coeficientes de & $B_{1}$ & 0,6805 & 0,6304 & 0,4887 & 0,7043 & 0,6826 & 0,4128 \\
\hline Regressão Poli- & $\mathrm{B}_{2}$ & $-0,0797$ & $-0,0807$ & $-0,0597$ & $-0,0866$ & $-0,0811$ & $-0,0525$ \\
\hline nomial p/Linha & $\mathrm{B}_{3}$ & 0,0022 & 0,0024 & 0,0017 & 0,0025 & 0,0023 & 0,0015 \\
\hline \multicolumn{8}{|l|}{ Coeficiente de } \\
\hline Determinação & $\mathbf{R}^{2}$ & 0,8124 & 0,9041 & 0,8572 & 0,9188 & 0,8982 & 0,9370 \\
\hline
\end{tabular}


Tabela 19 - Quadrados médios relativos aos componentes de regressão polinomial para o fator Linha dentro de cada tratamento e dentro de cada profundidade e as estimativas dos coeficientes de regressão com respectivos coeficientes de determinação $R^{2}$ em Magnésio $(\mathrm{Mg})$, $\mathrm{meq} / 100 \mathrm{~cm}^{3}$.

\begin{tabular}{|c|c|c|c|c|c|c|c|}
\hline \multirow[b]{2}{*}{ F.V. } & \multirow[b]{2}{*}{ G.L. } & \multicolumn{6}{|c|}{ QUADRADOS MÉDIOS } \\
\hline & & $T_{1}$ & $\mathrm{~T}_{2}$ & $\mathrm{~T}_{3}$ & $P_{1}$ & $\mathrm{P}_{2}$ & $\mathrm{P}_{3}$ \\
\hline $\mathrm{L}^{\prime}$ & 1 & $33,024 * *$ & $42,3566 * *$ & $50,559 * *$ & NS & NS & NS \\
\hline L" & 1 & $0,9581^{* *}$ & $1,1297 * *$ & $2,811 * *$ & NS & NS & NS \\
\hline L"” & 1 & $6,6883 * *$ & $8,4616 * *$ & $5,166 * *$ & NS & NS & NS \\
\hline Desvio de Regr. & 17 & $0,7073 * *$ & $0,2463 * *$ & $0,135 * *$ & NS & NS & NS \\
\hline Resíduo & 567 & 0,0684 & 0,0684 & 0,068 & - & - & - \\
\hline Estimativas dos & $\mathbf{B}_{0}$ & 1,4758 & 1,3383 & 1,1629 & NS & NS & NS \\
\hline Coeficientes de & $B_{1}$ & 0,2628 & 0,2935 & 0,2442 & NS & NS & NS \\
\hline Regressão Poli- & $B_{2}$ & $-0,0331$ & $-0,0372$ & $-0,0307$ & NS & NS & NS \\
\hline nomial $\mathrm{p} /$ Linha & $\mathrm{B}_{3}$ & 0,0009 & 0,0012 & 0,0008 & NS & NS & NS \\
\hline \multicolumn{8}{|l|}{ Coeficiente de } \\
\hline Determinação & $\mathrm{R}^{2}$ & 0,7718 & 0,9254 & 0,9624 & - & - & - \\
\hline
\end{tabular}


Tabela 20 - Quadrados médios relativos aos componentes de regressão polinomial para o fator Linha dentro de cada tratamento e dentro de cada profundidade e as estimativas dos coeficientes de regressão com respectivos coeficientes de determinação $\mathrm{R}^{2}$ em $\mathrm{H}+\mathrm{Al}$, meq/100 $\mathrm{cm}^{3}$.

\begin{tabular}{|c|c|c|c|c|c|c|c|}
\hline \multirow[b]{2}{*}{ F.V. } & \multirow[b]{2}{*}{ G.L. } & \multicolumn{6}{|c|}{ QUADRADOS MÉDIOS } \\
\hline & & T] & $\mathrm{T} 2$ & T3 & P1 & P2 & P3 \\
\hline$L^{\prime}$ & 1 & $110,794 * *$ & $587,2593 * *$ & $387,614 * *$ & 295,60 & $342,41 * *$ & $353,1081 * *$ \\
\hline L"' & 1 & 3,1565 & $4,0066 *$ & 2,8870 & 3,2418 & 1,258 & $25,016^{* *}$ \\
\hline L"' & 1 & $80,9384 * *$ & $50,066 * *$ & $25,554 * *$ & $48,59 * *$ & $48,501 * *$ & $51,717 * *$ \\
\hline Desvio de Regr. & 17 & $7,8061^{* *}$ & $2,8214 * *$ & $2,201^{* *}$ & 1,5678 & $2,583 * *$ & $4,5138 * *$ \\
\hline Resíduo & 567 & 1,0288 & 1,0288 & 1,0288 & 1,0288 & 1,0288 & 1,0288 \\
\hline Estimativas dos & BO & 5,101 & 3,3523 & 5,0680 & 4,2895 & 4,1996 & 5,0321 \\
\hline Coeficientes de & B1 & $-0,7931$ & $-0,4317$ & $-0,4167$ & $-0,6552$ & $-0,6121$ & $-0,3741$ \\
\hline Regressão Poli- & B2 & 0,1052 & 0,0815 & 0,0643 & 0,0876 & 0,0863 & 0,0771 \\
\hline nomial $p /$ Linha & B3 & $-0,0033$ & $-0,0025$ & $-0,0018$ & $-0,0025$ & 0,0025 & $-0,0026$ \\
\hline \multicolumn{8}{|l|}{ Coeficiente de } \\
\hline Determinação & $\mathrm{R} 2$ & 0,5949 & 0,9306 & 0,9175 & 0,9288 & 0,8993 & 0,8485 \\
\hline
\end{tabular}


Tabela 21 - Quadrados médios relativos aos componentes de regressão polinomial para o fator Linha dentro de cada tratamento e dentro de cada profundidade e as estimativas dos coeficientes de regressão com respectivos coeficientes de determinação $R^{2}$ em CTC, meq/100 cm .

\begin{tabular}{|c|c|c|c|c|c|c|c|}
\hline \multirow[b]{2}{*}{ F.V. } & \multirow[b]{2}{*}{ G.L. } & \multicolumn{6}{|c|}{ QUADRADOS MÉDIOS } \\
\hline & & $\mathrm{T} 1$ & $\mathrm{~T} 2$ & T3 & P1 & P2 & P3 \\
\hline$L^{\prime}$ & 1 & $32,445 * *$ & $27,018 * *$ & $12,251 * *$ & $5,9757 * *$ & 0,4995 & $7,6691 * *$ \\
\hline L"' & 1 & $46,129 * *$ & $16,889 * *$ & 2,4378 & 1,1253 & $14,3504 *$ & $57,9704 * *$ \\
\hline L", & 1 & 0,0396 & $4,6679 *$ & 3,1042 & $6,9378 * *$ & 3,2755 & 0,5190 \\
\hline Desvio de Regr. & 17 & 1,1046 & $2,369 * *$ & $5,3659 * *$ & 4,2464 & $1,6975 *$ & $2,9360 * *$ \\
\hline Resíduo & 567 & 0,9547 & 0,9547 & 0,9547 & 0,9547 & 0,9547 & 0,9547 \\
\hline Estimativas dos & BO & 9,6299 & 7,531429 & 8,9524 & 8,8646 & 8,8368 & 8,0533 \\
\hline Coeficientes de & B1 & 0,1935 & 0,4631 & 0,0364 & 0,3058 & 0,1533 & 0,3516 \\
\hline Regressão Poli- & B2 & $-0,0131$ & $-0,0339$ & - & $-0,0338$ & $-0,0073$ & $-0,0147$ \\
\hline nomial $p /$ Linha & B3 & - & 0,0007 & - & 0,0009 & - & - \\
\hline \multicolumn{8}{|l|}{ Coeficiente de } \\
\hline Determinação & $\mathbf{R} 2$ & 0,8723 & 0,5466 & 0,1124 & 0,3985 & 0,3161 & 0,5655 \\
\hline
\end{tabular}


Tabela 22 - Quadrados médios relativos aos componentes de regressão polinomial para o fator Linha dentro de cada tratamento e dentro de cada profundidade e as estimativas dos coeficientes de regressão com respectivos coeficientes de determinação $\mathrm{R}^{2}$ em Saturação por Bases $(\mathrm{V} \%)$

\begin{tabular}{|c|c|c|c|c|c|c|c|}
\hline \multirow[b]{2}{*}{ F.V. } & \multirow[b]{2}{*}{ G.L. } & \multicolumn{6}{|c|}{ QUADRADOS MÉDIOS } \\
\hline & & $\mathrm{T} 1$ & $\mathrm{~T} 2$ & T3 & $\mathrm{PI}$ & P2 & P3 \\
\hline$L^{\prime}$ & 1 & $22785,57 * *$ & $49639,01^{* *}$ & $18880,46 * *$ & $36054,16 * *$ & $38428,55 * *$ & $24893,95 * *$ \\
\hline L" & 1 & $450,86 * *$ & 50,05 & $353,59 *$ & 279,90 & $688,28 * *$ & 100,17 \\
\hline L"” & 1 & $6688,42^{* *}$ & $6765,47^{* *}$ & $3054,48^{* *}$ & $7433,53 * *$ & $5775,37^{* *}$ & $3259,11 * *$ \\
\hline Desvio de Regr. & 17 & $11008,05^{* *}$ & $238,51^{* *}$ & $176,98 * *$ & $185,81^{* *}$ & $254,70 * *$ & $343,41 * *$ \\
\hline Resíduo & 567 & 79,08 & 79,08 & 79,08 & 79,08 & 79,08 & 79,08 \\
\hline Estimativas dos & $\boldsymbol{B}_{0}$ & 47,5498 & 56,6659 & 42,1104 & 52,1423 & 52,0967 & 42,0871 \\
\hline Coeficientes de & $B_{1}$ & 8,2196 & 6,3228 & 5,0366 & 8,1057 & 7,3336 & 4,1396 \\
\hline Regressão Poli- & $B_{2}$ & $-1,0280$ & $-0,9791$ & $-0,7033$ & $-1,0728$ & $-0,9678$ & $-0,6697$ \\
\hline nomial $\mathrm{p} /$ Linha & $\mathbf{B}_{3}$ & 0,0299 & 0,0301 & 0,0202 & 0,0315 & 0,0278 & 0,0209 \\
\hline \multicolumn{8}{|l|}{ Coeficiente de } \\
\hline Determinaçāo & $\mathbf{R}^{2}$ & 0,7311 & 0,9330 & 0,9148 & 0,9327 & 0,9122 & 0,8288 \\
\hline
\end{tabular}



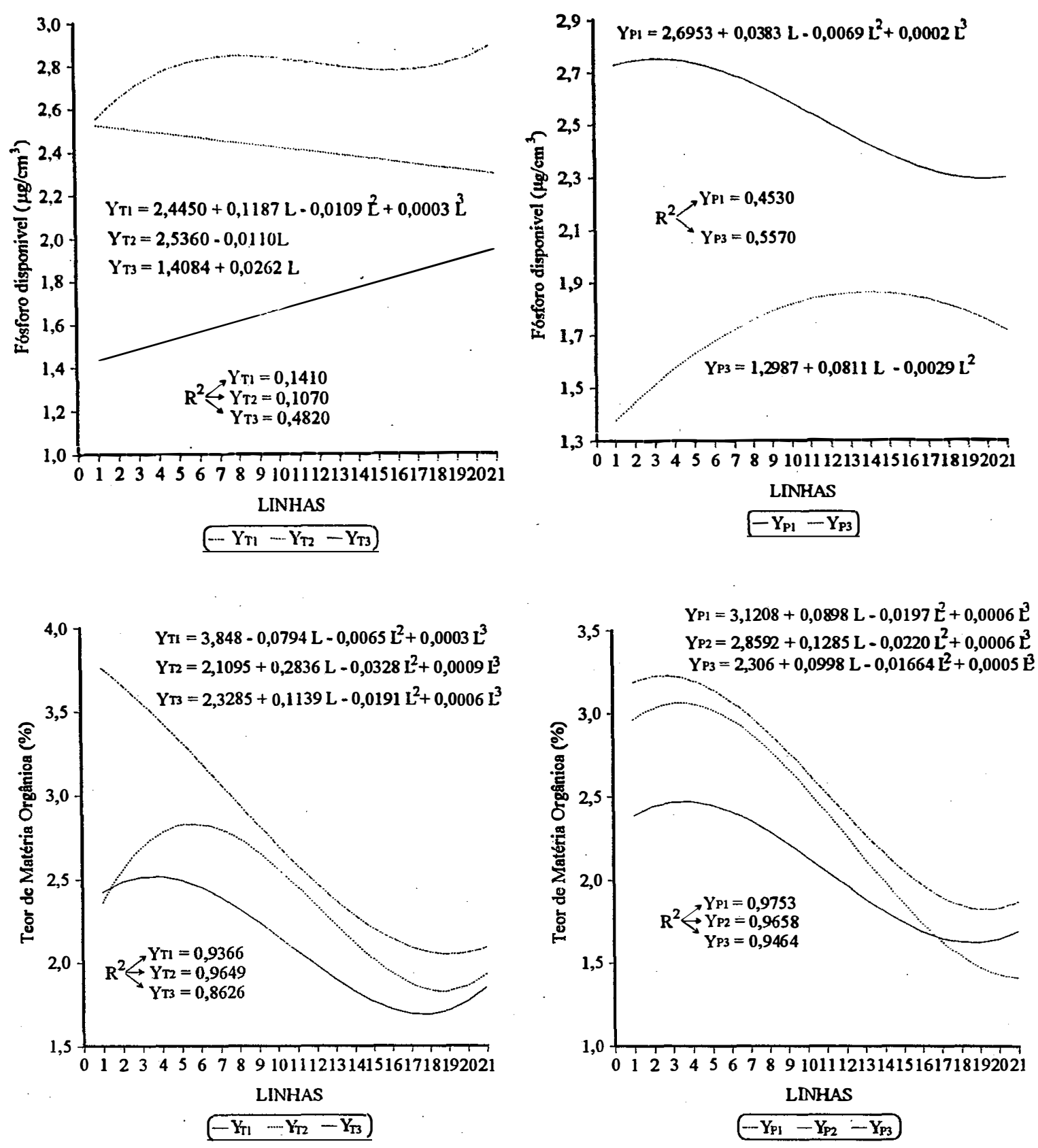

Figura 3. Comportamento do $\mathrm{P}$ (tranformado) e $\mathrm{MO}$ em relação às linhas, seguindo a profundidade de raspagem de solo de 0 a $40 \mathrm{~cm}$ dentro de cada tratamento e profundidade de amostragem do solo $(P 1=0-10 \mathrm{~cm} ; \mathrm{P} 2=10-20 \mathrm{~cm} ; \mathrm{P3}=20$ 40cm). Obs: ( Linha $1=0 \mathrm{~cm}, \mathrm{~L} 2=2 \mathrm{~cm}, \ldots . . \mathrm{L} 21=40 \mathrm{~cm}$ ). 

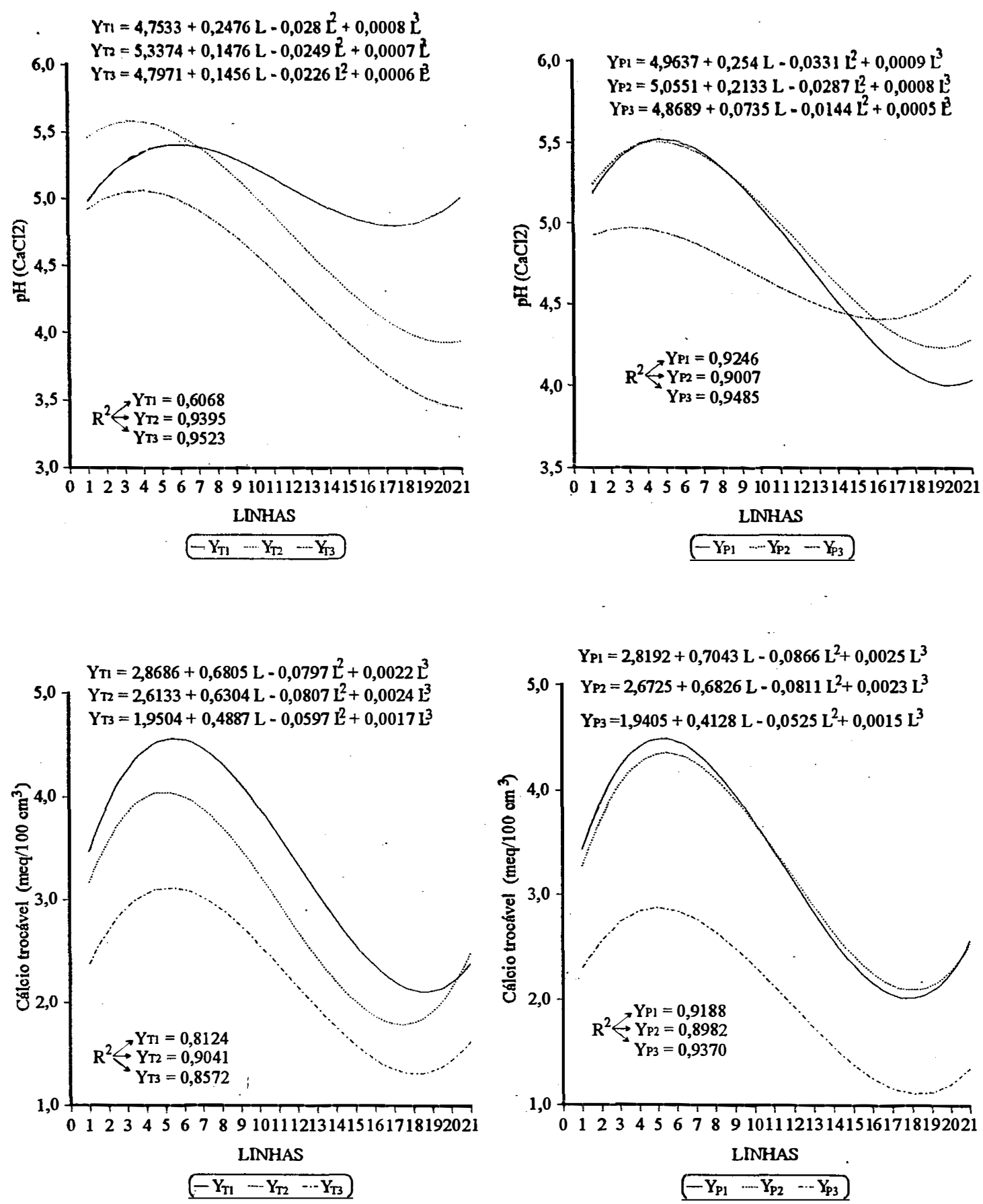

Figura 4. Comportamento do $\mathrm{pH}$ e $\mathrm{Ca}$ em relação às linhas, seguindo a profundidade de raspagem de solo de 0 a $40 \mathrm{~cm}$ dentro de cada tratamento e profundidade de amostragem do solo $(\mathrm{P} 1=0-10 \mathrm{~cm} ; \mathrm{P} 2=10-20 \mathrm{~cm} ; \mathrm{P} 3=20-40 \mathrm{~cm})$.

Obs: ( Linha $1=0 \mathrm{~cm}, \mathrm{~L} 2=2 \mathrm{~cm}, \ldots \ldots, \mathrm{L} 21=40 \mathrm{~cm}$ ). 

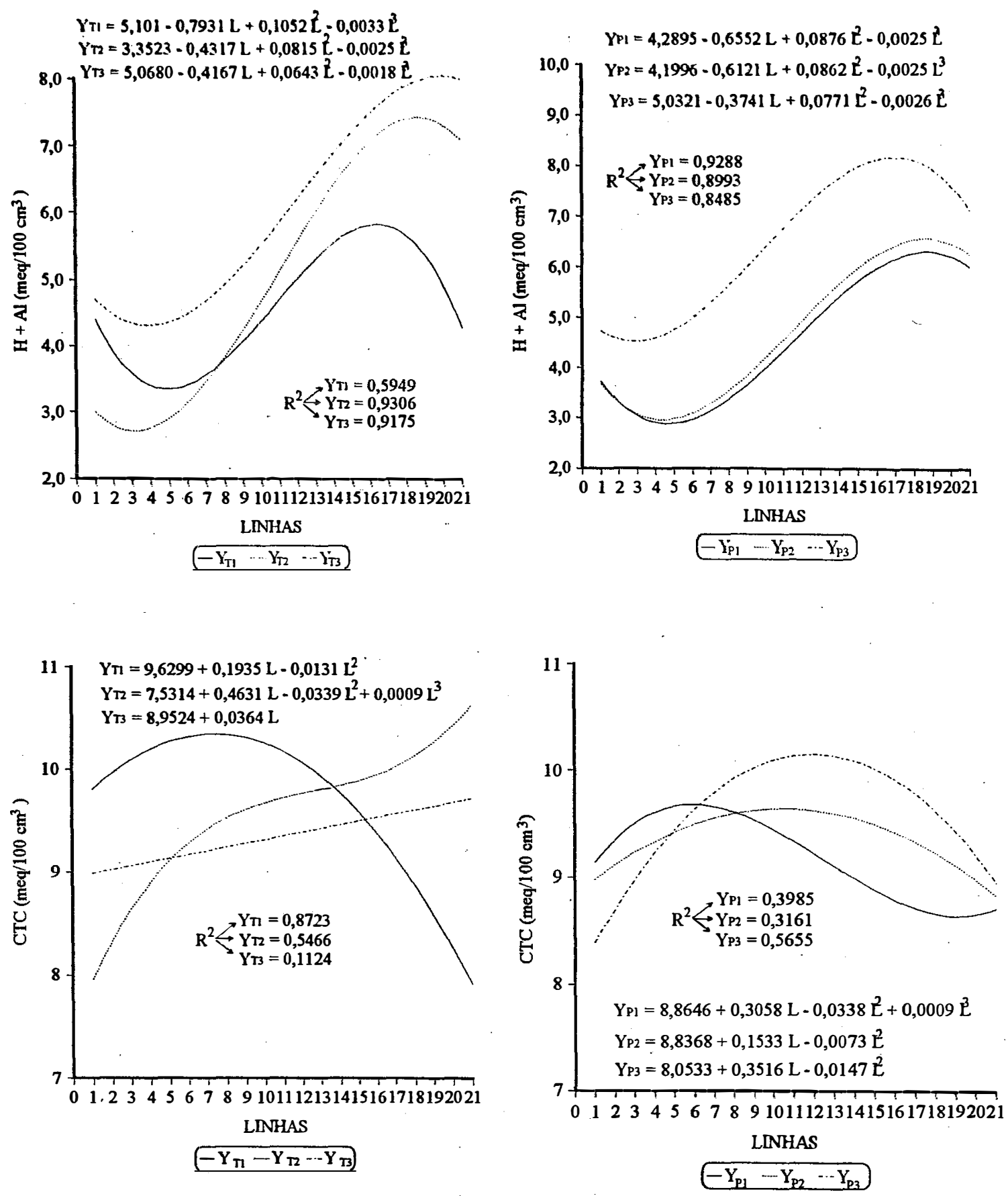

Figura 5. Comportamento do $\mathrm{CTC}$ e $\mathrm{H}+\mathrm{Al}$ em relação às linhas, seguindo a profundidade de raspagem de solo de 0 a $40 \mathrm{~cm}$ dentro de cada tratamento e profundidade de amostragem do solo $(P 1=0-10 \mathrm{~cm} ; \mathbf{P} 2=10-20 \mathrm{~cm} ; \mathbf{P} 3=20$ $40 \mathrm{~cm}$ ). Obs: ( Linha $1=0 \mathrm{~cm}, \mathrm{~L} 2=2 \mathrm{~cm}, \ldots . ., \mathrm{L} 21=40 \mathrm{~cm})$. 

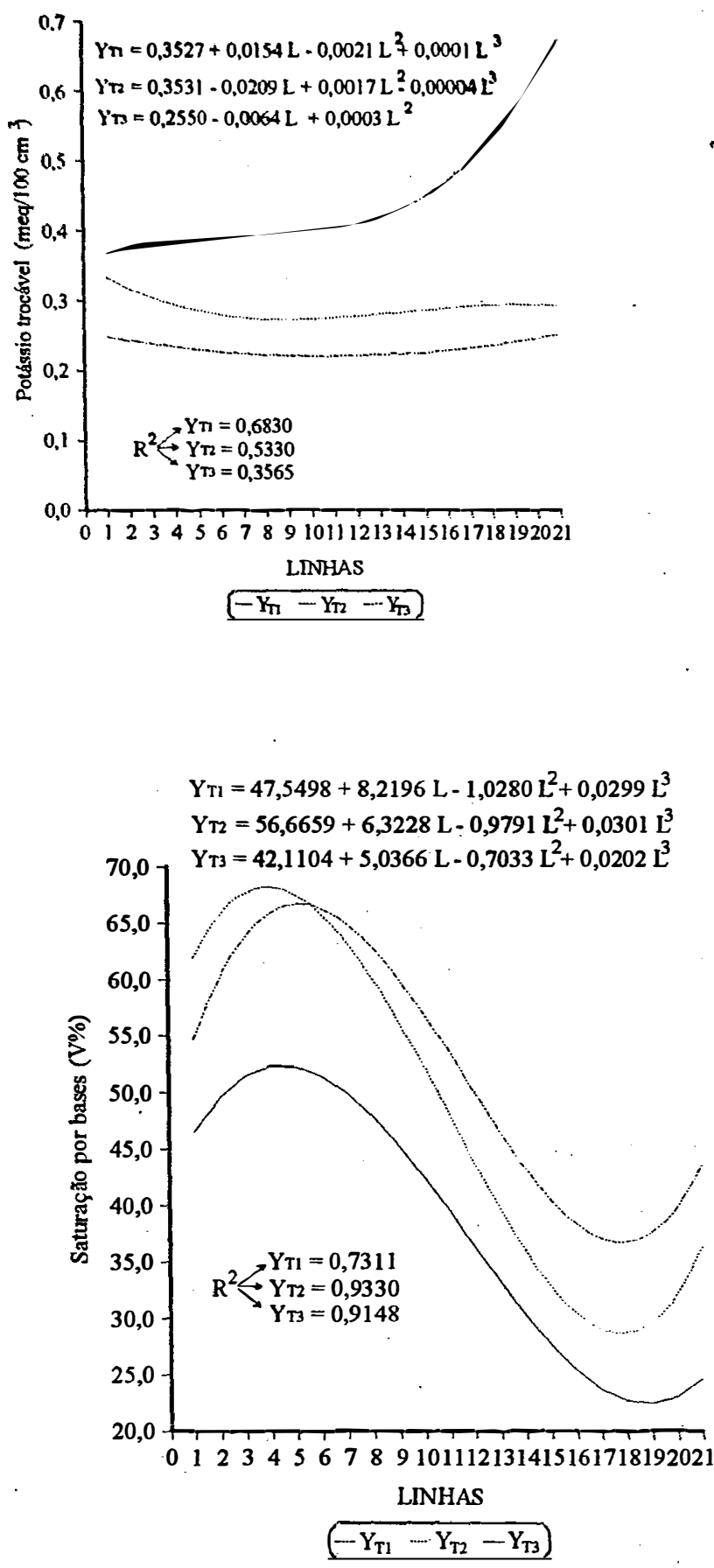
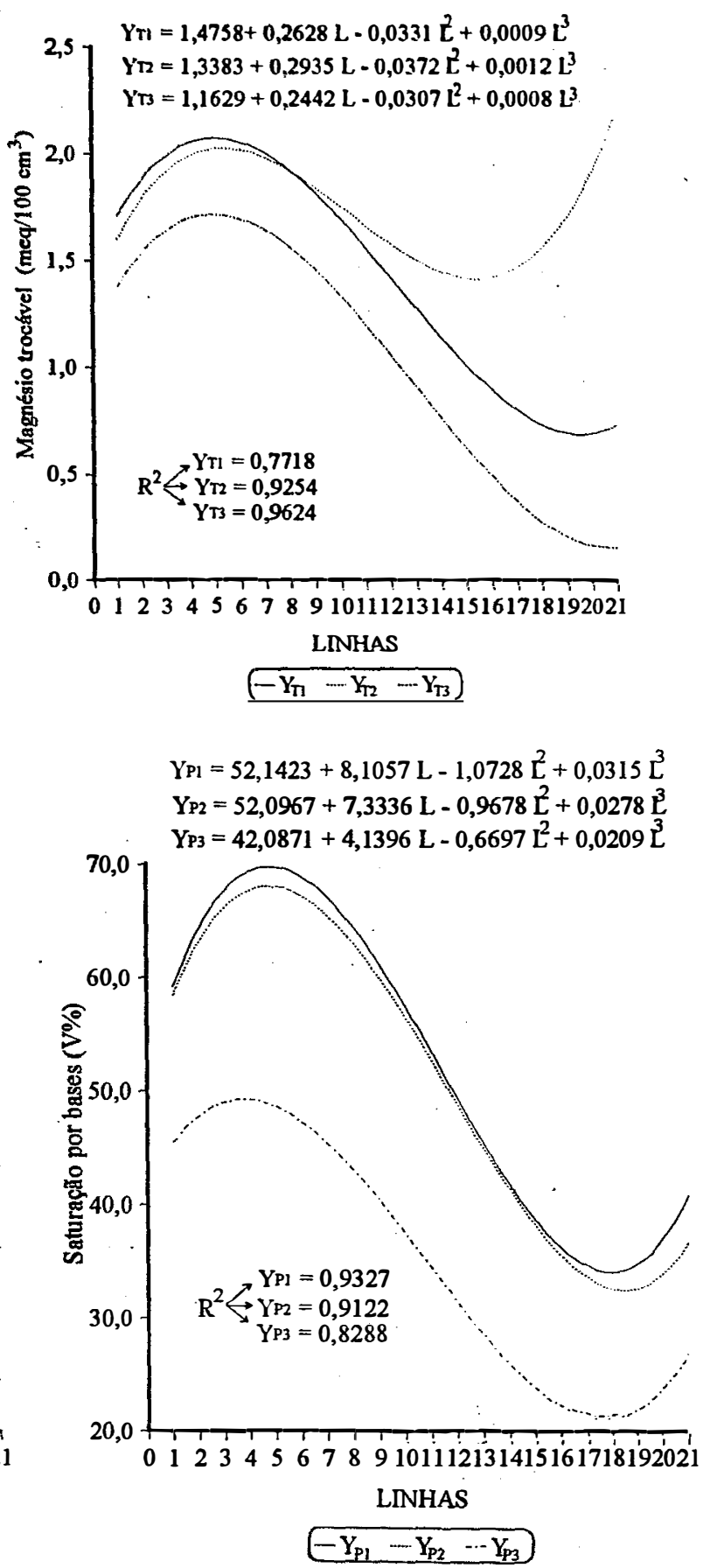

Figura 6. Comportamento do $\mathrm{K}, \mathrm{Mg}$ e Saturação por bases (V\%) em relação às linhas seguindo a profundidade de raspagem de solo de 0 a $40 \mathrm{~cm}$ dentro de cada tratamento e profundidade de amostragem do solo $(\mathrm{P1}=0-10 \mathrm{~cm} ; \mathrm{P} 2=10-20 \mathrm{~cm}$; P3 $=20-40 \mathrm{~cm})$. Obs: ( Linha $1=0 \mathrm{~cm}, \mathrm{~L} 2=2 \mathrm{~cm}, \ldots \ldots, \mathrm{L} 21=40 \mathrm{~cm})$. 
Quanto à interação Profundidade $x$ Linha, a mesma não apresentou significância estatística ao nível de $5 \%$ de probabilidade pelo teste $\mathrm{F}$, para as variáveis $\mathrm{K}$ (transformado) e $\mathrm{Mg}$. Nestas duas variáveis a interação tripla $\mathrm{T} \times \mathrm{P} \times \mathrm{L}$ também não apresentou significância estatística ao limite de $5 \%$. Desse modo, concluiu-se que o comportamento do $\mathrm{K}$ (transformado) e $\mathrm{Mg}$ em relação às linhas ou profundidade de raspagem dentro de cada profundidade de amostragem de solo são idênticos, conforme observado nas Tabelas $8,10,17$ e 19. Nas demais variáveis estudadas, a interação $P \times L$ apresentou significância estatística ao nível de $1 \%$ de probabilidade e esse fato leva a concluir que as variáveis apresentam respostas diferenciadas em relação às linhas dentro de cada profundidade de amostragem de solo e vice-versa, conforme mostram as Tabelas 5 a 22, excluindo às $8,10,17$ e 19 e as Figuras 3, 4, 5 e 6, onde a Figura 6 refere-se à saturação por bases, excluindo $\mathrm{K} \mathrm{e} \mathrm{Mg}$ trocável.

\subsection{Comportamento do rendimento de milho-espiga $(\mathrm{kg} / \mathrm{ha})$ em relação à profundidade de raspagem de 0 a $40 \mathrm{~cm}$}

A variável rendimento, apresentou muitas observações nulas na testemunha, impossibilitando que esta fosse incluída na análise da variância. Portanto, considerando-se apenas os dois tratamentos que foram adubados, os resultados da análise da variância estão apresentadas na Tabela 23. 
Tabela 23 - Resultado da análise de variância da produção do milho dos tratamentos 1 e 2 .

\begin{tabular}{lcrrr}
\hline \hline F.V. & G.L. & S.Q. & Q.M. & F \\
\hline Trat. (T) & 1 & $20.565 .302,6$ & $20.565 .302,6$ & 3,56 \\
L' & 1 & $188.057 .915,3$ & $188.057 .916,3$ & $32,52^{* *}$ \\
L', & 1 & $34.267 .663,0$ & $34.267 .663,0$ & $5,93 *$ \\
L', & 1 & $42.475,5$ & $42.475,5$ & 0,01 \\
Desvio de Regr. & 17 & $170.816 .357,8$ & $10.048 .050,5$ & $1,74^{*}$ \\
\hline Linha (L) & $(20)$ & $393.184 .911,6$ & $19.659 .245,6$ & $3,40^{* *}$ \\
Int. T x L & 20 & $154.906 .004,0$ & $7.745 .300,2$ & 1,34 \\
Resíduo & 126 & $728.612 .318,2$ & $5.782 .637,4$ & \\
\hline Total & 167 & & & \\
\hline \hline
\end{tabular}

CV\%: 27,2

Não foi observado efeito significativo para tratamento, isto é, os tratamentos 1 e 2 apresentaram produções estatisticamente iguais, que difere do rendimento observado por SPAROVEK et al. (1991), onde $T_{1}$ foi maior que $T_{2}$ em todas as profundidades de remoção de camadas do solo. Isto indica que é possível recuperar a produtividade do solo com o uso de fertilizante químico e a adubação verde a longo prazo com prévia correção do solo, como ocorreu no $T_{2}$ e a um prazo menor, com uso combinado com matéria orgânica, que também foi mostrado na Tabela 3. Com respeito ao fator linha, observou-se efeito 
significativo a $1 \%$ de probabilidade e as variações da produção em relação às linhas podem ser explicadas pelo polinômio do $2^{\circ}$ grau $\mathrm{Y}=11.925,27-478,73 \mathrm{~L}$ $+13,818 \mathrm{~L}^{2}$ com $\mathrm{R}^{2}=0,5655$. A Figura 7 mostra o comportamento da produção de milho, em relação às linhas ou profundidade de raspagem considerada no experimento, dentro de cada tratamento.

No confronto das médias $T_{1}=9.187,8 \mathrm{~kg} / \mathrm{ha}$ e $T_{2}=8.488,1$ $\mathrm{kg} / \mathrm{ha}$ não diferem entre si (DMS 5\% = 734,2 kg/ha). MBAGWU et al. (1984), MBAGWU (1985) e YOST et al. (1985), também observaram o efeito acentuado da remoção de solo no crescimento vegetativo e rendimento da cultura de milho. Isto também foi observado por SPAROVEK et al. (1991). Comparando a Figura 7 com a Figura 5, onde se observam o comportamento do rendimento e da acidez potencial do solo, indica uma relação da queda brusca do rendimento com a remoção de camadas de solo, devido ao aumento do $\mathrm{H}+\mathrm{Al}$ trocável no solo e sua influência no pH. Para achar o rendimento mínimo, deriva-se a função do segundo grau, obtendo-se como resultado $\mathrm{L} \min =17,31$, ou seja, entre as linhas 17 e 18 ocorrerá o rendimento mínimo, isto é, uma remoção de 32 a $34 \mathrm{~cm}$ de solo.

Para explicar o comportamento da produção do milho do tratamento $T_{3}$ (testemunha) em relação às linhas ou profundidade de raspagem de solo, foi feito um estudo de regressão polinomial e verificou-se que o modelo adequado foi a regressão linear conforme mostra os resultados da análise de variância na Tabela 24 . 
Tabela 24 - Resultado da análise de variância da produção do milho do tratamento 3 (testemunha).

\begin{tabular}{lcccc}
\hline \hline F.V. & G.L. & S.Q. & Q.M. & F \\
\hline Regressão linear & 1 & 190.754 .475 & $190.754 .475,00$ & $96,43^{*}$ \\
Resíduo & 82 & 162.213 .862 & $1.978 .217,83$ & \\
\hline Total & 83 & 352.968 .337 & & \\
\hline \hline
\end{tabular}

Observou-se que o tratamento 3 apresenta uma média de produção muito baixa $T_{3}=2284,3$ comparado com os outros dois tratamentos. As variações da produção em relação as linhas pode ser representada pelo polinomio de $1^{\circ}$ grau $\mathrm{Y}=5033,66-248,864 \mathrm{~L}$ com coeficiente de determinação $\mathrm{R}^{2}=$ 0,5404, como pode ser visto na Figura 7. Isto também foi observado por SPAROVEK et al. (1991), porém sem a tendência de decréscimo linear no rendimento de milho da testemunha. 


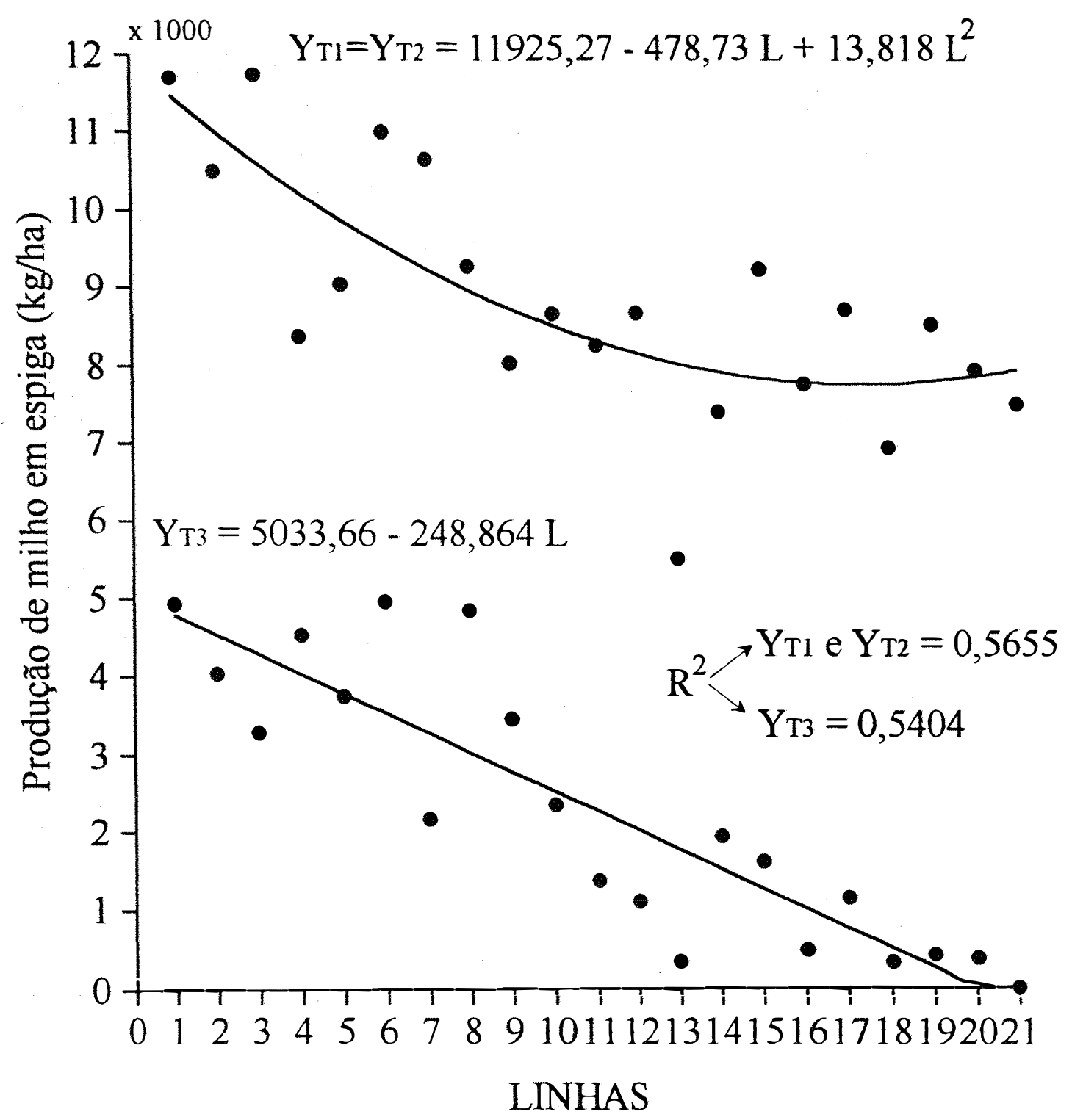

Figura 7. Comportamento do rendimento de milho-espiga $(\mathrm{kg} / \mathrm{ha})$ em relação às linhas seguindo a profundidade de raspagem de solo de 0 a $40 \mathrm{~cm}$. Obs: (Linha $1=0 \mathrm{~cm}, \mathrm{~L} 2=2 \mathrm{~cm}, \ldots . ., \mathrm{L} 21=40 \mathrm{~cm})$. 
Como na interação não apresentou significância estatística, conclui-se que os tratamentos $T_{1}$ e $T_{2}$ não diferem entre si dentro de todas as linhas, ou seja, o comportamento de produção em relação às linhas é quadrático tanto dentro de $T_{1}$ quanto dentro de $T_{2}$.

Quando a interação $\mathrm{T} \times \mathrm{P} \times \mathrm{L}$ apresenta significância estatística há necessidade de se estudar o comportamento de cada fator (Tratamento, Profundidade e Linha) dentro de cada combinação dos níveis dos outros dois ou de se estudar o comportamento das combinações dos níveis de dois fatores dentro de cada nível do $3^{\circ}$ fator.

Observa-se que para cada variável ou características químicas do solo considerado, há 693 testes de Tukey para verificar diferenças de médias de combinações de tratamentos, profundidades e linhas além de 36 testes F para verificar a significância dos componentes de regressão sobre linha, o que torna bastante confuso se tirar conclusões tão minuciosas. Portanto, as conclusões foram generalizadas a partir dos efeitos principais dos fatores e das interações de $2^{\circ}$ ordem. 


\section{CONCLUSÕES}

1 - Os teores de nutrientes do solo nos tratamentos que receberam adubação, em média, foram sempre superiores aos da testemunha, sendo que no tratamento com adição de esterco $\left(T_{1}\right)$ apresentou-se superior aos tratamentos sem adição, indicando a importância da matéria orgânica na disponibilidade dos nutrientes no solo.

2 - Para todas as características químicas analisadas em relação a profundidade de amostragem, ocorreu um comportamento decrescente com exceção do $\mathrm{H}+\mathrm{Al}$, principalmente na profundidade de 20 a $40 \mathrm{~cm}$, indicando a importância da acidez pontencial, influenciando os valores de $\mathrm{pH}$ e consequentemente a redução na disponibilidade dos nutrientes no solo.

3 - O comportamento geral das características químicas estudadas no solo em relação à profundidade de raspagem, foi muito bem explicado por um polinômio de terceiro grau para M.O. $\left(\mathrm{R}^{2}=0,9706\right), \mathrm{pH}\left(\mathrm{R}^{2}=0,9324\right), \mathrm{P}\left(\mathrm{R}^{2}=0,0842\right)$, 
$\mathrm{K}\left(\mathrm{R}^{2}=0,6153\right), \mathrm{Ca}\left(\mathrm{R}^{2}=0,9301\right), \mathrm{Mg}\left(\mathrm{R}^{2}=0,9472\right), \mathrm{H}+\mathrm{Al}\left(\mathrm{R}^{2}=\right.$ $0,9349)$, CTC $\left(R^{2}=0,5787\right)$ e V\% $\left(R^{2}=0,9322\right)$, com exceção dos nutrientes $\mathrm{P}$ e $\mathrm{K}$ que apresentaram grande variabilidade no solo.

4. Os tratamentos $T_{1}$ e $T_{2}$ apresentaram produções que não diferem estatisticamente ao longo da profundidade de remoção de solo de 0 a $40 \mathrm{~cm}$, explicadas pelo polinômio do $2^{\circ}$ grau $\mathrm{Y}=11.925,27-478,73 \mathrm{~L}+13,812 \mathrm{~L}^{2}$ onde $R^{2}=0,5655$ e para $L$ variando de 1 a 21 . No tratamento $T_{3}$ a produtividade foi sempre decrescente, chegando ao valor 0 aos $38 \mathrm{~cm}$ de profundidade de raspagem, conforme a equação $\mathrm{Y}=5033,66-248,864 \mathrm{~L}$ com $\mathrm{R}^{2}=0,5404$, para $\mathrm{L}$ variando de 1 a 21 .

5. Foi possível restaurar a produtividade do solo em estudo, submetido a erosão simulada em um prazo relativamente curto, através de uma correção prévia com calagem e com a adubação orgânica, complementada com adubação química. Para um prazo maior, a recuperação é possível, utilizando a adubação química e com a correção prévia do solo e complementada pela adubação verde. 


\section{REFERENCIAS BIBLIOGRÁFICAS}

AINA, P.O. \& EGOLUM, E. The effect of cattle feedlot manure and inorganic fertilizer on the improvement of subsoil productivity of IWO soil. Soil Science, Baltimore, 129(4):212-7, 1980.

BAVER, L.D.; GARDNER, W.H.; GARDNER, W.R. Física de suelos. México, UTEHA, 1973. 529p.

BERTOL, I. \& MICHELlUTI, D.J. Perdas de solo, água e nutrientes pela cultura do milho. Pesquisa Agropecuária Brasileira, Brasília, 28(10):120513, 1993.

BERTONI, J. \& LOMBARDI NETO, F. Conservação do solo. Piracicaba, Livroceres, 1985. 368p.

BLACK, A.L. Conservation bench terraces in Montana. Transactions of the ASAE, St. Joseph, 11:393-95, 1968.

CARLSON, C.W.; GRUNES, D.L.; ALESSI, J.; REICHMAN, G.A. Corn growth of gardena surface and subsoil as affected by application of fertilizer and manure. Soil Science Society of America Proceedings, Madison, 25:44-7, 1961. 
DANIELS, R.B.; GILLAM, J.M.; CASSEZ, D.K.; NELSON, L.A. Soil erosion as limited effect on field scale crop productivity in Southern Piedmont. Soil Science Society of America Proceedings, Madison, 53:917$20,1989$.

DEDECEK, R.A. Efeitos das perdas e deposições de camadas de solo na produtividade de um Latossolo Vermelho-Escuro do cerrado. Revista Brasileira Ciência do Solo, Campinas, 11:323-8, 1987.

ECK, H.V. Effect of topsoil removal on nitrogen - supplying ability of Pullman Silty Clay Loam. Soil Science, Baltimore, 32:686-91, 1968.

ECK, H.V. Characteristics of exposed subsoil - at exposure and 23 years later. Agronomy Journal, Madison, 79(6):1067-73, 1987.

FORSYTHE, W. Física de suelos; manual de laboratório. San José, IICA, 1980. $211 \mathrm{p}$.

GANTZER, C.L. \& McCARTY, T.R. Corn yield prediction for a claypan soil using a productivity index. In: NATIONAL SYMPOSIUM ON EROSION AND SOIL PRODUCTIVITY, New Orleans, 1984. Erosion and soil productivity; proceedings. St. Joseph, ASAE, 1985. p.170-81. (ASAE. Publication, 8-85). 
JOHNSTON, A.E. The effects of farming systems on the amount of soil organic matter and its effect on yield at Rothamsted and Woburn. In: BOELS, D.; DAVIES, D.B.; JOHNSTON, A.E., ed. Soil degradation. Rotterdam, A.A. Balkema, 1982. p.187-202.

HAAS, H.J. \& WILLIS, W.O. Conservation bench terraces in North Dakota. Transaction of the ASAE, St. Joseph, 11: 396-8, 1968.

HAUSER, V.L. \& COX, M.B. Evaluation of zing conservation bench terraces. Agricultural Engineering, St. Joseph, 43: 462-67, 1962.

KLANT, E. \& STAMMEL, J.G. Manejo adequado dos solos das encostas basálticas. In: SIMPÓSIO SOBRE MANEJO DO SOLO E PLANTIO DIRETO NO SUL DO BRASIL, 1., SIMPÓSIO DE CONSERVAÇÃO DE SOlO DO PlanaltO, 3., Passo Fundo, 1984. Anais. Passo Fundo: PIUCS/UPF, 1984. p.124-52.

LAL, R. Soil erosion problems on Alfisol in Western Nigeria, VI. Effect of erosion on experimental plot. Geoderma, Amsterdam, 25:215-30, 1981.

LAL, R. Soil erosion and its relation to productivity in tropical soil. In: EISWAIFY, S.A.; MOLDENHAUER, W.C.; ANDREW, L., ed. Soil erosion and conservation. Washington: Department of Agriculture, 1985. p.237-47. 
MAYS, D.A. \& BENGSTON, G.W. Lime and fertilizer use in land reclamation in humid region. In: SCHALLER, F.W. \& SUTTON, P. Reclamation of drastically disturbed lands. Madison, American Society of Agronomy, 1982. p.307-28.

MBAGWU, J.S.C. Subsoil productivity of an ultisol in Nigeria as affected by organic wastes and inorganic amendments. Soil Science, Baltimore, 140(6):436-41, 1985.

MBAGWU, J.S.C.; LAL, R.; SCOTT, T.W. Effects of disurfacing of alfisols and ultisols in Southern Nigéria: Crop performance. Soil Science Society of America Proceedings, Madison, 48(4):828-33, 1984.

MEDEIROS, R.B. de. Considerações sobre a integração lavoura-pecuária no Rio Grande do Sul. In: SIMPÓSIO SOBRE MANEJO DE PASTAGEM, 5., Campinas, 1980. Anais. Campinas, Fundação Cargill, 1980. p.235-301.

MICKELSON, R.H. Conservation bench terraces in Eastern Colorado. Transactions of the ASAE, St. Joseph, 11:389-92, 1968.

NEWBOULD, P. Losses and accumulation of organic matter in soils. In: BOELS, D.; DAVIES, D.B.; JOHNSTON, A.E., ed. Soil degradation. Rotterdam, A.A. Balkema, 1980. p.107-12. 
OOSTERBAAN, G.A. Blackground and scope of the seminar. In: BOELS, D.; DAVIES, D.B.; JOHNSTON, A.E., ed. Soil degradation. Rotterdam, A.A. Balkema, 1982. p.1-3.

PRITCHARD, K.E.; MASON, W.K., BYRNE, S.P. Land forming a red-brown earth - effects of topsoil removal and redistribution on irrigated crop production. Journal of Experimental Agriculture, Kyabram, 28(5):599$605,1988$.

RAIJ, B. van \& QUAGGIO, J.A. Métodos de análise de solo para fins de fertilidade. Campinas, Instituto Agronômico, 1983. 31p. (IAC. Boletim Técnico, 81).

SANTOS, D.R.; ALMEIDA, J.A.; SANTOS, E.J.S.; KRUNWALD, L.; GIACOMINI, L.A. Perdas de solo, água e nutrientes por erosão hídrica em diferentes sistemas de manejo do solo num cambissolo húmico do planalto catarinense. In: REUNIÃO BRASILEIRA DE MANEJO E CONSERVAÇÃO DO SOLO E DA ÁGUA, 10., Florianópolis, 1994. Resumos. Florianópolis: SBCS, 1994. p.246-7.

SAUERBECK, D.R. Influence of crop rotation, manure treatment and soil tillage on the organic matter content of German soils. In: BOELS, D.; DAVIES, D.B.; JOHNSTON, A.E., ed. Soil degradation. Rotterdam, A.A. Balkema, 1982. p.163-79. 
SPAROVEK, G.; TERAMOTO, E.R.; TORETA, D.M.; ROCHELLE, T.C.P.; SHAYER, E.P.M. Erosão simulada e a produtividade da cultura do milho. Revista Brasileira de Ciência do Solo, Campinas, 15:363-8, 1991.

STOCKING, M. Erosion and soil productivity: a review. Rome, FAO/Land and Water Development Division, 1984. 102p. (Consultant's Working Paper, 1).

TANAKA, D.L. \& AESE, J.K. Influence of topsoil removal and fertilizer application on spring when yields. Soil Science Society of America Proceedings, Madison, 53(1):228-32, 1989.

YOST, R.S.; EL-SWAIFY, S.A.; DANGLER, E.W. \& LO, A.K.F. The influence of simulated soil erosion and restorative fertilization on maize production on an Oxisol. Soil erosion and Conservation. Journal Series, Honolulu, 2761:248-61, 1985. 